\title{
Curriculum Transformation and Disability:
}

Implementing Universal Design in Higher Education 



\title{
Curriculum Transformation and Disability: Implementing Universal Design in Higher Education
}

\author{
Jeanne L. Higbee \\ Editor
}


Copyright $(92003$ by the Center for Research on Developmental Education and Urban Literacy, General College, University of Minnesota, Minneapolis, MN.

All rights reserved. No part of this publication may be reproduced, stored in a retrieval system, or transmitted, in any form or by any means, electronic, mechanical, photocopying, recording, or otherwise, without prior written permission of the publisher.

Printed in the United States of America.

The University of Minnesota is committed to the policy that all persons shall have equal access to its programs, facilities, and employment without regard to race, color, creed, religion, national origin, sex, age, marital status, disability, public assistance status, veteran status, or sexual orientation.

This publication/material can be made available in alternative formats for people with disabilities. Direct requests to the Center for Research on Developmenta Education and Urban Literacy, General College, 333 Appleby Hall, 128 Pleasant Street SE, Minneapolis, MN, 55455, 612-625-6411.

Printed on recycled and recyclable paper with at least 10 percent postconsumer material. 


\section{Table of Contents}

Introduction

Jeanne L. Higbee

\section{Understanding Universal Design and Universal Instructional Design}

Creating Curb Cuts in the Classroom: Adapting Universal Design Principles

to Education

Donna M. Johnson and Judith A. Fox

Developing the Curriculum Transformation and Disability (CTAD) Workshop Model

Judith A. Fox, Jennifer P. Hatfield, and Terence C. Collins

Perceptions of Universal (Instructional) Design: A Qualitative Examination

Jennifer P. Hatfield

Community Colleges and Universal Instructional Design

Judy Schuck and Jane Larson

\section{Classroom Strategies}

Making a Statement

Mark Pedelty

Charting New Courses: Learning Communities and Universal Design

Rashné R. Jehangir

Interpreting and Implementing Universal Instructional Design in Basic Writing 93

Patrick L. Bruch 
iv $\mid$ Table of Contents

Using Principles of Universal Design in College Composition Courses 105

Patricia J. McAlexander

Computer-Mediated Learning in Mathematics

and Universal Instructional Design

D. Patrick Kinney and Laura Smith Kinney

Universal Instructional Design in a Computer-Based Psychology Course

Thomas Brothen and Cathrine Wambach

Best Practices and Students with Disabilities: Experiences

in a College History Course

David L. Ghere

Universal Instructional Design in a Legal Studies Classroom

Karen L. Miksch

Empowering Students with Severe Disabilities: A Case Study

Jay T. Hatch, David L. Ghere, and Katrina N. Jirik

\section{Universal Design of Student Development Programs and Services}

Disability Services as a Resource: Advancing Universal Design

Karen S. Kalivoda and Margaret C. Totty

The First-Year Experience

Jeanne L. Higbee and Karen S. Kalivoda

Residential Living for All: Fully Accessible and "Liveable"

On-Campus Housing

Martha E. Wisbey and Karen S. Kalivoda

Implementing Universal Design in Learning Centers

Jeanne L. Higbee and Shevawn B. Eaton

Universal Design in Counseling Center Service Areas

Kathleen B. Uzes and Daley O. Connelly 


\section{Resources and Future Directions}

Universal Design and Technology

Karen S. Kalivoda and Margaret C. Totty

Technology Transformation and Universally Accessible Web Tables

Brian Shapiro

Where Do We Go From Here? Universal Design as a Model

for Multicultural Education

Heidi L. Barajas and Jeanne L. Higbee

\section{Appendices}

Resources: Assistive Technology

Karen S. Kalivoda and Margaret C. Totty

Bibliography of Suggested Readings

About the Authors 
vi $\mid$ Table of Contents 


\section{Introduction}

Jeanne L. Higbee

University of Minnesota

$\mathrm{n}$ inclusive institutions of higher

education no student should be an

afterthought. Thus, it is only natural that postsecondary disability service providers have embraced the concept of Universal Design, which proposes that spaces be planned at the outset to meet the needs of all potential users. Accommodation and inclusion are very different notions. When a student's family is provided with a van tour of the campus while the rest of the orientation group walks, when a student is able to view a famous celebrity giving a speech in an inaccessible lecture hall by watching from a remote site via television, or when a student is noticeably absent from the classroom every time a test is given because the student needs extended time, the student is accommodated, but excluded.

The purpose of this book is to introduce readers to the concepts of Universal Design (UD) and Universal Instructional Design (UID). This collection of essays addresses learning both within and outside the classroom, recognizing the role higher education plays in developing the "whole" person (American Council on Education, 1937, 1949; National Association of Student Personnel Administrators, 1989). Chapters authored by faculty members are intended to provide insights into teaching strategies that can be implemented in a variety of disciplines. It is hoped that these ideas will be helpful to both disabilities services staff members and faculty when exploring how to create universal learning experiences.

Similarly, concepts introduced in the student affairs section of this book can be applied to multiple student services. This book is available free of charge online (www.gen.umn.edu/research/crdeul or www.gen.umn.edu/research/ctad) as well as in hard copy so that individual chapters can be downloaded for purposes of discussion and for use in faculty and staff development.

The book begins with Johnson and Fox's introduction to the history and basic principles of UD and UID. Then Fox, Hatfield, and Collins describe the Curriculum Transformation and Disability (CTAD) model for providing professional development activities to prepare faculty 
and staff to implement Universal

Instructional Design, followed by Hatfield's qualitative study of perceptions of Universal Design. Schuck and Larson discuss the role community colleges play in providing access to postsecondary education for all students, and particularly for students with disabilities. They explain the attributes of community colleges that facilitate the implementation of Universal Design and Universal Instructional Design, as well as the unique challenges for both faculty and student development professionals when the student body is diverse and resources are scarce. Schuck and Larson emphasize the key role professional development plays in enabling institutions to implement UD and UID.

The second section of the book consists of chapters by CTAD participants and other faculty members who have been instrumental in developing curricula that meet the educational needs of all learners. These authors describe how they have created more inclusive classroom environments. Pedelty discusses the value of going beyond the usual syllabus statement to communicate to students that he is interested in providing equal access to his classroom. Pedelty relates how addressing issues of access on the first day of class has stimulated students' disclosure of hidden disabilities, and the impact that this communication has had on his teaching and on all students' learning. Next Jehangir explores the role learning communities can play in implementing Universal Design and Universal Instructional Design.

Bruch provides a theoretical perspective for implementing Universal Instructional Design in basic writing. His chapter is followed by McAlexander's practical suggestions for teaching composition in a universally designed classroom. Kinney and Kinney describe how the use of computermediated learning in the mathematics classroom can eliminate the need for most individual accommodations. Brothen and Wambach discuss the use of the Personalized System of Instruction (PSI), another computer-assisted model, to teach a universally-designed psychology course. Among the strategies proposed by Ghere for teaching history are simulations that enable students to experience historical events firsthand. Ghere elaborates on how to ensure that students with disabilities do not feel excluded from these activities. Similarly, Miksch engages students in mock trials in her legal studies classroom. Finally, Hatch, Ghere, and Jirik provide a case study that demonstrates how developing accommodations for a student with multiple disabilities resulted in a more universallydesigned educational environment that benefited all students.

The third section of this book focuses on student support services. Kalivoda and Totty provide a brief history of the creation of 
disability services offices in postsecondary educational institutions and explore the basic functions of those offices. They describe the nine categories of essential services identified in recent research and adopted by the Association for Higher Education and Disability (AHEAD). Next Higbee and Kalivoda discuss the implementation of Universal Design principles in the first-year experience, from admissions and orientation to models for "best practices." This chapter leads naturally to Wisbey and Kalivoda's examination of residence life. The authors address Universal Design as a means to create welcoming living spaces and to provide inclusive social and educational programs. Similarly, Higbee and Eaton discuss both physical facilities and educational programs when considering the implementation of Universal Design in college and university learning centers. Then Uzes and Connelly apply the same principles to counseling centers and provide case studies that demonstrate that students with disabilities face the same developmental tasks as all students, but may have to overcome additional obstacles in approaching these tasks.

The final section of the book provides the reader with further resources. Kalivoda and Totty's chapter describes the technology available to make it possible to accommodate students in a wide array of settings. Shapiro addresses web design, with a particular emphasis on web pages that contain content in tabular form, such as the exercises for many business courses. The book concludes with an exploration of the "logical next step," application of Universal Design to multicultural education, by Barajas and Higbee. The appendices include a list of assistive technologies, an extensive bibliography, and brief biographies for the authors.

The Center for Research on Developmental Education and Urban Literacy (CRDEUL) and the authors of this collection would like to thank the U.S. Department of Education and the University of Minnesota General College (GC) and Office of Disability Services, and specifically David Taylor, Dean of GC, and Terence Collins, GC Director of Academic Affairs, for their support of "Curriculum Transformation and Disability," the project that introduced so many of us to the tenets of Universal Design and Universal Instructional Design. As editor, I personally want to express my appreciation to Dean Taylor and Professor Collins, as well as to Judy Fox, Coordinator of the CTAD grant, to Dana Britt Lundell, Director of CRDEUL, and to Karen S. Kalivoda, Director of Disability Services at the University of Georgia, for encouraging me to compile this collection of essays in order to disseminate the work of CTAD more broadly. In addition, the authors and I would like to express our appreciation to Stan 
Carpenter, Chair, and the members of the American College Personnel Association (ACPA) Media Board for their feedback. We are also indebted to Karen Bencke, Information Technology Professional in the General College, for providing the layout and cover design.

Finally, I want to express my gratitude to the chapter authors, not only for their contributions to this book, but for their efforts in developing welcoming postsecondary learning experiences for all students. And there is one last group I feel compelled to recognize, although for reasons of confidentiality I cannot name them. I want to thank the many students I have worked with over the years-you know who you are-at the University of Wisconsin-Madison (where as an inexperienced graduate student coordinating the learning services program within the counseling center prior to the advent of learning centers, I was a major source of frustration to a student who could only sit erect for a couple hours per day due to a spinal injury when I tried to use traditional methods to teach time management and note taking strategies), Western Maryland College (including my thanks to my many students with hearing impairments, to the student coping with his loss of vision, and to one incredibly talented resident assistant who taught the members of the administration and her fellow studentswho would have discriminated against her on the basis of her disability - that a person with epilepsy can be an outstanding RA), at the University of Georgia (with special thanks to the guy who could not find his way back to Athens from the Atlanta bus terminal and to the young woman who overcame incredible odds to conquer math and to find her niche at the University), and at the University of Minnesota (with thanks to both the student and the interpreter who introduced me to real time captioning on my very first day of teaching at the $\mathrm{U}$ ). You know that I have not forgotten you and the many lessons that you have taught me!

\section{References}

American Council on Education (1937). The student personnel point of view.

Washington, DC: Author.

American Council on Education (1949). The student personnel point of view (rev. ed.). Washington, DC: Author.

National Association of Student Personnel Administrators (1989). Points of view. Washington, DC: Author. 


\section{Understanding Universal Design and Universal Instructional Design}



CHAPTER $1 \mid 7$

Implementing Universal Design

\title{
Creating Curb Cuts in the Classroom: Adapting Universal Design Principles to Education
}

Donna M. Johnson and Judith A. Fox

University of Minnesota

\begin{abstract}
Although recent legislation has improved access to higher education for college students with disabilities, some students continue to experience stigma when requesting and utilizing academic accommodations. Universal Instructional Design, a relatively new model that builds disability accommodations into the curriculum and incorporates a variety of learning styles, is one strategy to level the playing field. This chapter discusses the concept of Universal Instructional Design, describes its relationship to multicultural education and adult learning theory, and illustrates the importance of incorporating assistive technology in the curriculum. The authors also discuss the benefits and challenges of implementing Universal Instructional Design.
\end{abstract}

T he passage of the Rehabilitation Act of 1973 and The Americans with Disabilities Act of 1990 (ADA) has had a profound effect on the lives of students with disabilities by giving them extraordinary new access to postsecondary education. In the last 10 years, the population of students with disabilities on college campuses has increased significantly. Today, $9.4 \%$ of first-year college students report having a disability (Blackorby \& Wagner, 1996). Yet despite these gains in access, students with disabilities still are less likely than their nondisabled peers to complete their education, according to The National Longitudinal Study (Wagner, D'Amico, Marder, Newman, \& Blackorby, 1992).

Students with disabilities may be less likely to graduate due to an antiquated view. This perspective, often referred to as the medical model, focuses on fixing the individual with a disability rather than changing the environment (Gill, 1987; Hahn, 1988). The medical model stresses personal responsibility for having a disability while minimizing personal 
control. On college campuses, this approach may be played out in the implementation of academic accommodations.

Traditionally academic accommodations are provided on an individualized, case-by-case basis in which students present their medical documentation to the campus disability services office. That office then determines the appropriate accommodations and provides the student with individual letters to faculty to request specific accommodations for each course. Once students demonstrate that they have a disability, defined by the ADA as (a) a physical or mental impairment that substantially limits one or more major life activities, (b) a record of such impairments, (c) being regarded as having such an impairment (42 USC12101 [2]), they must continue to prove that they are eligible for accommodations and deal with the stigma of being different from other students. McCune (2001) states that, like students of color, students with disabilities are often perceived as "special admits who don't deserve to be here" (p. 7). This stigma is often exacerbated when students with disabilities are singled out by being required to take tests in separate locations in order to be afforded extended time, to request volunteer notetakers in class, or to enter through the back of the building when that is the only location of an accessible door. Arranging for accommodations also takes students an inordinate amount of time. Seymour and Hunter (1998) studied the experiences of students with disabilities in science, math, and engineering majors. Many of the interviewed students talked about being "time-disadvantaged" and stated that the time they spent on logistics, such as arranging for accommodations, presented obstacles over and above the limitations posed by their disabilities.

Providing accommodations to students on an individualized basis is a legitimate way to meet legal access requirements. However, in a recent effort to increase the retention and graduation rates of students with disabilities, some educators are calling for new models that are more "consistent with the spirit of the ADA which mandates that services be provided in the most integrated setting possible" (Aune, 2000, p. 57). One such model is the interactional, social constructivist model that "shifts analysis from one focusing on the disability itself to one recognizing the intersection of individual and society factors" (Jones, 1996, p. 348). According to this model, it is the resulting interaction between the individual and the environment that determines whether the functional limitation becomes a disability (Aune).

The interactional model was illustrated in the book, Everyone Here Spoke Sign Language (Groce, 1985). Groce described 
CHAPTER $1 \mid 9$

Implementing Universal Design

the treatment of deaf people on Martha's Vineyard in the early 20th century. The author stated that because there was such a large deaf population and most of the hearing residents knew sign language, the deaf Vineyarders participated freely in all aspects of life, as did their hearing relatives, friends, and neighbors. Because the communication barrier that ordinarily separates deaf people from the non-signing society did not exist, what is normally regarded as a profound disability garnered little attention.

\section{The Development of Universal Instructional Design}

The concepts found in the interactional model are integral to the concept of Universal Instruction Design, a relatively new model that encourages faculty to make their classes more accessible to students with disabilities by developing curricula that are flexible and customizable. Universal Instructional Design has its origins in a number of fields. The term itself is borrowed from the architectural concept of Universal Design, defined by the Center for Universal Design at North Carolina State University (1997) as "the design of products and environments to be usable by all people, to the greatest extent possible, without the need for adaptation or specialized design" (p. 1). Universal Design, which grew out of the recognition by architects that they needed to design the built environment so that it would be usable by all people, regardless of, for example, age or ability, was popularized by Ronald L. Mace of the Center for Universal Design (Bowe, 2000). The principles of Universal Design, as developed by The Center for Universal Design, are as follows: (a) equitable use; (b) flexibility in use; (c) simple and intuitive use; (d) perceptible information; (e) tolerance for error; (f) low physical effort; and $(\mathrm{g})$ size and space for approach and use. A classic and familiar example of Universal Design is the curb cut. Originally designed to allow people who use wheelchairs or other mobility devices to get safely from the sidewalk to the street, the curb cut in reality is used by many groups of people, including people pushing strollers or pulling luggage, rollerbladers, and elderly people.

Demographic changes in American society in the last 100 years have encouraged the development of Universal Design, as life expectancy has increased dramatically. In addition, people survive accidents and illnesses at a much greater rate than in the past. According to the Center for Universal Design, "at the end of 1994, 53.9 million people in the United States ( $20.6 \%$ of the population) had some level of disability . . and 26.0 million (9.9\%) had a severe disability" (Changing demographics section, II 3). Universal Design aims to be responsive to these demographic shifts. For 
example, Bowe (2000) notes that Universal Design has been used to market homes that allow for the changing needs of homeowners as they age. He also notes that many personal-use products, such as kitchen utensils and room temperature controls, have adopted the idea of making products as useable as possible.

Federal legislation has also significantly impacted the development of Universal Design. For example, The Architectural Barriers Act of 1968 required all buildings "designed, constructed, altered, or leased with federal funds" to be made accessible. Section 504 of the Rehabilitation Act of 1973 made it illegal for those entities that receive federal funds to discriminate on the basis of disability. The Fair Housing Amendments Act of 1988 expanded the Civil Rights Act of 1968 to include families and children with disabilities. The Americans with Disabilities Act of 1990 prohibited discrimination in employment, access to places of public accommodation, services, programs, public transportation, and telecommunications (Changing demographics section, I[ 5).

\section{Inclusion}

The elementary-secondary education inclusion movement also has played a major role in the development of Universal Instructional Design. Inclusion, as defined by York-Barr and Vandercook (1996), means "providing equal educational opportunity by co-creating learning communities in which unique needs and diverse capacities are recognized, understood, accepted, and valued" (p. 3). Those involved in the inclusion movement have added greatly to the discussion about changing teaching practices to meet the needs of students with disabilities, and, as they point out, strategies that work well when teaching students with disabilities generally work well for all students (York, Doyle, \& Kronberg, 1992; York-Barr \& Vandercook, 1996). Hodge and Preston-Sabin (1997) echo these ideas. They argue that providing reasonable accommodations to students with disabilities is part of good teaching practice, and that good teaching practice enhances learning for all students.

Many of the tenets of inclusion, such as valuing students' diverse capacities, directly apply to postsecondary education. There are, however, some important differences between the models of inclusion and Universal Instructional Design. Inclusion implies classrooms with multi-level participation, in which students participate in the same activities but at a different level, and overlapping curricula, in which some students may have different curricular objectives (York, Doyle, \& Kronberg, 1992). In postsecondary education, all students, with disabilities or not, must meet defined course objectives, although students with documented disabilities may receive 
CHAPTER $1 \mid 11$

Implementing Universal Design

reasonable accommodations. This distinction is an important one, as many faculty express concerns that they will be asked to "water down" their curriculum when they accommodate students with disabilities.

\section{Link to Multicultural Education}

The elementary-secondary education inclusion movement is just one response by educators who are increasingly aware that they are serving a very diverse student population. Many progressive educators strive to address their students' differences in race, ethnicity, class, and gender by applying theories of multicultural education. Nieto (1996) defines one such model of multicultural education as a process that centers on factors such as teachers' expectations, students' learning styles, and cultural variables. The rise of "Disability Culture," with its roots in common experiences of oppression, experience, and values, challenges the traditional race, class, and gender model of multiculturalism and argues for a broader definition that would include disability. Unfortunately, most people, including faculty, still hold to the "medical model" of disability, which defines disability as a deficiency residing in the individual, rather than as a difference deriving from the interaction between the individual and society (Gill, 1987).

Robertson (1994) argues for highlighting the socially constructed nature of disability as a way to help others better understand the concept of disability. As more and more faculty at the postsecondary level grow to understand issues of multiculturalism, people with disabilities and service providers will be better able to communicate the idea of disability as culture. Faculty then may be less inclined to see disability as a medical issue and more likely to address the needs of students with disabilities themselves.

Multicultural educators argue for a range of educational reforms. Some educators argue for new and multiple ways of assessing students' performance. According to Banks (2000):

Evaluating the progress of students from diverse racial, ethnic, and social-class groups is complicated by differences in language, learning styles, and cultures. Hence, the use of a single method of assessment will likely further disadvantage students from particular social classes and ethnic groups.... A variety of assessment procedures and outcomes that are compatible with different learning, performance, work, and presentation styles should be used to determine if students are achieving the levels of skills mastery needed to function effectively in a multicultural society. (p. 12) 
Others call for changes in the standard pedagogy of what Nieto (1996) calls "chalk and talk" to include other active learning opportunities, such as group work, cross-age tutoring, and projects. Banks (2000) points out that multicultural educators also need to address issues of classroom climate by helping students acquire the kind of social skills they need to work effectively with each other. Nieto also notes that multicultural education values diversity, encourages critical thinking, and acknowledges students' diverse cultural and linguistic backgrounds. In the next section of this book, several faculty members (e.g., Bruch, Pedelty) further describe the relationship between Universal Instructional Design and multiculturalism.

\section{Diverse Learning Styles}

Educators posit a number of different learning styles theories, all of which espouse some version of how people learn. For example, Galbraith and James (1987) argue for a scheme that includes the following seven perceptual modalities: print, aural, interactive, visual, haptic, kinesthetic, and olfactory. Because Galbraith and James' approach to learning styles focuses on the five senses, it can be particularly useful when considering how to teach students whose senses may be impaired. Higbee, Ginter, and Taylor (1991) argue that instructors should assess their classes' learning preferences and then structure the presentation of course material around those strengths. They say, "knowledge of learning styles allows instructors to more effectively convey information and also help reduce the level of frustration encountered by some students" (p. 9). As teaching to differing learning styles has become accepted practice in elementary and secondary education (and to some extent in postsecondary education), the natural result has been that teachers engaged their students in a variety of ways. That concept is integral to the development of Universal Instructional Design. In the next section of this book, faculty members will present a variety of strategies for implementing Universal Instructional Design across the curriculum.

\section{Assistive Technology}

No discussion of Universal Instructional Design would be complete without a nod to the development in the last few decades of computers and other technologies. These new technologies have given people with disabilities unprecedented access to information, as well as significantly improved access to education. Knox, Higbee, Kalivoda, and Totty (2000) point out that "technology will allow those with disabilities to achieve fuller participation in the academic venture" (p. 153). Screen readers read aloud the text on a computer screen, allowing students who are blind or 
CHAPTER $1 \mid 13$

Implementing Universal Design

have low vision to access computers. Voice input devices that record students' voices and display them as text on a computer screen allow students who have limited use of their hands or arms to produce written texts. Assistive listening devices, such as an FM System, provide amplified speech to a hard of hearing student through a receiver that picks up a small microphone worn by the instructor. Specialized software that allows students to manipulate text in a variety of ways and provides them with a variety of study tools helps students with learning disabilities more effectively work with text materials. Alternative keyboards provide access to computers for students with limited hand mobility. In real time captioning, a transcriptionist converts classroom lecture or discussion into text that is displayed on a computer monitor so that deaf students can participate in class when an interpreter is not present or when the student does not know American Sign Language. These are just a very few examples of the kinds of technologies now available. Information regarding web page design and the expansion of technological advances that can benefit all students is provided in the final section of this book.

The Center for Applied Special Technology (CAST) has been at the forefront of encouraging the use of technology to expand opportunities for people with disabilities. CAST (2001) defines Universal Design for Learning (an alternate term for "Universal Instructional Design") as "a new paradigm for teaching, learning, and assessment, drawing on new brain research and new media technologies to respond to individual learner differences" (Universal Design for Learning section, II 1). Their framework for Universal Design for Learning encourages instructors to: (a) develop flexible means of representing materials, such as presenting materials in alternative formats; (b) allow students to demonstrate their knowledge in flexible ways, such as giving an oral report instead of a written paper; and (c) engage students using a variety of methods, with the understanding that there is no one right way to teach. Their emphasis on flexibility and responding to individual learner differences resonates with the lessons learned from learning style theory and multicultural education and is good for all students.

\section{Applying Universal Instructional Design in PostsecondaryEducation}

Silver, Bourke, and Strehorn (1998), who originally coined the term "Universal Instructional Design" as it applies to postsecondary educational environments, argue that the implementation of Universal Instructional Design would mean that some students will no longer need to rely so heavily on support services because the 
support will be built into the course itself. They assert that the "Universal" in UID implies universal access to a course, not a "one size fits all" approach to teaching. However, it is important to point out that we can never expect to do away entirely with accommodating some students on a one-toone basis; rather, the goal of UID is to lessen the need for as many accommodations as possible by building them into the design of the course, creating an environment that is conducive to learning for all students. For example, putting a syllabus and other course materials online makes a course accessible in a number of ways. Suddenly, course materials are accessible to a student who is blind who uses a screen reader or downloads the text to be brailled. A student with a learning disability or attention deficit disorder benefits from using voice output technology to simultaneously listen to and read text, increasing comprehension of the material. Nondisabled students benefit as well (Silver et al.). Those who find it difficult to participate in class because of language or cultural barriers appreciate the ability to participate in an alternative, online class discussion, and everyone enjoys the convenience of accessing the materials anytime, anywhere, or using embedded links to conduct further research. Of course, using technology is only one solution.

Transforming teaching methods is the real challenge, as illustrated in the next section of this book.

\section{Benefits of Universal Instructional Design}

Because Universal Instructional Design is a remarkably inclusive model, it is most compatible with the spirit of the Americans with Disabilities Act, which states that programs and services must be provided "in the most integrated setting possible" (Aune, 2000, p. 57). Rose and Meyer (2001) report that Universal Instructional Design enables instructors to include students with disabilities among the diverse learners in their classroom rather than as a separate category. In a universally designed classroom, students use a variety of materials and learning aids that meet the needs of individual students. This flexibility in materials and testing helps reduce the stigma often felt by students with disabilities, who are often singled out as they leave the classroom to take a test in another location (CAST, 2001).

Researchers (e.g., Galbraith \& James, 1987; Higbee, Ginter, \& Taylor, 1991) have long postulated that students learn differently depending on their individual preferences, abilities, and disabilities (CAST, 2001). One benefit of Universal Instructional Design is that the model addresses individual learner differences by providing alternative methods of representation, expression, and engagement (CAST). For example, by utilizing 
CHAPTER $1 \mid 15$

Implementing Universal Design

alternative means of representation, a course module on homelessness could be taught through a series of lectures, through multimedia and videos, and through completing field trips or service-learning projects with local homeless shelters. By providing multiple means of expression, students are given a choice in how they will demonstrate their knowledge of course content. For example, one student may choose to demonstrate knowledge of cell biology via a research paper, whereas another student may choose to give an oral presentation. By providing multiple means of engagement, instructors seek the right balance in how students are engaged in the learning process. Scaffolding and strategic instruction (Caverly \& Russell, 2002; Nist \& Holschuh, 2000) may be used to provide academic supports. For example, instructors may make math or chemistry formulas available to students during quizzes in the beginning of a semester and then gradually take away this support as the students become more familiar with the material. Instructors may seek to vary the amount of new material covered in order to ensure that they repeat the essential components of the course (Orkwis \& McLane, 1998).

Just as Universal Design in architecture seeks to accommodate the widest variety of user needs in the built environment, Universal Instructional Design seeks to create alternatives to meet the wide range of users in the classroom (CAST, 2001). Also, just as it is more cost-effective to include ramps and include accessibility into the design of a new building, it is also more cost and time effective to consider the flexibility of learning materials when designing a course than in trying to provide individual accommodations after the fact (CAST). The expansion in technology has created opportunities for building inclusive classrooms. For example, by utilizing technology, students have the ability to access information and course materials anytime, anywhere, in a variety of formats. A student who is blind can access lecture notes posted on a web site via a screen reader. Students who have learning disabilities can highlight text and read in a distraction-free environment. Students who are deaf and generally require sign language interpreters have the ability to read the lecture without accommodation. Technology also has the ability to create communication networks between people who otherwise may have never come together by "facilitating the flow of communication without the meta processes of taping, brailling, and sign language interpreting" (Knox et al., 2000, p.145).

\section{Challenges of Incorporating Universal Instructional Design}

Although Universal Instructional Design may significantly impact the learning 
environment for all students, the main challenge in incorporating this new model is time limitations on the part of faculty. Silver et al. (1998) found that faculty were concerned that the time required to redesign their classes to incorporate principles of Universal Instructional Design may be prohibitive, even though such approaches may be beneficial in the long run. Faculty must be willing to rethink how they prepare for courses. For example, many faculty lecture from brief notes rather complete lectures. In order for a course to be more inclusive, the faculty member would have to be willing to spend more time initially preparing the lecture so it could be posted online, include Power Point notes, and so on. Some faculty may not be willing to spend their time on this (Knox et al., 2000). Smith (2000) stated that academic priorities such as research may take precedence over curriculum innovation. Another challenge is the faculty themselves. Because some faculty serve as "gate keepers" who believe their role is to monitor the academic readiness of students, they may not be prepared to accept a change in status quo or teach outside of the traditional lecture (Silver et al.).

In addition to concerns about time constraints, many faculty members are "experts in their discipline rather than in pedagogy" (Silver et al., 1998, p. 49). It is not uncommon for faculty to have limited awareness of diverse learning needs, adult learning theory, and its impact on college students with and without disabilities.

Finally, faculty may not be aware of the variety of technologies available or be trained in how to use them (Orkwis \& McLane, 1998). Faculty must have access to the appropriate software and then have adequate training for its use to be effective in the classroom.

\section{Budgetary Ramifications}

Although there are many benefits to implementing Universal Instructional Design, there may also be budgetary implications. Smith (1997) indicated time limitations on the part of faculty may impede the development of curricular innovation. In a 1998 ERIC/OSEP Topical Brief, the author stated that built-in accommodations, while requiring a significant amount of time initially, would save time and energy in the long run. Silver et al. (1998) concurred. They noted that although time was a critical factor in applying Universal Instructional Design, such strategies would save faculty and students time once they became a standard part of course design.

Limited access to technology and limited technology training may also hinder the implementation of Universal Instructional Design. Vanderheiden (1998) reported that 
CHAPTER $1 \mid 17$

Implementing Universal Design

customized technology may create a financial burden and the individuals for whom it is created may not have the requisite training. Smith (1997) said that there is still a digital divide that creates "haves and have-nots" in terms of technology access and use. This lack of technological access creates a barrier to curricular innovation and hence, to the implementation of Universal Instructional Design.

Finally, because this field is emerging, Smith (1997) called for more research to demonstrate the validity and reliability of the model. Smith stated that until more evidence is available, deans and department heads may be hard pressed to encourage their faculty to adopt innovative curricular models.

\section{Administrative Support}

Although it may require a significant investment of time, effort, and resources, strong and visible administrative support for any new curricular effort is crucial to its success. Bourke, Strehorn, and Silver (2000) found a significant relationship between faculty's understanding of the need to accommodate students with disabilities and their perceived level of support from service providers and their own departments.

Kalivoda and Higbee (1999) point out that in addition to lack of knowledge and time and budgetary constraints, some faculty may fail to provide appropriate accommodations because of perceived disapproval by the administration. They argue that visible administrative support, such as providing release time for faculty to address special needs or providing adequate resources to acquire assistive technology, will help reduce barriers to equal access for students with disabilities.

Anyone interested in implementing a new curricular effort such as the one detailed in this book should plan on meeting with key administrators early and often. Administrators can help set the parameters for workshop participation and be instrumental in the recruitment of workshop participants, perhaps by mailing out the recruitment notice directly from their offices. Administrators may also be able to provide incentives such as a small stipend or release time for faculty and staff participation in a workshop. Their presence at any workshop will lend credence to the effort. Student affairs professionals can also serve as powerful allies in this work, often assisting in creating the link between faculty and students.

In addition to working with key administrators, those interested in conducting a workshop will enhance institutional buy-in by conducting focus groups with faculty, student affairs staff, and with students with disabilities or by holding 
informal informational sessions for interested faculty and staff. The information gleaned from the focus groups and other meetings will allow for modification of the workshop to address the specific needs of participants at the institution, which will be key to the success of the workshop. (For more detailed information on gaining administrative support and recruiting participants for workshops, please visit the Curriculum Transformation and Disability website at www.gen.umn.edu/research/ctad)

Despite potential barriers posed by time, resources, or lack of administrative support, the benefits of implementing Universal Instructional Design can far outweigh the challenges. All students, not just those with disabilities, gain when instruction is individualized and when they are allowed to learn and demonstrate knowledge in a variety of ways that take into consideration their own preferred learning styles. Faculty members learn the advantages of creating a course from the outset so that it is accessible to all in as many different formats as possible, thus reducing the frequency of situations in which they must respond at the last minute, often with little or no notice, to specific requests for accommodations, which can be very time consuming. And administrators can take pride in the realization that they are fulfilling the spirit, not just the letter of the law, and providing truly equal access to a diverse student population.

\section{References}

Americans with Disabilities Act of 1990, P. L. 101-336, 42 US CA. 12, 101-12, 213, (West Supp. 1991).

Aune, B. (2000). Career and academic advising. In H. Belch (Ed.). Serving students with disabilities (pp. 55-67). New Directions in Student Services, No. 91. San Francisco: Jossey-Bass.

Banks, J. (2000). Diversity within unity: Essential principles for teaching and learning in a multicultural society. Seattle, WA: Center for Multicultural Education, University of Washington.

Blackorby, J., \& Wagner, M. (1996). Longitudinal postschool outcomes of youth with disabilities: Findings from the National Longitudinal Transition Study. Exceptional Children, 62, 399413.

Bourke, A. B., Strehorn, K. C., \& Silver, P. (2000). Faculty members' provision of instructional accommodations to students with LD. Journal of Learning Disabilities, 33(1), 26-32.

Bowe, F. (2000). Universal design in education. Westport, CT: Bergin \& Garvey. 
Caverly, D., \& Russell, L. (2002). Best practices for developmental education. In D. B. Lundell \& J. L. Higbee (Eds.), Proceedings of the Second Meeting on Future Directions in Developmental Education (pp. 17-23). Minneapolis, $\mathrm{MN}$ : Center for Research on Developmental Education and Urban Literacy, General College, University of Minnesota. Available: www.gen.umn.edu/research/crdeul

Center for Applied Special Technology. (2001). Universal Design for learning. [Online]. Available: www.cast.org

The Center for Universal Design. (n.d.). What is Universal Design? Retrieved March 6, 2002, from http:// www.design.ncsu.edu:8120/cud/ univ_design/udhistory.htm

The Center for Universal Design. (1997). The principles of Universal Design. (Version 2.0) [Brochure]. Raleigh, NC: North Carolina State University.

ERIC/OSEP Topical Brief. (Fall 1998). A curriculum every student can use: Design principles for student access. Retrieved March 4, 2002 from ERIC Clearinghouse on Disabilities and Gifted Education via http://ericec.org
Galbraith, M. W., \& James, W. B. (1987). The relationship of education level and perceptual learning styles. Journal of Adult Education, 15(2), 27-35.

Gill, C. (1987). A new social perspective on disability and its implications for rehabilitation. In F. S. Cromwell (Ed.), Sociocultural implications in treatment planning in occupational therapy (pp.49-55). New York: Haworth.

Groce, N. (1985). Everyone here spoke sign language: Hereditary deafness on Martha's Vineyard. Cambridge, MA: Harvard University Press.

Hahn, H. (1988). The politics of physical differences: Disability and discrimination. Journal of Social Issues, 44(1), 39-47.

Higbee, J. L., Ginter, E. J., \& Taylor, W. D. (1991). Enhancing academic performance: Seven perceptual styles of learning. Research and Teaching in Developmental Education, 7(2), 5-10.

Hodge, B. M., \& Preston-Sabin, J. (1997). Accommodations-Orjust good teaching? Westport, CT: Praeger.

Jones, S. R. (1996). Toward inclusive theory: Disability as social construction. NASPA Journal, 33, 347-354. 
Kalivoda, K. S., \& Higbee, J. L. (1999). Serving college students with disabilities: Application of the theory of planned behavior. Academic Exchange Quarterly, 3(2), 6-16.

Knox, D. L., Higbee, J. L., Kalivoda, K. S., \& Totty, M. C. (2000). Serving the diverse needs of students with disabilities through technology. Journal of College Reading and Learning, 30(2), 145-157.

McCune, P. (2001). What do disabilities have to do with diversity? About Campus, 6(2), 5-12.

Nieto, S. (1996). Affirming diversity: The sociopolitical context of multicultural education (2nd ed.). White Plains, NY: Longman.

Nist, S. L., \& Holschuh, J. L. (2000). Comprehension strategies at the college level. In R. F. Flippo \& D. C. Caverly (Eds.), Handbook of college reading and study strategy research (pp. 75-104). Mahwah, NJ: Lawrence Erlbaum.

Orkwis, R., \& McLane, K. (1998). A curriculum every student can use: Design principles for student access. ERIC/OSEP Topical Brief. (ERIC Document Reproduction Service No. ED423654) [Electronic version]. Available: www.cec.sped.org/osep/ udesign.htm
Rehabilitation Act of 1973. P.L. 193-112. Section 504.

Robertson, B. A. (1994). Disability culture, community, and pride. Unpublished manuscript. Minneapolis, MN: Project L.E.E.D.S. (Leadership Education to Empower Disabled Students), University of Minnesota.

Rose, D., \& Meyer, A. (2001). Universal design for learning. Journal of Special Education Technology ejournal. Retrieved November 30, 2001 from www.cast.org

Seymour, E., \& Hunter, A. B. (1998). Talking about disability: The education and work experience of graduates and undergraduates with disabilities in science, mathematics and engineering majors. Boulder, CO: The University of Colorado.

Silver, P., Bourke, A., \& Strehorn, K. C. (1998). Universal Instructional Design in higher education: An approach for inclusion. Equity and Excellence in Education, 31(2), 47-51.

Smith, K. L. (1997). Preparing faculty for instructional technology: From education to development to creative independence. Cause/Effect, 20 (3), $36-44$. 
CHAPTER $1 \mid 21$

Implementing Universal Design

Vanderheiden, G. C. (1998). Universal design and assistive technology in communication and information technologies: Alternatives or complements. Assistive Technology, 10, 29-36.

Wagner, M., D’Amico, R., Marder, C., Newman, L., \& Blackorby, J. (1992). What happens next? Trends in postschool outcomes for youth with disabilities. The second comprehensive report from the national longitudinal transition study of special education students. Menlo Park, CA: SRI International.

York, J., Doyle, M. B., \& Kronberg, R. (1992). A curriculum development process for inclusive classrooms. Focus on Exceptional Children, 25(4), 1-16.

York-Barr, J., \& Vandercook, T. (1996). The evolution of inclusive education. Impact, 9(2), 2-3. 
22 CHAPTER 1

Curb Cuts in the Classroom 
CHAPTER $2 \mid 23$

Implementing Universal Design

\title{
Developing the Curriculum Transformation and Disability Workshop Model
}

\author{
Judith A. Fox, Jennifer P. Hatfield, and Terence C. Collins \\ University of Minnesota
}

Despite significant gains in access to higher education, college students with disabilities still are less likely than their peers to complete their education. In response to this problem, educators participating in the University of Minnesota's Curriculum Transformation and Disability project designed, tested, and implemented a faculty development workshop that encourages faculty to incorporate principles of Universal Instructional Design in their courses. Midstream formative evaluation of the project shows that faculty appreciate the workshop and are beginning to make changes in their courses, particularly around issues of information access, instructional design, and classroom climate.

A $\mathrm{s}$ indicated in the previous chapter, the population of students with disabilities on college campuses has increased significantly in the last decade. The passage of the Rehabilitation Act of 1973 and the Americans with Disabilities Act of 1990 (ADA), together, have had a profound effect on the lives of students with disabilities by giving them extraordinary new access to postsecondary education. Yet retention and graduation rates for students with disabilities still lag behind those of their peers.

The reasons for this disparity are complex, and the research is limited. Much of the existing research focuses on asking the student to change (e.g., through the development of self-advocacy skills), on providing support to the student through service delivery, or on examining attitudinal barriers. Few studies examine how to effectively teach students with disabilities in postsecondary education. In fact, educators interested in looking for solutions to the problem of how best to serve students with disabilities in postsecondary education often find they must look to other fields, including architecture, learning styles, multicultural education, disability studies, and the elementary-secondary inclusion movement for information. Only recently have 
postsecondary educators been able to synthesize this information and begun to advocate for the use of Universal Instructional Design, a relatively new model that encourages faculty to make their classes more accessible by developing curricula that are flexible and customizable.

\section{A History of Collaboration}

For well over a decade, the University of Minnesota's General College and the Disability Services office have worked jointly to improve the climate and service level for students with disabilities. Together, these two units have sponsored a variety of programs aimed at improving the experience of students with disabilities on college campuses. Over the years, these key units and their staffs have developed an atmosphere of mutual trust and have shared a common commitment to institutional change. Thus, when in 1999 the U.S. Department of Education, Office of Postsecondary Education, began accepting applications to an exciting new grant competition titled "Ensuring Students with Disabilities Receive a Quality Higher Education," key staff at The General College and Disability Services proposed an innovative project aimed at working with faculty to make their classes more accessible through the use of Universal Instructional Design. The project, Curriculum Transformation and Disability, or CTAD, received a three-year award to create a model demonstration project that encourages faculty to transform their curriculum by adopting principles of Universal Instructional Design.

\section{Model Development}

Working from past experience and from the available literature from a variety of fields, project staff created a two-day faculty development workshop with the goal of developing a nationally replicable workshop model that could be facilitated by specialists or nonspecialists alike. The project conducted workshops at a number of upper Midwest two-year and four-year colleges and universities. Recruitment of faculty varied by institution, as administrators at different sites chose to focus recruitment efforts either within one department, or across a broader spectrum of disciplines. The project primarily worked with full-time faculty because it assumed they would have broad and long-term impact on institutional practices. However, some participants held full- or part-time instructor, administrator, or advisor positions. This was particularly true at smaller institutions where staff serve in a variety of instructional and service roles. For purposes of this chapter, the term "faculty" will refer to all workshop participants, regardless of their rank.

Project staff designed the following learning objectives for all faculty: (a) build on their own experiences, (b) learn about 
CHAPTER $2 \mid 25$

Implementing Universal Design

relevant legislation, (c) become familiar with and begin to apply the principles of Universal Instructional Design, (d) identify specific ways to create inclusive classrooms and programs, (e) learn about assistive technology, (f) learn about local resources, and $(\mathrm{g})$ develop a personal action plan.

\section{CTAD Curriculum}

\section{Teaching Methods}

Project staff intentionally designed the twelve-hour, two-day workshop to be an interactive experience, incorporating lecture, small and large group discussion, application activities, and exercises. Facilitators strive to model good teaching practices and incorporate elements of Universal Instructional Design whenever possible. For example, all faculty receive a notebook of materials at the start of the workshop, which includes printouts of all PowerPoint slides. Termed a "natural support" because it provides assistance to all faculty regardless of their disability status, these printouts allow faculty to more fully engage with the materials being presented, rather than hurriedly copying down what appears on the screen. With this natural support, a person with a disability who is unable to take notes will not have to ask for an individual accommodation; it's already there.

\section{Day 1 Workshop Agenda}

Understanding disability. In this opening section of the workshop, facilitators provide faculty with a brief overview of disability types and discuss issues specific to hidden disabilities. Facilitators also introduce the "interactional model" of disability, which argues that rather than being viewed as a deficiency in the individual, disability should be considered a difference. Under this model, disability resides not within the individual but derives from the interaction between the individual and society (Gill, 1987). Facilitators of this section endeavor to draw out faculty's previous experiences with students with disabilities and knowledge of available resources.

Exploring legal issues. This section briefly explores the three major laws affecting postsecondary educators: Section 504 of the Rehabilitation Act of 1973, the Americans with Disabilities Act of 1990, and, indirectly, the Individuals with Disabilities Education Act, or IDEA (1994). Facilitators discuss the impact of each of these three major laws and introduce definitions of disability, reasonable accommodations, and mandated services. Faculty work through a scenario that asks them to apply their knowledge of the law and disability to a specific case relevant to postsecondary education. 


\section{Listening to student perspectives.} Student voices are an integral part of the workshop. Presenting them early in the workshop allows both facilitators and faculty to refer back to the students' comments throughout the workshop. When it is feasible, facilitators recruit a group of college students or recent graduates with disabilities and facilitate a discussion about their experiences in postsecondary education, followed by a question and answer session with the faculty. Because it is sometimes not feasible to assemble a live panel of students, facilitators occasionally use a videotape of students with disabilities discussing these same issues.

\section{An introduction to Universal}

Instructional Design. This section illustrates the architectural concept of Universal Design through a series of slides of well designed architectural features such as door levers; signage containing text, symbols, and Braille; adjustable laboratory and classroom tables; and power-assisted doors. After reviewing universally designed features in these slides, faculty tour the building in which the workshop is held and identify additional examples of universally designed features.

Next, faculty learn to apply these architecturally-based concepts to the instructional environment to produce Universal Instructional Design. Asking faculty to apply architectural principles to an educational context seems, however, awkward at best, so facilitators introduce a set of "Principles" to help workshop faculty explicitly apply the model to their particular classes. The Principles, which are meant to be seen as guidelines more than as a definitive list, were synthesized from Chickering and Gamson's (1987) “Seven Principles for Good Practice in Undergraduate Education" and North Carolina State University's "Principles of Universal Design" (1997). They are as follows:

1. Create a classroom climate that fosters trust and respect.

2. Determine the essential components of the course.

3. Provide clear expectations and feedback.

4. Explore ways to incorporate natural supports for learning.

5. Provide multimodal instructional methods.

6. Provide a variety of ways for demonstrating knowledge.

7. Use technology to enhance learning opportunities.

8. Encourage faculty-student contact. 
These are, at first glance, practices that all good teachers follow. They also apply to all students, with or without disabilities. However, it is important to note that most postsecondary faculty are hired because they are content experts, not necessarily good teachers. Even those with the best intentions may lack sufficient resources or training in how to be good teachers, and these principles engender useful discussions about teaching and help faculty to articulate best practices in their own disciplines. Much of the remainder of the workshop focuses on applying these principles.

Applying the Principles of Universal Instructional Design. In this section, faculty begin to apply two of the principles of Universal Instructional Design to their own courses. First, facilitators lead faculty through a discussion about classroom climate, or what makes a classroom welcoming, such as establishing ground rules for class discussion, honoring cultural differences, and attending to the physical needs of students. Each participant writes or adapts a disability access statement suitable for use in a course syllabus. Next, facilitators introduce the idea of "essential components" and guide faculty through a series of questions designed to help them articulate the outcomes they expect for their students by defining what is essential about their course, and what may be important, but negotiable. For example, a "timed essay" exam, which asks students to produce brief, coherent answers in finished prose under strict time limitations, may be seen as an essential component of a journalism or newswriting class. In a composition class, however, where the aim is to develop students' critical writing, reading, and thinking abilities, resulting in a series of longer papers produced outside of class, that same timed essay may be considered an important skill, but not an essential one. Having identified this, the composition instructor may feel more comfortable providing an accommodation such as extended test time or a quiet testing space to students requiring these accommodations for the timed essay. The journalism faculty member, on the other hand, may choose to have a discussion with the student and the student's disability specialist in order to determine how best to provide accommodations without altering the essential requirements of the course. Facilitators in this section strongly encourage faculty to maintain high academic standards in their courses while considering some flexibility in assignments considered important but not essential.

\section{Day 2 Workshop Agenda}

Learning about assistive technology. Facilitators introduce faculty to a wide range of assistive technologies, both low and high-tech, that might be useful for college students with disabilities. When possible, faculty get to practice with or see a live 
demonstration of these technologies. Faculty receive additional reference materials, such as guidelines for creating accessible web pages and lists of technological resources available on their campuses. This section provides faculty with the tools to address the Principle of Universal Instructional Design that asks them to use technology to enhance learning opportunities.

Investigating local resources. Ideally, the facilitator of this section is the disability services provider at the workshop site. In a question and answer session with this service provider, faculty learn about policies of their own Disability Services office, available resources, and the demographics of their particular student population. Faculty are encouraged to think of themselves as part of a triangle of support that includes students, faculty, and the disability service provider.

Working with case scenarios. This section gives faculty a chance to integrate and apply much of the knowledge they have gained in the preceding sections. In small groups, faculty work through a series of cases involving students with disabilities in postsecondary classes. The facilitator then asks the groups to share their ideas with each other.

Applying Universal Instructional Design, continued. The facilitator of this section guides faculty through a discussion of the remaining Principles of Universal
Instructional Design. Faculty are encouraged to share their own experiences with each other as they talk about ways to provide clear expectations and feedback to their students, as well as ways to increase contact with their students. The facilitator then leads a discussion about ways to employ natural supports, which are those nonaccommodation-based supports faculty can provide to all students, such as providing class notes to all students, whether or not those students have disabilities. Finally, the facilitator leads faculty through a discussion of how and when to employ multimodal instructional methods in the classroom and how to design a course so that students may demonstrate their knowledge in a variety of ways.

Creating an action plan. In this final, brief section, faculty distill what they have learned and develop a series of concrete "next steps" to guide them as they begin to make changes in their courses. Faculty briefly note the three most important changes they plan to make in their own courses, how they can request follow-up assistance, how they might share what they have learned with their colleagues, and what barriers or impediments they foresee. The facilitator asks each faculty member to share, briefly, one item from the action plan.

The above discussion is intended only to provide an overview of the workshop. For information on how to obtain a complete set of workshop materials, including 
facilitator's notes, PowerPoint slides, videotapes, and handouts, please visit the Curriculum Transformation and Disability website at www.gen.umn.edu/research/ctad

\section{Workshop Participants}

At the close of the project's second year, 73 faculty, administrators, and student services personnel had participated in CTAD workshops. The majority $(76.7 \%, n=56)$ of participants were tenured or tenure track faculty; $13.7 \%(n=10)$ were non-tenure track instructional faculty; $5.5 \%(n=4)$ were advisors, and $4.1 \%(n=3)$ served in an administrative capacity. Tenured and tenure track faculty were targeted because they have both longevity and curricular

Figure 1. Distribution of Disciplines in Which Faculty Teach

\begin{tabular}{lcc}
\hline Disciplinary area & $\mathrm{n}$ & $\%^{\mathrm{a}}$ \\
\hline Business & 4 & 5.9 \\
Education & 6 & 8.8 \\
Health/human services & 6 & 8.8 \\
Humanities & 8 & 11.8 \\
Language arts & 9 & 13.2 \\
Math/computer science/engineering & 8 & 11.8 \\
Science & 10 & 14.7 \\
Social science & 17 & 25.0 \\
\hline
\end{tabular}

${ }^{a}$ Percentages were calculated based on total number of faculty who had instructional duties $(n=68)$. 
responsibility. Targeting them was seen as an opportunity for greatest impact at the heart of the teaching and course design process. Many of the advisors and administrators also had some instructional duties. Social Science was the most common discipline in which faculty taught; however, there was an appropriate balance of other disciplines as well (see Figure 1). Fifty-five percent of the faculty were women and $45 \%$ were men. Faculty had a wide range of job experience and averaged 13.5 years ( $S D=10.09, M d n=11$, Range $=1-43$ years $)$ in their current field. Faculty were fairly evenly distributed in terms of their experience working with students with disabilities: $24 \%$ had worked with fewer than 6 students with disabilities in their career; $17 \%$ had worked with 6 to $10 ; 17 \%$ had worked with 11 to $15 ; 16 \%$ had worked with 16 to 30 ; and $26 \%$ had worked with more than 30 students with disabilities.

\section{Program Evaluation}

A variety of methods were used to gather data for formative and summative program evaluation, including workshop evaluation forms, participant interviews and longitudinal progress reports. What follows is a brief summary of formative and summative evaluation results from these data sources.

\section{Formative Evaluation}

After each workshop, all faculty were asked to fill out a questionnaire asking for their feedback regarding their workshop

Figure 2. Average overall workshop content rating from pilot and year 2 workshops.

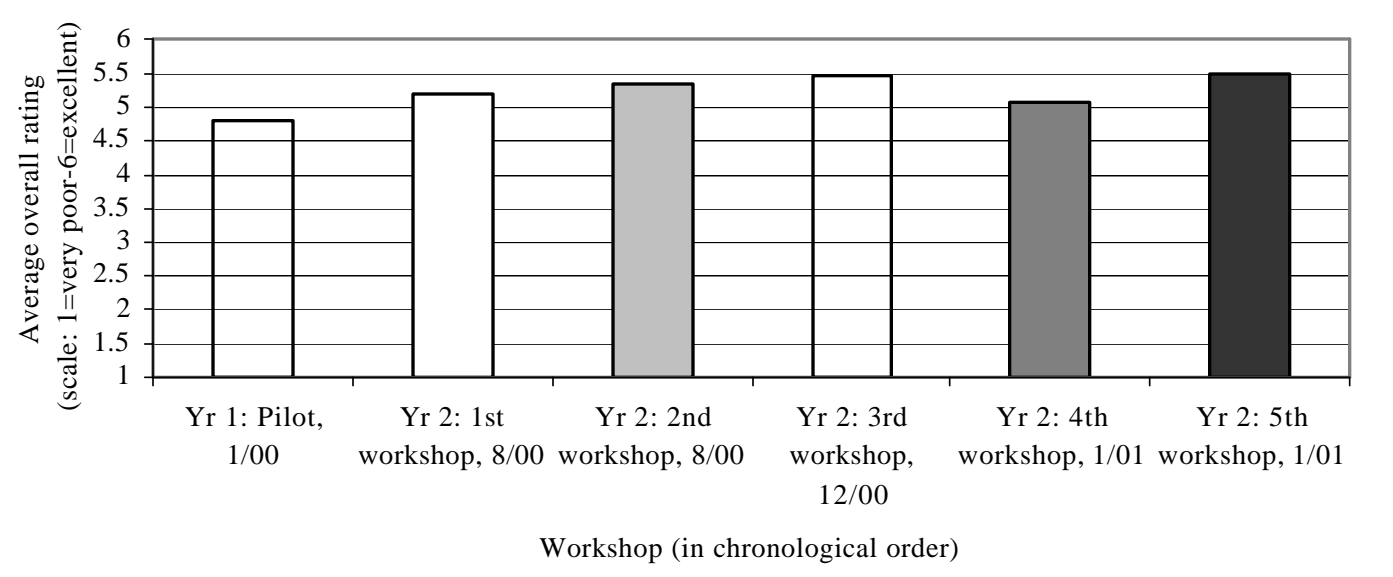


experience. Data from these evaluations were used to improve the workshop curriculum. The workshops were regarded very favorably by faculty in the first (i.e., pilot) workshop; however, over time curriculum revision efforts have resulted in an increasingly well-received faculty development program. This trend is illustrated in Figure 2, which depicts the average ratings given by faculty over the 10 workshop content segments.
Furthermore, as illustrated by Figure 3, year two faculty were more likely to believe that workshop participation was a valuable experience, that presentation of material was appropriately balanced, and that information presented was relevant to their needs. They were somewhat more likely to think that presentations and lectures were clear and easy to follow.

Figure 3. Reactions to workshop experience from pilot and year 2 sites

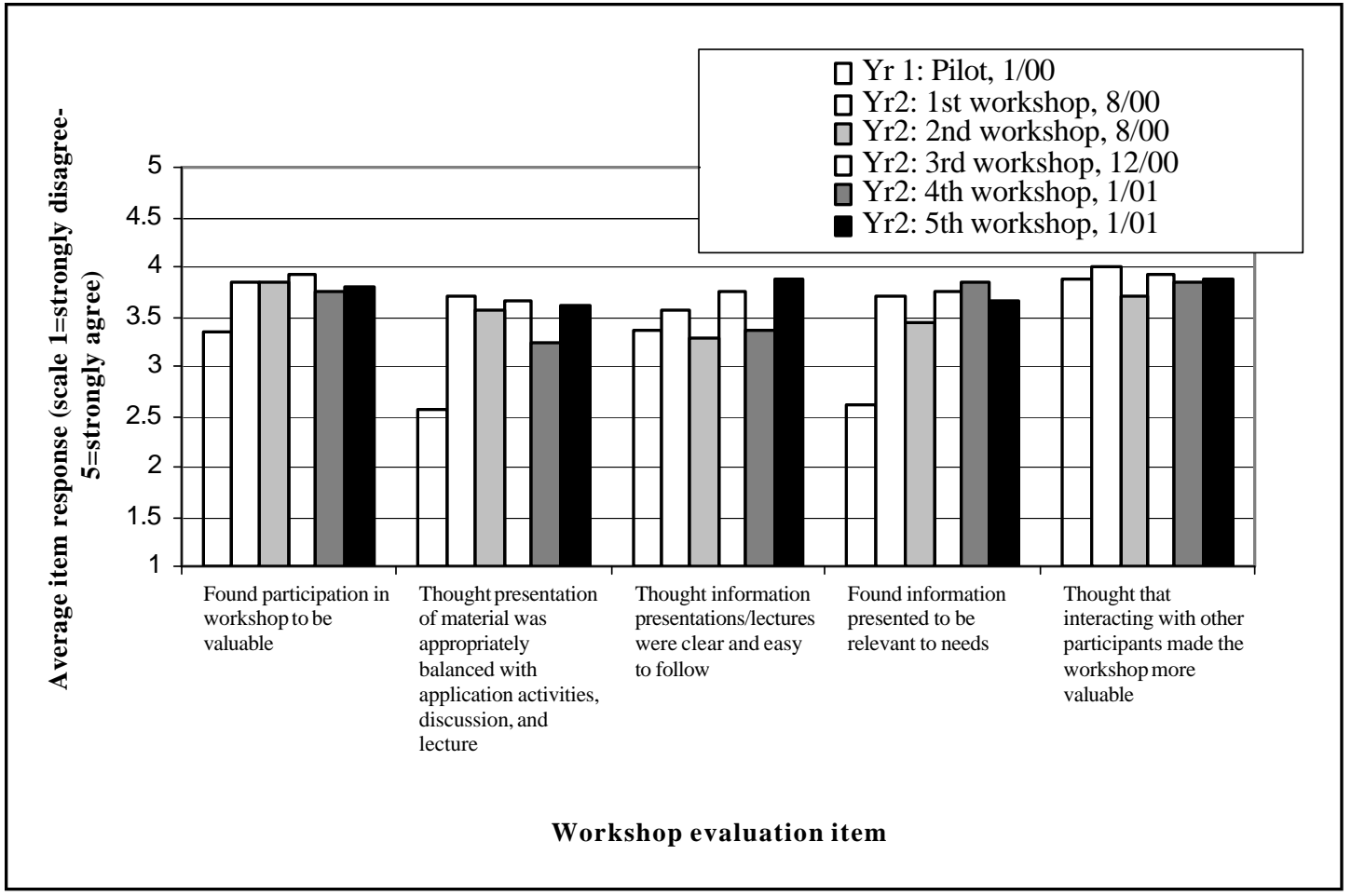


In general, faculty indicated a high appreciation for the information presented and the interactive and "hands on" nature of the workshops. One person's statement from a workshop evaluation sums up the positive regard for the workshops:

What I left with is the most valuable and that is the wider view regarding disabilities, a more positive outlook on various approaches to use, a renewed sense of "what I should be doing," tons of useful knowledge regarding the law, access issues, and what [my campus] has to offer.

\section{Summative Evaluation}

In order to capture the impact of workshop participation, several data collection activities have been implemented. First, longitudinal progress reports have been sent out three times per year to all participants. These progress reports contain open-ended questions asking faculty to report changes they have made on the job as a result of workshop participation. Second, interviews with self-selected faculty have been conducted several months after their participation in the workshop. The interviews are designed to explore in more detail faculty's reactions to their workshop experience. At the end of the second project year, longitudinal progress report data were available from 60 faculty (58 instructors and 2 advisors), and interviews had been conducted with 8 faculty ( 7 instructors and 1 advisor).
The primary outcomes of interest have been the degree, both in quality and quantity, to which faculty have modified their instructional practices and taken measures to improve the classroom climate. From progress report and interview data, CTAD appears to have impacted faculty's actions, attitudes, and awareness. What follows is a discussion of this impact within the framework of the Universal Instructional Design principles, which were presented earlier in the chapter. A brief discussion of CTAD's impact on participating administrators will also be presented.

\section{Modification of Instructional Practices}

Instructional practices refer to the means by which faculty impart knowledge to students. There are two important components of instructional practice: (a) information access, or the degree to which course content is equally accessible to all students; and (b) instructional design, or the ways in which faculty engage students in the teaching-learning process. Faculty can improve in both of these areas by practicing the following principles of Universal Instructional Design: (a) provide clear expectations and feedback, (b) explore ways in which to incorporate natural supports for learning, (c) implement multimodal instructional methods, (d) provide a variety of ways for demonstrating knowledge, and (e) use technology to enhance learning opportunities. 
CHAPTER $2 \mid 33$

Implementing Universal Design

\section{Information access. Faculty took} measures to promote information access in a variety of ways. In the progress reports, $31 \%$ $(n=18)$ of faculty indicated making at least one modification to course materials in ways such as providing copies of lecture notes and overhead or PowerPoint information, reformatting course materials, and providing audiotapes of lectures. For example, one participant noted:

I am now more aware of the individual needs of students in my classes. I have arranged for note takers who will copy notes for my sight impaired students who find it difficult to read my "whiteboard notes." I previously had my notes available on the computer (power points slides with written info). I am having our printing services make larger print copies of selected handouts.

Another participant indicated that: "Lecture notes have been made available to all students with the intent that this will help those that have a disability as well as all other students who may choose to access the information." This participant appears to have been motivated by UID notions that promoting access for students with disabilities can benefit all students. Another participant observed how promoting information access for a student with a disability was appreciated by other students for whom the modification was not directly intended:

I also distributed handouts for all overheads and computer projections that I demonstrated in class. This, essentially, was an accommodation for [a disabled] student, and to help students who might have more difficulty with simultaneously processing visual and verbal information. Most students in the class, however, commented at one time or another on the helpfulness of all the handouts.

Another participant noted the specific benefits of electronic information access for all students:

I have one student that has difficulty in reading and writing, thus, I have provided all my classes with my power-point lecture notes in advance. Students are able to access my lecture outline through the web. By providing my lecture outline in advance, this allows students to do more discussion in class, and allow more time writing down examples given in class.

Information access can also be promoted by slight modifications to lecture or presentation style, as reported by one faculty member: 
For example, with a deaf student, I tried to limit my use of vague terms and pronouns, such as "this" and "that." The deaf student needed to use an interpreter. When I pointed to something and said "this," I was usually pointing to something else or nothing at all by the time the deaf student understood the interpretation. By being more specific, the student had a better understanding of my references, and I'm sure the specificity was beneficial to the rest of the class.

Many faculty $(36 \%, n=21)$ also promoted information access through the use of technology. Most accessible technology use involved making course materials available electronically or taking measures to ensure that current course websites were accessible to a diverse range of abilities; $31 \%(n=18)$ of faculty made course materials available electronically by posting their syllabus to the web or providing online or disk copies of lecture notes, assignments, and exam review materials. Some faculty $(n=7,12 \%)$ mentioned that they had either tested their current websites for accessibility or that they were more attentive to accessibility issues when designing or redesigning websites. Several faculty who were interviewed mentioned that the CTAD workshops made them more aware of how technology use could promote equal access to the curriculum. For example, when talking about accessibility of course components for students with disabilities prior to CTAD, one faculty member said "I wasn't that interested in putting my syllabus on the web because I didn't really think about how that may help students with disabilities."

Faculty also made course content more accessible by using multimodal methods for instruction and assessment. In their followup progress reports, many faculty explicitly mentioned attending to students' diverse learning modalities; $21 \%(n=12)$ noted that they had made changes such as balancing the modes in which information is presented, allowing alternative modes by which students can demonstrate knowledge, or including more multimedia in the classroom. For example, one participant noted a much greater use of visual stimuli, such as overheads, videos, use of whiteboard, and various props. Another acknowledged "trying to hit a concept from many directions ... on the web, in lecture, on CDROM, in groups, etc." A third said she offers a wider range of activities in class that play to different students' learning styles. "We are tackling some material in new ways," notes one participant, "with students doing presentations rather than listening to me lecture and we will see how that works."

Participant responses from both the follow-up reports and interviews evince that faculty appear to be more "aware of how an accommodation for a student with a 
CHAPTER $2 \mid 35$

Implementing Universal Design

disability can be beneficial to most students in a course" and more aware of how important it is to "have more of a grab bag of ways to both communicate [information] and to ensure that it is being communicated." UID principles have helped faculty to see value in pre-planning and building up a stock of well organized course materials that would be on hand whenever a student might need them. For example, when talking about the provision of class notes, one participant said:

I hadn't thought of it as, you know, that's a good reason for doing it. I thought, well making notes available to students is a nice thing, but I hadn't thought of it as Universal Design, in the event that I should come across a student with a disability who might need them.

The CTAD workshops have appeared to result in many faculty taking less for granted and thinking more critically about information access. For example, one faculty member, in light of heightened awareness promoted by CTAD workshop participation, noted that he was

concerned that some of the technologies that we are using, we are kind of getting into some video streaming things, and again my concern with that is that in the event that it should have to go to a person that can't hear or has difficulty

hearing, what then?

Instructional design. Faculty indicated that they had taken measures to redesign instruction in order to more effectively engage students in the teaching-learning process.

In their progress reports, $26 \%(n=15)$ of respondents indicated making at least one modification to their testing and assessment practices. Because extended time is a common accommodation for many students with disabilities, and because many students who do not have disabilities also struggle with issues of test anxiety, many faculty who made testing and assessment modifications chose to administer shorter, more frequent tests so all students would have adequate time to finish. For example, one participant said:

We went from 4 to 6 exams so that the material on each exam represents a smaller chunk of the course, thus making it easier to prepare for exams. And the number of items on each exam has been reduced from typically 10 to 6-8, which allows students more time to answer each question and reduces the anxiety that they might otherwise feel.

A few faculty indicated that they had made progress in developing alternative means by 
which students could demonstrate knowledge. For example, one faculty member said:

I also started giving weekly short answer written quizzes in addition to the writing intensive papers and multiple choice tests. My hope is that a student's grade does not all fall on multiple choice tests or written work. There are a number of different types of evaluation measures to match different students' strengths.

Finally, one faculty member took measures to provide more clear expectations by "providing students with a detailed list of objectives, location of the instruction in the book, and representative problems to study for exams." The faculty member noted that this was done "in response to students with learning disabilities indicating that clearer expectations as to what to study for on exams, and where to find that material, would be helpful."

Fourteen percent $(n=8)$ of faculty indicated making at least one modification to course assignments in ways such as restructuring feedback, tailoring assignments to individual student needs or providing alternative assignment options, and relaxing assignment deadlines. For example, one participant reported:
I have offered assignments in multiple formats - print, web based, and verbal. I have become more attentive to different learning preferences that may result from physical or other disabilities. I give assignments that make available alternative ways of demonstrating knowledge.

Another participant noted that she has "been much more aware of the various needs of the students and tried to address those needs" and consequently "changed the design of certain assignments to hopefully better meet the needs of each student."

Many faculty $(n=13,22 \%)$ also said that they had modified their instruction or instructional philosophy in some more general way. For example, one faculty member reported tailoring "the class to fit the individualized needs and interests of each student [and] moving away from lecture and discussion formats to more of a workshop mode." Other faculty reported providing more structure, support, and feedback. One faculty member did this by creating "a class e-mail list, which reviews the week's lecture material and offers suggestions for writing topics and encourages student responses online" and another did this by explaining her expectations on the syllabus so that students would have "a good idea of the workload issues up front." Some faculty indicated a 
better ability to more critically examine the success of instructional strategies, as exemplified by one response:

I have approached the project of teaching with much higher sensitivity to the presence of different physical and cognitive learning styles and abilities in the classroom. This has resulted in an ongoing discussion over the course of the term about classroom strategies, how they are working for the individuals and the class as a whole, and ongoing discussions about individual strategies for getting the most out of the class's activities.

Some faculty even included UID principles in course content. For example, one faculty member reported, "Telling my new classes about universal design including all students' recognition of how they learn best. I have had several students come talk to me, two of whom contacted disability services for evaluation as a result of this class discussion."

\section{Measures to Improve the Classroom Climate}

Workshop faculty appear both to have a heightened sense of awareness regarding students' needs and to be better equipped to work with students with disabilities in the classroom. In their follow-up progress reports, many faculty $(n=17,29 \%)$ indicated having made specific accommodations for students with disabilities since the workshop; in the past year, 37 faculty indicated that at least one student with a disability had been enrolled in their course(s). Twenty-six percent $(n=15)$ of faculty noted an increase in their awareness regarding the needs of students with disabilities or a better capacity to work with students with disabilities. In an interview, one participant said that since the workshop:

I have been working more closely with our Office of Disability Services and particularly I think I've been a little faster to recommend students to find a tutor when I seem to recognize that they are having problems in class .... I seem to be more aware and be able to pick out a student that is struggling and be able to realize that it's not the content- there is something else here that is probably causing this.

Another participant mentioned a new found awareness for how the socially-based pedagogy in her class-a method she previously "always thought of as empowering"- might indeed be "hard for somebody who has some kind of social anxiety disorder, or even just a shy student ... or a student from another culture who is self conscious about their English language use." 
One third $(n=19)$ of faculty indicated in their follow-up progress reports that they either had taken steps to encourage interaction between themselves and their students or had taken steps to create a climate that fosters trust and respect. Some reported that they had increased their efforts to encourage disability disclosure by including or updating disclosure and accommodation statements on their syllabus or verbally expressing that they support needs of diverse learners. For example, one faculty member said:

I asked students on the very first day of class to let me know if they had any types of impairment (either documented or undocumented) which could influence their participation in the class. Many students who experience communication anxiety and test anxiety came and talked to me- this was a great way to open up the class for dealing with communication anxiety.

Other faculty helped make students aware of university support services by, for example, making "a point at the beginning of the semester to verbally inform students about disability services available at our campus" or informing students "that there are university resources for testing of LD' $\mathrm{s}$ " for "students who are concerned that they may have a learning disability."

\section{Conclusion}

The Curriculum Transformation and Disability Project has designed, tested, and implemented an ambitious program of faculty and staff development, with the goal of creating a core of educators capable of using the Principles of Universal Instructional Design in course development and course delivery. These Principles of Universal Instructional Design have shown promise in illuminating faculty responsibility in making courses more fully accessible and have begun to find their way into courses and faculty practice.

Midstream formative feedback shows the workshop to be welcome in our professional development of educators in different disciplines and in different institutional settings. The promise of strong impact on educators who take the time to participate in CTAD workshops is beginning to emerge.

\section{References}

Americans with Disabilities Act of 1990,

P.L. 101-336, 42 US CA. 12, 101-12,

213, (West Supp. 1991).

The Center for Universal Design. (1997).

The Principles of Universal Design.

(Version 2.0) [Brochure]. Raleigh, NC:

North Carolina State University. 
CHAPTER $2 \mid 39$

Implementing Universal Design

Chickering, A. W., \& Gamson, Z. F. (1987,

March). Seven principles for good

practice in undergraduate education.

AAHE Bulletin, 3-7.

Gill, C. (1987). A new social perspective on disability and its implications for rehabilitation. Sociocultural Implications in Treatment Planning in Occupational Therapy, 49-55.

Higbee, J. L., Ginter, E. J., \& Taylor, W. D. (1991). Enhancing academic performance: Seven perceptual styles of learning. Research and Teaching in Developmental Education, 7(2), 5-10.

Individuals with Disabilities Education Act. 20 U.S.C. 1400-1485 (1994), as amended by 20 U.S.C.A. 1400-1487 (West 1977).

Rehabilitation Act of 1973. P.O. 193-112. Section 504. 
$40 \mid \begin{aligned} & \text { CHAPTER } 2 \\ & \text { The CTAD Model }\end{aligned}$ 
CHAPTER $3 \mid 41$

Implementing Universal Design

\section{Perceptions of Universal (Instructional) Design: A Qualitative Examination}

Jennifer P. Hatfield

University of Minnesota

This chapter reports the results of a qualitative study of the impact of Curriculum Transformation and Disability (CTAD) training on the work of eight participants.

$\mathrm{n}$ order to instigate a shift in the experience of undergraduate students with disabilities, Curriculum Transformation and Disability (CTAD), a Model Demonstration Project sponsored by the U.S. Department of Education, has undertaken the continuing professional development of faculty, administrators, and advisors. Since January 2000, 147 faculty, administrators, and student services personnel from colleges and universities in the Upper Central and Lower Great Lakes Region have participated in CTAD professional development workshops. Workshop curricula, founded upon principles of Universal Instructional Design (UID), have been designed to facilitate understanding of disability issues and implementation of accommodations as part of the regular curriculum (for more on UID and the CTAD program, see chapters 2 and $3)$.
Program evaluation data show that participants have been modifying curriculum, instruction, policy, and practice in accordance with UID principles.

However, attitude theory suggests that it is important to examine the attitudes behind these actions (Ajzen \& Fishbein, 1980; Bourke, Strehorn, \& Silver, 1997; Chubon, 1992; Kalivoda \& Higbee, 1998). Such an examination lends useful information regarding the general merit of this relatively new instructional philosophy. For example, Ajzen's theory of planned behavior (as cited in Kalivoda \& Higbee, 1998) posits that actions are a function of three belief and attitude constructs. First, a person's action is contingent upon personal beliefs regarding the degree of control he or she has over that action. In the context of applying UID, a person might therefore be influenced by the degree to which he or she feels the 
principles can be applied in practice. CTAD Participants have obviously applied UID principles to modify curriculum and instruction, but without further inquiry, the thought processes behind these actions remain unknown. Participants could have acted out of a sense of obligation rather than out of beliefs that implementing UID is generally feasible. A person's action is also determined by the semantic valence he or she attributes to performing the action. If a person feels that UID principles have little merit, he or she may have negative or neutral feelings about applying the principles, and therefore will not be intrinsically inclined to practice the principles. Finally, according to the theory, a person's action is influenced by personal beliefs regarding "the presence or absence of social support for engaging in the [action]" (Kalivoda \& Higbee, 1998, p. 14). A person may feel that UID is a useful and practicable model, but might be deterred from using the principles in practice due to flak received from colleagues or administration.

Attitude theory suggests that a description of how UID principles have intersected with participants' pedagogical philosophies and personal backgrounds can adumbrate the future of this approach. If this approach is not well-received, malleable, and applicable to a variety of situations, how enceinte with possibilities can it be? If this approach is easily subject to theoretical criticism, perhaps it may be a passing fad, not to be built upon or perseverant in the face of competing approaches. This chapter will qualitatively examine these issues and describe the appeal (or lack thereof) that UID principles held for a group of CTAD workshop participants.

At the outset, it was postulated that participants' reactions to UID and resultant post-workshop actions would be a function of pre-workshop "real-life context". It was also postulated that outcomes would not be uniform across participants, both because of the wide array of options for action suggested by workshop curricula and because of the potentially complex interactions between participants' interpretations of UID, pre-workshop lived experiences, and innumerable psychological characteristics such as personality, affect, and motivation.

\section{Method}

\section{Data Collection}

In order to gather qualitative, summative information about the short and long term impact of CTAD, a study was designed to collect in-depth conversational data about participants' experiences with the CTAD project. Data were collected using semi-structured interviews (i.e., open-ended conversations prompted by a structured set 
of questions) designed to allow participants the opportunity to reflect on their experiences and perceptions of CTAD and its principles. Specifically, interviewees were asked to share anecdotes and personal experiences regarding their work with students with disabilities prior to CTAD workshop participation as well as the changes they had made as a result of workshop participation. Interviewees were also asked to discuss their attitudes toward UID principles and the kinds of transformations that these principles may or may not imbue. The interview protocol is displayed in Figure 1.

\section{Participants}

Interviewees self-selected into the study by responding to an e-mail message from the project director alerting them of the opportunity. All volunteers were first interviewed approximately six months after workshop participation, and a second time approximately one year after workshop participation. At the end of the second project year, interviews had been conducted with eight participants (seven faculty and one advisor) from three different public institutions of higher education in the Midwest: an urban research University, a small liberal arts college, and a small college specializing in science and technology education. The interviewees came from diverse backgrounds, covering the disciplines of science, history, economics, art, writing, foreign language, and the social sciences, and ranging in job experience from 6 to 31 years.

\section{Data Analysis}

A case study approach was used to analyze the interview transcripts from the eight participants. Other available data from these participants (i.e., pre-workshop surveys and post-workshop activity reports) were consulted at times to complement, verify, or add additional context to emerging themes from the interviews. The objective of this inquiry was not simply to capture "mere frequencies or incidence" of behaviors, but rather, to examine "operational links" between participants' pedagogical philosophies and experiences, personal backgrounds and characteristics, and exposure to UID principles. Due to the explanatory nature of this objective, the case study method was chosen because of its potential to help build both rich explanations about how UID principles were received by CTAD participants and conjectures about why they were received in the ways they were.

Although some might criticize the use of case study methods because "they provide very little basis for scientific generalization" (Yin, 1989, p. 21), this criticism is a moot issue for this study. The intent of this inquiry is not to make population statements about how UID principles might be 
Figure 1. Interview Protocol for CTAD Participants

\begin{tabular}{|c|c|}
\hline Content area & Interview prompt* \\
\hline Anecdotes and personal experiences & $\begin{array}{l}\text { Prior to going through the CTAD training, how would you } \\
\text { describe your level of awareness about and types of } \\
\text { interactions with students in your classes who have } \\
\text { disabilities? } \\
\text { Describe some specific challenges or successes you have } \\
\text { experienced in teaching students with disabilities. What } \\
\text { in particular was challenging or successful for you and } \\
\text { the student? } \\
\text { Has any aspect of CTAD training made you think any } \\
\text { differently about your interactions with students who } \\
\text { have disabilities in terms of teaching and level of } \\
\text { curricular accessibility? } \\
\text { Prior to CTAD, how would you describe your course } \\
\text { components/curriculum in terms of its level of } \\
\text { accessibility for students with disabilities? What in } \\
\text { particular made it accessible or not? }\end{array}$ \\
\hline Value and impact of CTAD & $\begin{array}{l}\text { After participating in CTAD training, have you implemented } \\
\text { any changes in your course as a direct result? If you did, } \\
\text { what are they, and what in particular about CTAD made } \\
\text { you decide to make these changes? If you did not, why } \\
\text { have you decided not to make any specific changes to the } \\
\text { course? Were there any specific barriers which prevented } \\
\text { you from implementing planned changes? If you are not } \\
\text { making changes now, do you think you might make } \\
\text { changes over the long term? } \\
\text { In general, what aspects of curricula in your discipline do } \\
\text { you perceive as accessible or not to students with } \\
\text { disabilities? Did CTAD training impact your views about } \\
\text { this in any way? } \\
\text { What is your perception of (or attitude toward) the } \\
\text { application of principles of Universal Instructional } \\
\text { Design (UID) and Disability Culture as it specifically } \\
\text { relates to the courses you teach, and more broadly to } \\
\text { curricula your discipline? }\end{array}$ \\
\hline
\end{tabular}


Figure 1 continued. Interview Protocol for CTAD Participants

\begin{tabular}{|l|c|}
\hline \multicolumn{1}{|c|}{ Content area } & Interview prompt* \\
\hline Value and impact of CTAD & $\begin{array}{c}\text { What kinds of "transformation" do you think are facilitated, } \\
\text { (or not facilitated), by CTAD principles? For example, one } \\
\text { principle was the notion of challenging traditional views of } \\
\text { "accommodation" with notions of "UID" - what is your } \\
\text { perspective on this as it relates to your practice/research? } \\
\text { What kinds of transformation could result from this } \\
\text { "challenging"? } \\
\text { Beyond the initial CTAD training this year, what do you plan } \\
\text { to do in the future related to these concepts? Will you } \\
\text { continue to work with CTAD principles or with the CTAD } \\
\text { training team? }\end{array}$ \\
\hline $\begin{array}{l}\text { Perceived impact of CTAD in } \\
\text { different contexts }\end{array}$ & $\begin{array}{c}\text { How would you describe the climate on your own campus and } \\
\text { in your department related to the instruction of students } \\
\text { with disabilities, particularly in terms of CTAD principles } \\
\text { like UID? } \\
\text { What kinds of resources and support (departmental and } \\
\text { campus) exist for these students? What barriers exist for } \\
\text { students and for faculty/administrators in supporting them? }\end{array}$ \\
\hline $\begin{array}{l}\text { *For interviewees whose job duties were not strictly related to instruction, language in the interview } \\
\text { prompts was modified to reflect their job function. }\end{array}$ \\
\hline
\end{tabular}

received, but rather, to examine the degree to which case study evidence supports or refutes the theoretical proposition that UID principles can facilitate curricular or programmatic design.

A fatal flaw in doing case studies is to conceive of statistical generalization as the method of generalizing the results of a case. This is because cases are not "sampling units" and should not be chosen for this reason.
Rather, individual case studies are to be selected as a laboratory investigator selects the topic of a new experiment. Multiple cases, in this sense, should be considered like multiple experiments (or multiple surveys). (p. 38)

Data analysis followed procedures suggested by Miles and Huberman (1994). Analysis was grounded in a semiotic analytic approach (Feldman, 1995) and 
focused by the primary proposition that CTAD impact has meaning within a person's context and history. In the analysis, specific attention was paid to the following context topics: disability awareness, historical frustrations and roadblocks when working with students with disabilities; accommodation style; pedagogical style; and dilemmas in curriculum and instruction. Coded transcripts were used to generate an interpretive case summary sheet for each interviewee. The next step was to reread the transcripts looking specifically for content related to CTAD impact. This content was used to characterize each interviewee's reaction to UID. The context topic and UID reaction characterizations were brought together in an attempt to more fully describe participants' reactions to UID by explaining how UID principles had intersected with participants' pedagogical philosophies and personal backgrounds to produce, or not produce, behavioral or affective outcomes.

\section{Results}

Faculty reactions to UID appeared to approximate one of several types. There was "enlightenment," where UID principles seemed to facilitate solutions to (or advances in solving) an existing problem. There was the "cold shoulder," where the model met with more skepticism and found scant place to rest and grow into practice. Finally, there was the "revelation," where the model appeared to open a frontier of pedagogical opportunities either by introducing a completely new concept or by putting definition to current instructional practices that had previously been sublimated and intuitive. Three cases representative of the typologies that emerged in data analysis are presented below followed by a case summary of the one student services interviewee.

\section{Case 1: Enlightenment}

John is a professor of history and economics at an urban Midwestern research university. He teaches mostly freshman students in a college that has a history of providing supportive and responsive pedagogy to a student body that is diverse in terms of race, ethnicity, socio economic status, and disability status. At the time of the first interview, John had been teaching at the postsecondary level for 15 years, and in that time indicated that over 30 students with disabilities (of whom he had been aware) had passed through his classroom.

John's reaction to UID principles could be characterized by enlightenment. He talked mainly about UID principles in terms of one specific application, namely the way in which technology could be used to increase curricular access. There was also some element of revelation in his reaction, because UID principles did mollify some skepticism and reveal to him the benefit of 
using technology in instruction. However, he seemed to better approximate the enlightenment theme because, in terms of behavioral and affective outcomes, a "light bulb turned on" resulting from the confluence of a specific pre-existent "dilemma" and exposure to UID principles.

John reported having a high degree of disability awareness, which he attributed to his wife and the college he attended as an undergraduate. His wife had over 20 years of experience working with students with disabilities as a physical therapist, and he reported that he had "learn[ed] a lot by just listening to her talk about either issues the parents had or issues the school had or whatever surrounding handicapped students." He also attributed his awareness to the college he attended, which was a forerunner in promoting equal access so "what [he] assumed was normal, was unique" at the time.

In working with students with disabilities in the past, he indicated taking fairly common measures, like giving students materials before class and administering exams in separate rooms. He seemed to have thought mainly about modifying current materials rather than changing how they were delivered (i.e., content versus media). In general, he seemed to have a very open and receptive attitude about working with students with disabilities, and expressed a willingness to "do whatever work was necessary," even in light of fear or skepticism. Furthermore, he was also very willing to communicate with students about what they might need and took the time to work with students to ensure that they understand content.

In some ways, in the past he seemed to be operating from the traditional notions of accommodation. He talked about providing specific accommodations to specific students, rather than describing course components that had worked well for the students with disabilities who had passed through his classroom. The modifications to course materials were made specifically in response to students with disabilities. In terms of exams, he did indicate that: "additional time was never a problem because I really don't have time limits on my tests anyway." Also, his words did echo UID when talking about how he presented some information in class:

When I am showing a map or discussing a map I am explaining it in more detail. This ends up benefiting all students in the class, but I think I've done a fairly good job of accomplishing that so that a blind person who can't see the map still understands whatever the teaching point is.

In terms of classroom climate, his practice aligned with tenets of UID. He was 
attentive to students' needs when confronted, though he seemed to lack a certain proactiveness. When talking about working with students with disabilities, much of his discussion was reactive. $\mathrm{He}$ would be confronted with a student, or the need to accommodate, which would stimulate receptiveness, rather than his attentiveness prompting him to approach students.

John discussed a few issues with which he had been concerned: one related to disability access and another related to course materials. First, although he was generally satisfied with the degree to which his courses were accessible to diverse learners, the question of how to successfully reach blind students in one of his classes had remained a conundrum. This course relied heavily on visual information in the form of charts and graphs, and he had not yet found a way to express the information to blind students. Even after CTAD, the question of how to represent this information in other modes still remained, so UID did not make its impact here. UID made its impact on the tails of the other dilemma with which John was struggling: namely, the quest to find a better, less Eurocentric textbook. He was drawn toward the UID principle that advocates using technology to enhance learning opportunities, saying that "the idea of Universal Instructional Design has really appealed to me and particularly, at this point the way I envision it is through using technology." He went on to say that he has been "a little slow to jump on the technology bandwagon" because in the past he felt like technology was simply redundant—-"a new toy to deliver the same stuff." In the past, he also was even under the "misconception that putting things on the computer might actually make it less accessible to students with disabilities." $\mathrm{He}$ noted that the notion of building accommodations into the course itself, in conjunction with the technology demonstrations in the workshop worked to "[open] up an advantage of technology that I hadn't really been aware of." The intersection between past curriculum development issues and UID conceptualizations became evident when he discussed how he was planning to include web-based assignments in one of his courses, the idea for which he attributed partly to "CTAD and the idea of making this all more accessible" and partly to his quest for a "balanced world history book." When asked whether he had previously considered using the internet to supplement a textbook, he said:

The light bulb turned on after those [above two things]. I was trying to figure out other ways to do it and I hadn't really been thinking in terms of the internet or technology. So that light bulb didn't go on until after this [putting CTAD knowledge and current dilemma together]. 


\section{Case 2: Cold Shoulder}

Jerry is a science instructor at an urban Midwestern research university. Like John, he also teaches mostly freshman students in a college that has a history of providing supportive and responsive pedagogy. At the time of the first interview, he had been teaching for 10 years. In that time he indicated that between 6 and 10 students with disabilities (of whom he had been aware) had enrolled in his courses; however, he also noted that "in one way, all of them" are disabled to some degree, reflecting a more progressive notion of disability rooted in individual difference rather than individual deficit theory.

His experience with CTAD was generally positive, but he reported two "issues" or observations about the program in general related to its novelty status and its theoretical relationship to prior curricular trends he had seen throughout the years. These "issues," in conjunction with his more progressive pedagogical style, appeared to result in a cold shoulder reaction to UID principles.

Jerry seemed to be quite aware of resources available for students with disabilities, which he attributed to time and experience. He reported a "very difficult" past experience when a student with a visual impairment had enrolled in his class.
Because both he and the student were not aware of the available resources, he felt like he was "trying to re-do a whole bunch of things that had already been done." But, with this experience and others, he came to learn that, for example, "there are services where you could take your lab book and get it converted into Braille."

When talking about past interactions with students with disabilities, Jerry, like John, seemed to have been more receptive than advocating. He did indicate some uncertainty in terms of the appropriateness in approaching and offering help to people with disabilities, and, like John, he struggled with how to make his course accessible to students with visual impairments. In the classroom, he appeared to have both acted from traditional notions of accommodation where standard and prescribed actions are taken, and more progressive notions where dynamic actions are taken in response to the voice of the student with a disability. His approach to instruction seemed very flexible and unconventional within the traditions of his scientific discipline. He seemed to be very much led by students in the walk toward providing an equal opportunity education; for example, he said: "I am always fine with plan B. you know, 'what do you want to do? OK well we can't cut apart a pig, what should we do instead?' and then I usually am saying 'propose something'." 
He went on to talk about how he was struggling, trying to balance pedagogy in support of learning with pedagogy in support of tradition. When talking about providing students alternatives to lab activities, he went on to say: "and that is where the different committees at the University say: 'Well that is not a lab activity.' And that is where [another instructor] hit the wall too in a few things that he was doing ... and you just kind of shake your head and say 'bureaucracy'."

In many respects, Jerry already seemed to be incorporating UID principles in his pedagogy before CTAD. He realized that "students change all the time so your activities have to change in some way." His instructional flexibility supported a variety of ways in which students could demonstrate knowledge. Providing multimodal instructional methods also seemed to play a key role in his pedagogy, as exemplified by his statement that "you hit the same topics in different ways I think. You hit on the web, you hit it on a videotape, you hit it orally, you hit it visually, you hit it tactically in the lab." Jerry also actively worked on determining essential components, as exemplified in his statement that "a general theme of each year [is that] I teach less and less ... [which] means that each year I am trying to pick out what is most important." Finally, he was also very adept in the use of technology, which he used heavily in instruction.
Furthermore, unlike John, even before CTAD Jerry saw technology's potential for improving access to education for students with disabilities.

This faculty member, progressive in many ways, had an interesting reaction to UID. Although he did say that, possibly as a result of CTAD, "more and more and more redundancy is what I'm seeing," no light bulb appeared as it had for John. Jerry saw UID as "a new player, you know, one player. You have other players, too. You have conceptual change, you have problem solving, you have cooperative learning, you have concept mapping, you have Universal Design." He was more skeptical of UID, and instead of seeing it as a new bandwagon upon which to jump, he seemed to have a scientist's reservation, distrusting a new theory until it has been proven. When asked whether he felt that UID was "an old player with a new name," he went on to say:

I don't even know what the old player is. Is the old player education? I think so, I think that's the old player. A new player, Universal Design, is still a new concept or a new tool to throw in there and see how it works. Just like open classrooms were big in the 60s. Did they work? No, they went away. The tool went away.

His skepticism toward UID appeared also to be a function of a view that teaching, and 
our knowledge about how to teach, is an evolving process and not an absolute endpoint. This was evident when he went on to say:

Universal Design might stay, you know constructivism, probably not, I hope not, something better will come along. Likewise, am I going to be teaching the same way 40 years from now, 30 years from now? I hope not, I hope something better comes along.

In terms of pedagogy and curriculum design, Jerry marched to his own beat. Even though he did indicate struggling with some issues, like how to effectively engage students with visual impairments and how to balance the tension between "old school, new school" pedagogy, UID principles appeared to have no place upon which to alight (as they had for John), even fleetingly, in Jerry's mind. Rather, to him, UID principles were but another fruit to be observed in his journey through the forest, a fruit simply left to ripen on the branches of theory and of little need to him, already sustained by current practice: his own beat, his pedagogical predilection to have "students do things in their strengths."

\section{Case 3: Revelation}

Margaret is a professor of Humanities and French at a small Midwestern liberal arts college. At the time of the first interview, she had been teaching for nine years and in that time had been aware of between 11 and 15 students with disabilities who had enrolled in her courses.

Margaret's reaction to UID principles was very enthusiastic, and embodies the revelation type of response. In the past, she had relied heavily on Disability Services to provide accommodations for students with disabilities, but UID principles helped reveal her role in creating an equal access classroom. For Margaret, UID principles promoted a way of thinking about access that is contrary to the notion of accommodation. As a result, she reported a broad array of behavioral and affective outcomes.

Unlike John and Jerry, Margaret was perhaps more of a novice in working with students with disabilities, though she didn't report having encountered fewer students in the classroom than had Jerry. When asked about her level of disability awareness, she admitted that it was "fairly low ... in terms of knowing that students had a particular disability, but not really knowing how to accommodate them unless I got information from Disability Services."

Margaret's approach to accommodation was very traditional and reactive, rather than proactive. For example, she said that: "when disability services would contact me with a student who had a disability we would try 
to, you know, find a substitute way for that student [to do an activity]." She talked about having been "fairly successful in trying to find alternative testing, ways to take tests for students with dyslexia, for example, just giving them extra time or putting them in a different room." She also talked about how, in response to specific students with disabilities, she had provided tape-recorded lectures or made modifications to the physical environment.

In some ways, Margaret appeared to be more of a "clean slate" than Jerry or John, in terms of her receptivity to UID principles. She received UID principles very enthusiastically, saying that it was "just sort of the idea of Universal Design," which lay behind the myriad ways in which she had changed her course since participation in the workshop. Unlike John, who honed in on the use of technology to enhance learning opportunities, Margaret made use of many principles. She incorporated natural supports for learning by "making printed materials in advance" for her classes, and building up a reserve of these materials. She had become more flexible and creative in terms of instructional methods and assessment practices. For example, she indicated that she was doing "more active, more performance-based things in class", doing "more in class presentations as a basis of evaluation," and evaluating students "on some less formal levels . . . ways for them to show that they have learned something ... [other than] high powered written tests." She had also started to use more peer collaboration in the classroom as a way to "give [students] extra opportunity and reinforcement" in the learning process. This created another instructional mode and performance feedback mechanism. She also mentioned the positive effect that UID principles had on the classroom climate and how she now thinks differently "in terms of interactions with students, in terms of making, or trying to improve, the comfort level of [her] students." Even though, prior to CTAD, she felt that she "had always been somewhat good at creating a good classroom climate," after the workshop the UID principles helped further bolster classroom climate by promoting a classroom community where "everyone [has] a responsibility within the class," and pedagogy plays to students' strengths and moves toward a more collaborative endeavor where students work together, and with the instructor, to develop knowledge and understanding.

For Margaret, UID principles appeared to be rather transformative. When talking about how her notion of accommodation had changed, she said that UID principles helped move her from "that idea of "well, there is this one student that I have to figure out what to do with" "toward the more progressive idea of "restructuring the whole 
CHAPTER $3 \mid 53$

Implementing Universal Design |

class." Her reservations about "the idea of restructuring the whole course to accommodate one student" were mollified by "the idea of Universal Instructional Design [which] really changes the way that you can think about [course restructuring]." Furthermore, the principles seemed to operate as a pedagogical heuristic - a toolbox to help improve instruction-as evinced by her statement that:

I have a little 3 by 5 card on my computer now with a list of all the UID strategies that I can use. You know, and there is a list of like 15 things that I can do, like criteria and base learning, putting all materials on reserve, testing in the same manner as teaching and things like that.

In applying UID, Margaret was seeing positive results in her own classroom as well as the model's potential appeal for her discipline. She noted how "some of those principles are very similar to what's going on in language pedagogy these days," but that "some of the aspects of what we do aren't working quite well yet." She went on to say how she hoped that as she learned more about UID she would be able to dovetail UID principles with current movements in language pedagogy. With this vision in mind, she felt that UID "is definitely going to influence us positively in the future."

\section{Case 4: An Advisor's Perspective}

Edward is an advisor at an urban Midwestern university in a unit that serves a population of students diverse with respect to race, ethnicity, socioeconomic status, and disability status. Although Edward does have some teaching duties, his primary role is as an academic advisor. He also has done some work as an advocate for students with disabilities. At the time of the first interview, he had been advising students for approximately eight years. He indicated having a high degree of disability awareness, although he did indicate that CTAD had "piqued my curiosity to look into learning disabilities a little bit more." In the past he had primarily worked with students with physical or sensory disabilities.

Edward described how several UID principles could be used by student services personnel and administration to lessen the barriers for students with disabilities in postsecondary education. He described how his advising unit had taken actions to enhance the institutional climate for students with disabilities by incorporating more disability information in admissions and orientation materials and student services training. He described how he was attempting to work with university governance in order to increase the accessibility of the disability documentation process. He also mentioned how the administration should work to determine the 
essential components of general and specific degree requirements.

Edward talked about being frustrated by students who might not disclose their disability: students who get "into trouble [and have] never told me of a learning disability until they are in trouble." He noted how characteristics of the institution and of the student both contribute to nondisclosure. Students with disabilities may come to postsecondary education lacking self advocacy skills because someone else had "made sure that they had got all of their accommodations in K-12." Students may get to college thinking that it is a fresh start, that their disability will not pose barriers, and that "everything is going to be magically different." Nondisclosure may further be propagated by postsecondary policy, which requires that a disability be documented before services can be provided but does not require that the postsecondary institution be responsible for documentation. Edward noted how this is especially problematic for students with learning disabilities, who may need current documentation in order to receive services. If this documentation does not come from the high school, the financial burden of testing and documentation will fall upon the student, and many students simply can't afford the testing. In order to address issues of student-institution relations and institutional climate that might preclude students from disclosing their disability, Edward noted how, since participating in the workshops, he and other student services staff have been

looking at things we can do in terms of working with [Disabilities Services] and admissions along the lines of sending out information ... [coming] up with a parent's package ... something ... to parents saying if your child is diagnosed with an LD make sure that you go to the high school to get a copy of the file and the paper work and forward it to the office for students with disabilities.

As well as talking about easing the transition into postsecondary education, he also talked about how measures were being taken to improve the institutional climate for students with disabilities. He noted how the student services staff in his unit has

had a frank discussion that our definition of culture was too narrow, and we work hard to make this place as comfortable to students who are racially and ethnically different from the dominant culture, and we do a good job, but we do have a fair number of disabled students and wonder if we are doing the same thing.

Furthermore, he noted how "since CTAD [we have] set up kind of a special training 
for staff with disabilities services where we really spent a better part of the day with them ... all morning discussing various services."

In order to increase student access to accommodation, through his membership on a university governance committee, he was also exploring ways to incorporate natural supports for disability documentation. He noted how there are "competent people" on campus who could provide testing for disability, but that currently the university is "farming it all off campus," hence creating more roadblocks for students with disabilities.

Edward also noted some concern over the inflexibility of policy and procedure in institutions, programs, or departments. $\mathrm{He}$ noted how some degree requirements just might not make sense for students with certain disabilities and how UID principles could be used by administration to make programs more flexible and accessible in the same way that the principles are used by faculty to make courses more flexible and accessible.

Edward's case demonstrates how some UID principles can be used in the student services context to design or modify materials, communications, and policies and procedures. He did note, however, that "Universal Design is a little bit harder to incorporate" in advising. He did seem to believe that the principles had merit; he was just struggling with how they could specifically be translated into practice for student advising. He talked about how he and other advisors were using UID principles when engaging in course schedule planning with students to "put all students in classes their first term that would better guarantee that they would be successful." However, he did go on to say how this approach met with conflict from other administration. There were certain courses in the college for which there was an implied "one rule fits all" approach in terms of when the courses should be taken in a student's career. Following UID and being flexible in course scheduling had been difficult for advisors because they were getting conflicting messages from enrollment management personnel who were concerned that advisors were recommending students away from certain classes that needed to be filled.

Edward appeared to be seeking out other ways in which UID could be applied to advising. He noted how he and other advising staff were "trying hard" to find other ways UID could be incorporated in advising. But, he went on to acknowledge that some of this difficulty could be due to the nature of the advising model used in his college. He said that "the difference between being in the classroom and utilizing Universal Design and working in advising, 
which is $99 \%$ a one-on-one activity, is in advising you have the opportunity to really treat each student ... as a unique individual." He clearly regarded the UID model in a very positive light, noting how the principles would definitely have an application if the college were to move to a group advisement model. He did feel that UID had a place in advising, but that its place had not yet been fully realized. He said that he would look for "Universal Design in advising" at professional conferences and in the literature, noting that maybe "just hearing [Universal Design] presented in a different way will pop off some flashlight enlightenment."

\section{Conclusion}

Based upon participants' reactions to UID, it appears that this model does hold promise as a viable approach to curricular and programmatic design. Despite individual differences in job duties, discipline, personal and pedagogical philosophies, and instructional challenges most participants were attracted to some aspect of UID. Only one of the eight participants interviewed exhibited the cold shoulder reaction to the model. However, this person was skeptical of UID not because of the basic fundamental tenets of the model, but because to him, UID was simply "a new word for an old thing [i.e., good teaching]." It appears that participants were motivated to apply UID principles out of personal beliefs that the instructional model is truly useful and generally feasible. Although many of the participants interviewed had already been teaching in a manner aligned with UID, this did not diminish the appeal that UID principles held for them.

There was little indication that vituperation of UID principles by other faculty or administration had interfered with intentions to use the model in practice. However, most of the interviewees did work in a relatively progressive and supportive atmosphere. One interviewee noted her observation that the way in which UID is articulated can make a difference in how it is received by other faculty. She noted that:

When you can talk to [other faculty] about Universal Design . . . and principles of curricula transformation to promote accessibility to everybody ... they are much more open to the principles than when you frame the discussion as "you have a responsibility to make your class accessible to students with a range of disabilities.'

This person's experience talking with other faculty who had not participated in the CTAD program indicated that many faculty may hold misperceptions about accommodation that could ablate the appeal 
of UID for curricular transformation. Indeed, literature suggests that many faculty and administrators lack knowledge regarding students with disabilities and the accommodation provision (Aksamit, Morris, \& Leuenberger, 1987; Bigaj, 1995; Foster, Long, \& Snell, 1999; Hart \& Williams, 1995; Leyser, Vogel, Wyland, \& Brulle, 1998; Williams \& Ceci, 1999). Furthermore, some research has shown that faculty may balk at providing accommodations if the effort they must expend in making the accommodation exceeds the benefit (Bourke, Strehorn, \& Silver, 1997; Kalivoda \& Higbee, 1998). It thus appears that, in general, faculty and administrator attitude toward UID may be most positive when the model's promise for improving education for all students is first emphasized, followed by articulations of the specific

subpopulations for whom it holds benefit.

\section{References}

Ajzen, I. (1985). From intentions to actions: A theory of planned behavior. In J. Kuhl \& J. Beckman (Eds.), Action-control: From cognition to behavior (pp. 11-39). Heidelberg, Germany: Springer.

Aksamit, D., Morris, M. \& Leuenberger, J. (1987). Preparation of student services professionals and faculty for servicing learning-disabled college students. Journal of College Student Personnel, 28, 53-59.
Bigaj, S. J. (1995). Accommodation strategies for postsecondary students with learning disabilities: A survey of faculty attitudes and use. Unpublished doctoral dissertation, University of Connecticut, Storrs, CT.

Bourke, A., Strehorn, K. C., \& Silver, P. (1997, March). Tracing the links in the chain of accommodation: A study of University of Massachusetts' faculty members' provision of accommodations to students with learning disabilities. Paper presented at the annual conference of the American Educational Research Association, Chicago, IL.

Chubon, R. C. (1990). Attitudes toward disability: Addressing fundamentals of attitude theory and research in rehabilitation education. Rehabilitation Education, 6, 301-312.

Feldman, M. S. (1995). Strategies for interpreting qualitative data. Thousand Oaks, CA: Sage.

Foster, S., Long, G., \& Snell, K. (1999). Inclusive instruction and learning for deaf students in postsecondary education. Journal of Deaf Studies and Deaf Education, 4, 225-235. 
58 CHAPTER 3

Perceptions of UID

Hart, R. D., \& Williams, D. E. (1995).

Able-bodied instructors and students with physical disabilities: A relationship handicapped by communication.

Communication Education, 44, 140-154.

Kalivoda, K. S., \& Higbee, J. L. (1998).

Influencing faculty attitudes toward accommodating students with disabilities: A theoretical approach. Learning Assistance Review, 3(2), 12-25.

Leyser, Y., Vogel, S., Wyland, S., \& Brulle, A. (1998). Faculty attitudes and practices regarding students with disabilities: Two decades after implementation of Section 504. Journal of Postsecondary Education and Disability, 13, 5-19.

Miles, M. B., \& Huberman, A. M. (1994). Qualitative data analysis: An expanded sourcebook. Thousand Oaks, CA: Sage.

Williams, W. M., \& Ceci, S. J. (1999). Accommodating learning disabilities can bestow unfair advantages. The Chronicle of Higher Education, 45, B4-B5.

Yin, Y. K. (1989). Case study research: Design and methods. Newbury Park, CA: Sage. 


\title{
Community Colleges and Universal Design
}

\author{
Judy Schuck \\ University of Minnesota
}

Jane Larson

Minneapolis Community and Technical College

Community colleges are committed to serving all segments of society through open access admissions, allowing equal and fair access to all students. The diversity of community colleges makes Universal Design's "one size does not fit all" approach very compelling. At the same time, community colleges face significant challenges in fulfilling the promise of Universal Design (UD) and Universal Instructional Design (UID) because of this diversity and the limited resources available to both students and institutions. This chapter presents a description of community college students, their diversity and challenges in accessing higher education, as well as the opportunities and challenges colleges encounter in the implementation of UD and UID.

W hen we consider the history and mission of community colleges, it seems particularly fitting to include this chapter in a book on Universal Design (UD). In fact, we could view the community college model itself as a metaphor for this inclusive approach to delivering education. If we change the question an architect first asks in universally designing a building, "Who are the people who will need to access this building?" to "Who are the people who will need to access this education?" we get some idea of what the founders of community colleges had in mind.
Community colleges were formed in the early $20^{\text {th }}$ century with the goal of providing a gateway to opportunity for many young people who otherwise would have been denied access to higher education (Phillippe $\&$ Patton, 2000). Although the earliest junior colleges may differ from today's comprehensive community colleges, this goal of access still remains central to the community college mission. This mission is characterized by a commitment to serving all segments of society through an open-access admissions policy (i.e., open enrollment) that offers equal and fair treatment to all students (Vaughan, 1999). Whether young or old, affluent or 
economically disadvantaged, new to college or returning after time out, planning to enhance basic skills or transfer to ultimately earn a graduate degree, students who attend community colleges are seeking an environment that has been designed to accommodate them. Such an environment calls for a flexible and inclusive model of delivering education and makes UD's "one size does not fit all" approach particularly compelling.

In this chapter, we will first present a description of community college students, addressing both their diversity and the characteristics that make it more difficult for them to access higher education. We will then consider the features of community colleges that facilitate the implementation of Universal Design and Universal Instructional Design (UID) as well as the special challenges community colleges face in its implementation.

\section{Characteristics of Community College Students}

For the students who enroll in them, community colleges are often the first student experience in accessing higher education, a first experience in education in this country, or a return to school after several years of absence. Community colleges serve students of all ages and ethnic and cultural heritages, students with life and time conflicts, and students possessing a great range of skill levels. Community colleges also serve as the entry point to higher education for many students with disabilities. More adult students than traditional-age students are likely to access education in the community in which they live. Students who are still in high school, or who have left school before the age of 18 , also access community colleges through concurrent enrollment during high school. Only $32 \%$ of community college students are between the ages of 18 and 22, often considered the "traditional" college age. Forty-six percent of students are 25 years or older; $32 \%$ are age 30 years or older. On the other hand, $4 \%$ of students are under the age of 18 . Across the nation the average age of students attending community colleges is 29 years (National Center for Education Statistics, as cited in Phillipe \& Patton, 2000).

Ethnic and cultural diversity varies with the community being served. Nationally, over $30 \%$ of community college enrollment is comprised of students representing minority groups. This number is growing; minority student enrollment increased from 25\% in 1992 to over 30\% in 1997.

Meanwhile, at four-year colleges, minority enrollment increased from $21 \%$ to $24 \%$ during the same period. In 1997 students of Hispanic origin represented $11.8 \%$; Black students, $11.1 \%$; and Asian students, 5.8\%. 
Today, more Native American and Hispanic students attend community colleges than all other postsecondary institutions combined (National Center for Education Statistics, as cited in Phillipe \& Patton, 2000).

Nearly two-thirds of community college students attend college less than full time, compared to only $22 \%$ at four-year colleges. More than $80 \%$ of students work either full or part time, and 50\% work full time. Many students under the age of 18 enroll part time as concurrent college students while still attending high school. Many students have additional responsibilities for raising children and caring for relatives (National Center for Education Statistics, as cited in Phillipe \& Patton, 2000).

Open enrollment means that students enter community college with a large range of skill levels and preparedness, from students at remedial levels to those already having degrees. Thirteen percent of college students report that English is not the primary language spoken at home. More than half of all students report that neither of their parents had attended a postsecondary institution (National Center for Education Statistics, as cited in Phillipe \& Patton, 2000).

The community college system is also the entry point for a majority of students with disabilities. Community colleges serve a higher percentage of students with disabilities than any other sector of higher education (Henderson, 1998). Over 50\% of these students report a disability that affects learning (Henderson), and many bring additional complexities to the educational environment. Because community colleges serve as an initial higher education opportunity for students new to this country or a second chance for those who have previously failed, many of these students may have newly-acquired disabilities or disabilities that have gone previously undiagnosed. They may also have multiple disabilities or additional challenges associated with the other facets of college diversity already mentioned.

Because of the diversity described above, it is not possible to describe a typical community college student, but the following examples are representative of students who attend community colleges:

1. Fatima is 25 years old. She has lived in the United States for less than a year and, other than taking introductory classes in English as a Second Language (ESL), she has not attended school in this country. Her first contact with college is through the admissions, assessment, and orientation process. Her assessments indicate that she needs to complete ESL classes before she is ready for college level work. She also appears to have an undiagnosed hearing impairment. 
2. Craig is 41 years old. For the past 20 years he has been employed in farming but is no longer able to work because of a back injury. He is married, has three children, and is very motivated to be employed again. $\mathrm{He}$ is undecided about a new career. He reports that he liked farming: it was hands-on work; there was variety in what he did all day; and he admits that he was not "much of a student" when he was younger. He attended one year of college after high school, but was not successful and dropped out.

3. Shawna is 19 and has not yet graduated from high school. She has an Individualized Educational Plan (IEP) because of a learning disability and is taking two classes at the community college as part of her transition program. As a high school student, she has had parents who have been very involved in her education and have advocated for her. This is the first time she has been independent in school.

These examples reflect the multiple challenges faced by students at a community college. The student with a disability often faces other challenges such as learning English, supporting a family, and learning to navigate a system that is new and unfamiliar.

\section{Characteristics That Enhance UD Implementation}

By their very design, community colleges have many characteristics that make them a setting in which Universal Instructional Design can flourish. An emphasis on teaching, small classes, hands-on and experiential learning, flexibility in designing and changing curricula, and meeting students where they are-all these features facilitate the implementation of UID.

At the heart of UID is the emphasis on flexible instruction and reflective teaching. Many of the strategies employed under the UID rubric could be considered "just good teaching" (Hodge \& Preston-Sabin, 1997); in fact, UID has been described as "a complement to the more flexible and innovative approaches to higher education that are currently proffered" (Silver, Bourke, \& Strehorn, 1998, p. 48). Because a commitment to teaching is an integral part of their mission, community colleges are a particularly good fit with UID. Unlike professors in most universities, who are often not trained to teach and who are experts in their own disciplines rather than in pedagogy, community college faculty members are hired for their pedagogical skills. They are also recognized and rewarded for good teaching and are not faced with the research and publication demands that generally are placed upon faculty in other institutions of higher education. Community colleges also have the advantage of small class size. Although applying UID principles certainly enhances 
instruction in all classes, it may require more creativity to utilize such recommended approaches as cooperative learning, multiple means for students to demonstrate knowledge, and experiential learning in large classes than in small classes. In fact, experiential and hands-on learning is central to much of the technical and vocational instruction in comprehensive community colleges. It is hardly necessary to encourage or train faculty in programs such as cabinet making, information technology, or practical nursing to offer labs, field trips, practica, or other forms of experiential learning when these experiences form the core of the curriculum.

A related advantage that technical and vocational curricula offer in the implementation of UID is that in most courses the identification of essential components and technical standards has already been accomplished in order to meet certification and licensure requirements.

This identification, which is so critical in the execution of Universal Instructional Design, is especially important in open enrollment institutions if they are to fulfill their commitment to serving students of varying ability levels without compromising standards.

Flexibility is another characteristic of the community college academic environment that enhances the implementation of UID.
Flexibility in design and delivery of instruction is a central tenet of UID (ERIC/ OSEP, 1998) and a core principle of community colleges (Phillippe \& Patton, 2000), which are designed to be responsive to the needs of students and the communities from which they come. Consequently, the processes for making necessary changes to the curriculum are generally less cumbersome and can be completed in a shorter period of time than those found in four-year colleges and universities.

Finally, one of the most important attributes that aids in the realization of UID in community colleges is their goal to meet students where they are, not where the institution might wish them to be. Universal Instructional Design is based on the premise that as long as standards are not compromised, the academic environment can be changed to meet the needs of diverse students (Center for Applied Special Technology, 2001), rather than requiring these students to change in order to fit into a static mode of instructional delivery.

Community colleges often address this goal of meeting students where they are through their ESL and developmental or remedial education programs. Most community colleges test incoming students and require completion of prerequisites before students can take advanced classes (Phillippe \& Patton, 2000). A recent study of remedial education in community colleges revealed 
that a majority of the institutions surveyed require assessment for all students and $75 \%$ of those institutions also require placement into remedial courses (Shults, 2000). The aim of these policies is not to keep unqualified students out, but to give them the tools in remedial classes that they need to succeed in their ultimate goals, which may include degree programs and highly technical vocational training (Phillippe \& Patton, 2000).

\section{Special Challenges}

Although community colleges have many characteristics that facilitate the implementation of UID, they also face unique challenges that can make its implementation especially difficult. These challenges derive from both the diversity of their student population and from a lack of resources.

The student diversity that is one of the greatest strengths of community colleges also poses one of their greatest challenges. In spite of the best efforts of skillful teachers and advisors, it is often difficult and sometimes impossible to provide access, without compromising standards, to all of the students who may enroll in a particular course in an open enrollment institution. They may simply lack the prerequisite skills or have too many external conflicts in their lives to be successful in their academic pursuits. This diversity does not affect just the academic program in community colleges; it poses challenges in the delivery of student services as well. For student services to be universally designed, they must be accessible to the same wide range of students that instruction must reach, including students who may be very unsophisticated about higher education. This is particularly true in delivering disability services. When beginning college, many students with disabilities may have trouble determining how to access assistance even when the college has published and posted information on disability services. What may seem intuitive to others may not be to the student who comes from a high school with a different form of service delivery, who has never taken on the role of self-advocate, who speaks English as a second language, or who did not have a diagnosed disability at the time of last attendance in school.

Also related to the overall challenge posed by a diverse student body is the challenge posed by the large numbers of economically disadvantaged and older students who access community colleges without even a basic level of computer literacy. Findings of a recent survey of more than 100,000 students at 245 community colleges revealed that the cost of computers for education is a major problem for $20 \%$ of these students. A significant percentage of survey respondents-including $30 \%$ of noncredit students—also reported that they 
had never used the Internet (Phillippe \& Valiga, 2000). Given that many recommended UID strategies, such as providing materials in multiple media and creating digital, networked learning environments (Center for Applied Special Technology, 2001), assume a basic level of computer competence, this lack of exposure and access to computers presents a formidable obstacle to be addressed.

In addition to the challenges inherent in an extremely diverse student body, the other major challenge that faces community colleges in the implementation of UID is a widespread lack of both staff and financial resources. Professional development is a key component in any institution that wishes to adopt Universal Design and Universal Instructional Design. Even in colleges where teaching has been the top priority, many of the principles on which UID is based will be new to a significant number of faculty members, and all faculty will benefit from an interdisciplinary exchange of strategies that promote access. In some disciplines where essential components have not yet been identified, training and time will be needed for departmental review of their entire curriculum.

The resources needed to accomplish this professional development effort are often not available in community colleges. In an ideal situation, members of the disability services staff can provide the training. Yet, in many of the smaller colleges, there is no disability services office. Services are coordinated by a single person who already fulfills many roles, and the additional role of "trainer" may not easily be assumed. The alternative to providing in-house training, hiring external consultants with expertise in UID, requires financial resources that are either lacking or already committed to other training that is mandatory, not merely desirable (e.g., compliance with the Americans with Disabilities Act [ADA]). Although this competition for scarce funding is a widespread problem throughout higher education, it is particularly acute in community colleges, which traditionally receive lower per-student funding than four-year colleges and universities (S. Nemitz, personal communication, May 2001).

A further challenge in providing community college faculty with training in UID is devising ways to reach the large number of adjunct faculty. In the academic year 1996-1997, 66\% of the faculty in public community colleges was employed on a part-time basis (Phillippe \& Valiga, 2000). As with the funding needed for UID training, there are many competing demands for the time needed when the training must reach so many part time instructors.

Still another challenge in finding staffing resources for UID implementation is inherent in the very structure of community 
colleges - the lack of an upper division. Many strategies that help make class content more accessible, such as Supplemental Instruction or tutoring, can be effectively implemented by juniors and seniors or graduate teaching assistants in four-year institutions, but are more difficult to accomplish in two-year community colleges.

Finally, the lack of financial resources mentioned above not only impedes the provision of staff training in UID, but it also severely inhibits community colleges from utilizing technology to its fullest degree. Just as many of their students have not been able to afford access to computers prior to enrolling in school, the community colleges themselves have had great difficulty finding sufficient funding to acquire the state-of-the art technology needed to realize the full potential of UID.

\section{Conclusion}

By their very nature, community colleges are educational institutions that provide a good fit with Universal Design and Universal Instructional Design. Their mission of access and their core values of diversity and flexibility create an environment in which UD and UID can flourish. At the same time, community colleges that seek to implement UD and UID will be faced with many challenges. In spite of these challenges, this model holds great promise as an approach that community colleges can adopt to enhance their commitment to providing access while maintaining excellence.

\section{References}

Center for Applied Special Technology. (2001). Universal design for learning. Retrieved January 25, 2002, from http:// www.cast.org/udl/

ERIC/OSEP. (1998). A curriculum every student can use: Design principles for student access. (Topical Brief). Retrieved January 25, 2002, from http:// www.cec.sped.org/osep/udesign.html

Henderson, C. (Ed.). (1998). College freshmen with disabilities: A statistical profile. Washington, DC: American Council on Education.

Hodge, B., \& Preston-Sabin, J. (1997). Accommodations-Orjust good teaching? Westport, CT: Praeger.

Phillippe, K., \& Patton, M. (2000). National profile of community colleges: Trends and statistics ( $3^{\text {rd }}$ ed.). Washington, DC: Community College Press.

Phillippe, K., \& Valiga, M. J. (2000, April). Summary findings. In Faces of the future: A portrait of America's community college students. Retrieved January 25, 2002, from http:// www.aacc.nche.edu/faces/ 
CHAPTER $4 \mid 67$

Implementing Universal Design |

Shults, C. (2001, June). Remedial

education: Practices and policies in community colleges. (Research Brief).

Retrieved January 25, 2002, from http://

www.aacc.nche.edu/Content/

ContentGroups/Research_Briefs2/

Remedial.pdf

Silver, P., Bourke, A., \& Strehorn K. C.

(1998). Universal Instructional Design in higher education: An approach for inclusion. Equity and Excellence in Education, 31(2), 47-51.

Vaughn, G. (1999). The community college story. Washington, D.C.: Community College Press. 
68 CHAPTER 4

Community Colleges and UID 


\section{Classroom Strategies}





\title{
Making a Statement
}

\author{
Mark Pedelty \\ University of Minnesota
}

\begin{abstract}
After participating in the Curriculum Transformation and Disability (CTAD) workshop, the author began presenting a concerted oral accommodation and access statement on the first day of class. The results were immediate and positive, as illustrated with three examples. The author argues that individual accommodations, like those illustrated here, are an essential part of the process of developing Universal Instructional Design (UID) courses.
\end{abstract}

$\mathrm{M}$ y participation in the Curriculum Transformation and Disability (CTAD) workshops yielded numerous benefits. The most significant outcome was a course remodeled with Universal Instructional Design (UID) principles in mind. With UID and access as the goal, I completed a fairly radical remake of my Introduction to Cultural Anthropology course. I turned what was a course mixing mini-lectures, multiple modes of student writing, performance, oral presentation, and independent field research projects to a lab largely based on student research projects tailored to their individual and collective needs, abilities, and interests. What could be more universal than curricula designed by and for students in collaboration with their instructor?
However, perhaps the most important course modification to come out of my participation in the workshops was also the simplest and easiest to institute. In fact, it only took a few minutes. I added an oral statement to my written syllabus statement concerning disability, accommodation, and access issues. Although I had put accommodation statements in previous syllabi, I had never thought to perform an oral accompaniment in class. Part of the reason is that I find repeating syllabi page by page to be a fairly perfunctory ritual. As a result of this general antipathy for the typical syllabus introduction, I had never before thought to orally reinforce the written accommodation statement. The CTAD workshop motivated me to do so, with positive results. 
The results of the oral announcement were immediate and profound. In previous semesters I often had to wait weeks before discovering that a student needed accommodation. The written statement simply was not sufficient. However, in several of the courses I have taught since adding the announcement, students have approached me that same day to tell me about their particular needs and, in a few cases, to request accommodations. I have been reminded that the seemingly insignificant act of articulation makes all the difference. More of a text based learner myself, I often forget that for many people information is not relevant until put into oral, and perhaps even dialogic, form.

This chapter is about the oral accommodation statement I now perform in my classes. After a short description of that performance, I will describe three cases where it has made a difference. I will then discuss the ancillary benefits of making the statement. The goal is not simply to argue for the inclusion of an oral statement, but also to examine the role of accommodation, in general, as it relates to Universal Instructional Design (UID). I suggest that minor acts of accommodation, such as those described here, help us move closer to the ultimate goal of creating courses with universal access.

\section{The Statement}

My typical method for presenting the syllabus is to give students an "open syllabus" quiz on the first day of class. The quiz questions relate to the most essential elements of the syllabus and get students in the habit of using it as a working document. A quiz question concerning the accommodation statement can help emphasize the point.

However, nothing is as useful as oral performance in getting across a point, especially when the rest of the presentation is more text based. The move from text to talk signals that something important is about to be announced. With that in mind, I decided to add a short statement after we discuss the open syllabus quiz. Rather than repeat the written statement, I put down my syllabus for an impromptu lecture on the point. I said something like the following:

I want to say a few words about access. I think that it is very important for all students to have complete access to the course. Sometimes there are aspects of a course that make it difficult for some students to fully participate. For example, students with disabilities may need accommodations so that they will have the same level of access to the course as other students. I encourage 
you, if you have a disability that requires such an accommodation, to approach me after class, visit office hours, or contact me immediately so that together we can make such arrangements. Also, if you have not visited Disability Services to receive a letter certifying and explaining your disability, you should do so as soon as possible. You will find them very helpful. If you have never been diagnosed with a learning disability, but have reason to believe that you have a learning disability, I encourage you to visit Disability Services to be tested and, if so, receive the help you need and deserve to have full access to your college education. Every student has a right to full educational access and I want to do whatever is necessary to make certain that you gain such access in this course. Please read the syllabus statement for further information, including the campus address for Disability Services.

As is true in much of teaching, the performative act of delivering the statement is more important than its specific content. I make a point of presenting the accommodation invitation with a level of inflection, eye contact, and projection that goes beyond that which I typically use for delivering course content.
I have been struck by the amount of attention students pay to the statement. The glossy-eyes and distant stares that normally greet introductory syllabus presentations give way to rapt interest. Either this issue is of intrinsic interest to the students or the statement works as intended, raising student awareness of and interest in access issues. It is probably a bit of both. Regardless of the reason, the statement has worked to a surprising degree. I am pleased to have discovered the importance of the oral performance, while at the same time I am a bit embarrassed that I did not think of doing it earlier in my teaching career. If it were not for CTAD, I might never have bothered.

\section{Student Impact}

The statement produced immediate results. In the first case, a student with a visual impairment asked me to change the color of my PowerPoint font from blue to black. It was a subtle change, and extremely easy to execute. However, it was remarkable in the sense that rarely before had a student asked me for accommodation after the very first class meeting. Usually, students would wait to feel comfortable with me before making such an approach. In other words, the statement worked; it produced a more immediate sense among the students that I was approachable, particularly when it came to questions of access, diversity, and equity. 
I might have written off that very cursory experience had I not continued to experience the same response in subsequent classes.

The next semester, a student came up to me, thanked me for making the statement (a sad commentary on students' low expectations) and told me about his particular learning disability. It would be inappropriate to provide further details for reasons of anonymity, but suffice it to say that the invitation produced the intended results once again.

The student presented his Disability Services letter after the next class meeting and we discussed potential accommodations. Because I do not use timed tests and allow students to choose from a variety of methods to communicate their learning, there was not need for significant accommodations.

However, my awareness of his disability and the relationship we began to establish as a result bore obvious fruit. The student did well in the course.

A third and final case took place during a course involving field study in Mexico. I made another pitch concerning the need for all students to have full access to the course, including the experiential field components. I did not want any students to encounter obstacles to the field experience. For example, we were planning on climbing a pyramid at Teotihuacan and reading a short story from the summit. In addition to trying to ascertain the accommodation needs of individual students, I designed the statement to appeal to students who might begrudge a modified course schedule. Hopefully, if they were aware that there could be students among them requiring other options, they might be less resistant to group changes.

A student approached me that day, noting that he had limited mobility and several health conditions that I should be aware of. Once again, it would be inappropriate to elaborate. However, it is fair to say that more learning was made possible thanks to the student's helpful approach. He specifically cited the oral statement as his motivation for doing so. Would he have climbed the pyramid if I had not made the statement? Would he risk health and learning for sake of participation in an activity for which there were definite collective alternatives?

We met at the base of the pyramid, in a delightful garden that was more conducive to discussion anyway. Those who desired to climb would have plenty of time to do so later. I have adopted that as my metaphor for the issue of accommodation, in general, and the importance of making the oral statement, in particular. I imagine generations of students struggling to climb over educational barriers, simply because I never bothered to invite them to talk to me about obstacle-free alternatives. 
As a result, I have begun to think of it not as a statement, per se, as much as an open invitation. The oral performance provides a more personal and human invitation to the student to engage in collaborative discussion. Not one of the three students mentioned here had an obvious disability. I would have remained unaware had they not approached me. Based on comparative experience, I doubt any of them would have approached me based on the written statement alone. The resulting discussions have produced not only individual remedies, but also permanent course modifications in the spirit of UID.

\section{Universal Design and Access}

I have discovered several other benefits to the oral performance of the accommodation statement. For example, it has helped me deal with the occasional gratuitous or manipulative use of disability claims. We would like to believe that this never happens, but I have experienced it three times, each time involving Attention Deficit Disorder (ADD). On each occasion, students who were off task during class have shouted something like, "But I've got ADD!" when asked to get back to class work.

My response to such a statement would be the same, regardless of whether or not I made the oral statement. I later take the student aside and suggest that the student should visit Disability Services, if he or she has not done so already, and I discuss potential accommodations with the student. As might be expected for students who present their disability in that public and vocal fashion, they often do not follow up when encouraged to do so. Either these students are not dealing well with their ADD or ADHD (i.e., Attention Deficit

Hyperactivity Disorder) and are not looking for the help they need, or, in certain cases, they may not even have been diagnosed as ADD or ADHD, but are instead making an extremely bad joke out of a very serious learning problem. This is the sort of disingenuous and manipulative act that causes other students and faculty to question the validity of some learning disabilities (LD) attention deficit diagnoses and makes the lives of those struggling with disabilities like LD, ADD, and ADHD that much more difficult (Williams \& Ceci, 1999).

This is certainly not to say that ADD and ADHD claims should be dismissed. To the contrary, the general constellation of behaviors that we in the United States have defined as ADHD are also evident in other cultural contexts, albeit there is great variability in terms of how children exhibiting such "behaviors are evaluated and managed" (Brewis, Schmidt, \& Meyer, 2000, p.826). It is a serious problem for those who experience it. However, the students in question use public exclamation 
of their condition to excuse extremely disruptive behavior. Having established that I am open to matters of accommodation by presenting the introductory statement, I feel on much more solid ground when dealing with these potentially gratuitous uses of very serious disabilities later in the course.

On a related point, making the introductory statement helps to establish a relationship of trust with students with disabilities. Many students harbor a wellfounded fear that they will be treated differently in class if they reveal their disability to the professor. There are numerous pedagogical benefits to that sort of trust. For example, I challenge students constantly, asking them to take risks and stretch in order to learn. Without trust, that is difficult to achieve. Students think that I am picking on them. They invent reasons why I would select them in particular. For example, students with disabilities might think that it has something to do with their disability. The relationship of trust first forged by the initial statement and contact with the student facilitates this later work. I do not have to be overly concerned that students will think of my challenges as something related to their particular abilities or some perceived lack thereof.

The most interesting and unanticipated benefit of the statement, however, is the effect it has upon the general student population. As mentioned above, nearly all students demonstrate inordinate attention to the statement, regardless of whether or not they have a diagnosed disability. Part of this may be the nature of my performance. As I mentioned earlier, I indicate by verbal and physical cues that the statement is of special importance. However, I believe that it goes beyond that. I teach in a developmental education program. That means that students are often stigmatized by their placement in my classes. They often see it as punishment for past academic failures and, therefore, they view me as judge and jury. In short, they are wary of me.

The statement begins to chip away at the executioner's mask students project upon me. They interpret my statement concerning accommodation as an indication that I maintain a positive orientation toward student success in general. The statement thus sets a positive tone for the course and allows me to start establishing a relationship of trust with the class as a whole.

\section{Accommodation and UID}

The meaning of the accommodation statement goes beyond the fairly limited intent denoted in the words (i.e., to find reasonable accommodations for students with disabilities). The accommodation statement performance connotes deeper meanings, particularly in a developmental education setting. It reaches all students at some level, presaging, acknowledging, and 
speaking toward potential feelings of discrimination and resistance, while positively signifying the instructor's intent to make the course universally accessible and adaptable to students' needs and proclivities.

The outcomes of the three examples of accommodation described above may help illustrate the point. After changing my PowerPoint fonts, I was that much more aware of the need for clearer text and redundant methods for delivering essential information. Similarly, after being approached by the field study student, I reconstructed the field assignments so that the basic core of the experience could be accomplished regardless of physical abilities. Now those particular accommodations will no longer be necessary, because they have been built into the course. Just as the curb cut evolved from a disability-based accommodation to a design used for a range of access purposes, so too, these seemingly small course accommodations can accrete to produce more robust and accessible courses benefiting all students.

The same was true of the third case. The student taught me how to better teach others with his particular disability. I learned in practice what I had read in theory: that students with that particular condition need extra time. Instead of my typical, often frenetic teaching style, I began to develop a more sedate approach, to the benefit of all students. Particularly when dealing with students with the learning disability in question, I now sit, often silently, for long periods, and generally mirror their pace of communication, so that our conversation can produce meaningful results. Instead of simply expecting students to accommodate my own, often dysfunctional means and methods of communication, I reciprocate by adapting to and accommodating their communication and learning styles as well.

The difference between being slow, in the colloquial definition of the term (i.e., "slow" as in "lacking intelligence") and deliberate was made particularly clear to me in that case. The student in question produced perhaps the best work in the class, not despite his different mode of learning, thinking, and communicating, but because of it. He made me more aware of the problem many people like me have, that of going too fast. Although there can be conundrums involved (e.g., how does one teach courses where students in the same class require both faster and slower-paced communicational modes?), simply asking these difficult questions can lead to innovative and effective solutions.

\section{Conclusions}

As these fairly basic examples demonstrate, minor accommodations can lead to greater access for all students. In 
other words, accommodation is not necessarily a developmental step that needs to be surpassed in order to achieve the more lofty aims of UID. Rather, accommodation is part and parcel of the process of working toward what is ultimately an impossible goal: universal access. Just as considerations of accommodation gave rise to Universal Instructional Design in the field of Disability Studies, so too, careful attention to questions of accommodation by individual instructors may aid in the development of courses that respond better to a diverse range of students' proclivities and abilities.

Accommodation is the possible process that helps us continue working toward universal curricular access. In fact, accommodation is a prerequisite for teaching any student. We constantly ask students to adapt to our universe. In other words, we ask them to accommodate our way of communicating and thinking as teachers, and adapt to our instructional needs, interests, and idiosyncrasies. We must in turn learn to adapt to students' needs, interests, and desires, accommodating them so that effective learning can take place. Teaching always involves adaptation and accommodation. That process can begin with a simple statement.

\section{References}

Brewis, A., Schmidt, K. L., \& Meyers, M. (2000). ADHD-type behavior and harmful dysfunction in childhood: A cross-cultural model. American Anthropologist, 102(4), 823-828.

Williams, W. M., \& Ceci, S. J. (1999, August 6). Accommodating learning disabilities can bestow unfair advantages. The Chronicle of Higher Education, B4-B5. 


\title{
Charting a New Course: Learning Communities and Universal Design
}

\author{
Rashné R. Jehangir \\ University of Minnesota
}

This chapter will examine the manner in which learning communities can serve as an effective vehicle for incorporating Universal Design into courses that are already thematically tied together. Clearly Universal Design can be incorporated successfully into individually taught courses. Learning communities, however, present the additional dimensions of affective connections, peer support, cooperative learning outcomes, and faculty collaboration that naturally lend themselves to the tenets of Universal Instructional Design (UID).

A ny college or university catalog or literature includes images and language suggesting that students who attend this institution are special. They may be especially bright, in the top $10 \%$ of their high school classes, especially talented in a broad range of extracurricular activities, or simply special because each one will be treated not as a number but as a unique individual. Interestingly enough, when these students arrive on campus and in our classrooms, the term "special" takes on a wholly different meaning. "Special populations" is the common catch phrase for adult students, students of color, student athletes, multilingual students, developmental students, and, of course, students with disabilities.
Because language shapes thought and nomenclature, it is important to consider how terminology can perpetuate the labeling that we are seeking to remove from our classrooms and communities. Terms like special populations serve only to add to the "othering process" (Anzaldua, 2001) with which students are already struggling. I am not suggesting that we assume that everyone is the same, but rather that the students bring with them a wealth of knowledge that allows us to celebrate differences rather than view them as deficient, lacking, or incomplete. In this vein, Universal Instructional Design (UID) suggests that imbedding accommodations into curricular structure benefits not only students with disabilities, but all students (Silver, Bourke, \& Strehorn, 1998). 
Like the implementation of Universal Instructional Design, participation in learning communities can facilitate achievement among all students. Goodsell Love (1999) argues that the growth in learning communities is the result of two recent shifts in higher education. The first is a shift from teaching to learning (Barr \& Tagg, 1995) and the second a "shift from viewing knowledge as an acquisition of information to the social construction of knowledge" (Goodsell Love, p. 6). Similarly, UID complements flexible and innovative approaches to postsecondary education such as cooperative learning and computer-assisted instruction (Silver et al., 1998). Both approaches expand the student learning experience; they equally challenge teachers to reexamine their own biases and return to the role of learner themselves. Consequently, these teaching approaches necessitate a type of interdependence between instructors and students and a focus on "student learning rather than subject-matter teaching" (Evenbeck, Jackson, \& McGrew, 1999, p. 55).

Finally, the intent of these approaches is to create access to learning. There is a tendency to equate accessibility with simplicity in the same way as it is often assumed that access and excellence are mutually exclusive. Accessible education acknowledges the diversity of today's learners and uses the strengths of this diversity to create environments that make learning attainable and excellent. Universal Instructional Design presents a means of ridding ourselves of a divided curriculum and replacing it with a learning space that capitalizes on the learning styles of all students. The collaborative environment of learning communities can be a good fit for implementing an inclusive curriculum.

\section{What Is a Learning Community?}

There is a large body of literature on learning communities and their outcomes. Increased student involvement, interdisciplinary learning, retention, improved quality of thinking and communicating, a superior ability to bridge the gap between academic and social worlds, and an avenue for faculty development have been attributed to successful well-developed learning communities (Elliot \& Decker, 1999; Goodsell Love, 1999; Lenning \& Ebbers, 1999, Tinto, 1998). Lenning and Ebbers' review of the literature identified three specific ways that the term learning community is used:

Most commonly, learning community refers to a curricular approach that links and clusters classes around an interdisciplinary theme and enrolls a common cohort of students. Second, in technology circles, learning community refers to a way to link students and faculty through the 
Internet. Third, in international circles, learning community describes linking people from different countries. (p. ix)

Other definitions reflect criteria for learning and teaching:

A learning community centers on a vision of faculty and students - and sometimes administrators, staff and the larger community—working collaboratively towards shared, significant academic goals in environments in which competition, if not absent, is at least de-emphasized. In a learning community, both faculty and students have the opportunity and responsibility to learn and help teach each other. (University of Miami, 1998, as cited in Goodsell Love, 1999, p.1)

The intent of learning communities is to create a space for dialogue and connections between disciplines and ideas, but also to extend the intellectual into the socio-cultural experience of students. Tinto argues that most learning communities have "two things in common, shared knowledge and shared knowing" (1998, p.171). It is this relationship of collaborative, experiential, and active learning that blurs the line between the classroom and the outside world, thus setting the stage for inclusiveness and democratic thinking.
Thus, learning communities present a safe space to incorporate Universal Instructional Design. There are many different components and approaches to developing a successful learning community. For the purposes of this chapter I will focus on two aspects: cooperative learning and faculty collaboration. The three critical components for curricular development using UID include providing a flexible means of representation, a flexible means of expression and a flexible means of engagement (Orkwis,1998). The following paragraphs will explore how learning communities can be particularly effective at imbedding these components into the classroom.

To provide a context for the examples I use, it will be helpful to understand the framework for the multicultural learning community in which I teach. This learning community contains three classes: a social science course titled Multicultural Relations, a first year composition course, and Creativity Art Lab. Students registering for this community were required to register for all three classes concurrently. This learning community has been designed to help students examine issues of diversity from different lenses. Using the materials from the disciplines of writing, art, history, sociology, and psychology, the learning community as a whole will focus on an interdisciplinary examination of different ways of knowing and examining the diverse 
world we inhabit. While each class in the community has its own focus, the three courses relate to each other and the faculty teaching them encourage students to examine issues of diversity and critical thinking and to explore connections and distinctions between some of these ways of knowing.

\section{Cooperative Learning}

Cooperative learning has long been associated with group or team-based learning and is a natural fit for the learning community environment. The most critical components of this approach involve positive interdependence among students, shared leadership, individual accountability, development of social skills, and group processing (Johnson, Johnson, \& Smith, 1991a). Placing students in situations that encourage face to face (i.e., promotive) interaction and shared resources not only enhances critical thinking skills, but also heightens affective connections between students (Johnson, Johnson \& Smith; Stage, Muller, Kinzie, \& Simmons, 1998). This blending of social and cognitive components sets the stage for the incorporation of UID.

Flexible means of representation requires presenting materials in multimodal ways. This challenges instructors to present information in accessible formats while acknowledging that access for one student's learning style may pose barriers for another student (Orkwis, 1998). In cooperative learning communities, presenting materials in multi-modal formats is required not only of the instructor, but also of the students. In the social science course I teach within the multicultural learning community, one of the course requirements is student presentations. Students are required to work in smaller cooperative groups and present or lead classroom discussion on a variety of topics ranging from race, class, and gender to homophobia and ableism. Most students are not practiced at preparing presentations and can be quite nervous. If being a student teacher is intrinsic to participating in a learning community, then it behooves instructors to both model and train students to learn how to present information in flexible ways.

One semester a group of students used overhead transparencies or flip charts to present an overview of their arguments and then each took turns explaining the concepts to the class. Given the comfort level that had been established, the remaining student audience was quick to point out their concerns. "The writing on the overhead is too small," or, "You are going too fast and I can't find the page you are referring to, please tell me the page number before you begin reading." Other students asked for more background on specific readings rather than jumping straight into definitions or terms. 
The advantage of the learning community format is that the students' time together both in and out of their linked classes creates a camaraderie, and hence a trust for honest dialogue and critique. In this particular scenario the students learned to become adept at asking for means of representation that reduced perceptual and cognitive barriers.

Instructors within a learning community have the advantage of captured time. Their students see each other and engage with each intellectually and socially more often than non-learning community students simply on the basis of time spent in linked courses. This time plays a critical role in allowing students to gain ownership of their learning experience and view themselves as "members of a distinctive learning community" (Lenning \& Ebbers, 1999, p. 29). Pascarella and Terenzini's (1991) extensive research on the collegiate experience suggests that although a single college course can become a true learning community, it is not likely to happen, primarily because of lack of sufficient time together as a class and because lecturing tends to be the dominant mode of instruction.

Flexible means of expression can come about within the design of the learning community itself. In learning communities that cluster courses around a theme or metaphor, the nature of the disciplines themselves demands flexible means of expression. Because the learning community in which I teach is comprised of my social science course, a first year composition course, and a performance-based arts course, expression through student presentation, written word, and performance create opportunities for students to communicate their ideas in multiple ways. However, this is only the first layer. As one examines the limitations of any one means of expression, one can see that creating flexible means of expression within each course is also critical to student success.

Earlier I mentioned the use of student presentations in my classroom. Of course, there are challenges with that particular mode of presentation. Clearly, verbal expression is not accessible for students for "whom speech is not a viable presentation method" (Orkwis, 1998 p.3). Yet, demonstrating an understanding of central concepts in the social sciences and learning to dialogue and debate about how these concepts relate to the lived experience are essential components in my course. As a result, I have tried two strategies to incorporate UID without compromising the essential components of the course. First, students in cooperative groups can break up the responsibility of the presentation. A student who is more comfortable with visuals such as images or graphics might take the lead on that aspect of the presentation, while one who is more 
comfortable with organizing text may focus on creating a written outline, and a third member may serve as the reporter or present the information to the larger class. This approach allows students to draw on individual strengths for collective gain. As students familiarize themselves with the different tasks, they can be encouraged to take on roles they may have been less comfortable with at the start of the semester. Another method that encourages dialogue is via e-mail or web-based chat rooms that are limited to students enrolled in the learning community. Both methods suggest means of reducing motor barriers to expression.

Cognitive barriers to expression also need to be considered. Explicit strategies are referred to as providing students "with a series of steps to prepare and execute" (Orkwis, 1998, p.2) an assignment. Scaffolding is "a temporary support for learning that is gradually reduced as the student develops confidence with the new content or skills" (Orkwis, p.2). These cognitive strategies are especially relevant in a learning community where students are being encouraged to learn via sharing and cooperation rather than an individualistic competitive model that is often more familiar to them.

As a community, faculty and students need to come together to create a set of ground rules for classroom behavior, debate, and healthy disagreement. This set of rules may be something to which we continue to refer until the students can incorporate these ideas into regular communication. The same can be said of small learning groups; throwing students into groups without explicit instructions on sharing workload, individual accountability, and participation can be detrimental to the success of the community. With specific assignments, different instructors within the community may create a variety of ways to provide scaffolding. In my course, students get a detailed outline on how to write their first paper. For the second paper they create an outline together in the classroom. In the composition course, students write drafts for each paper and may also engage in peer editing. Consequently, students are simultaneously engaging in flexible means of presentation, expression, and engagement in each of the three courses while examining issues of diversity and oppression from different lenses. Given that this multimodality exists both within and across the three courses, it can often serve as a road map for students who are trying to discern what types of learning are most beneficial to them.

Providing flexible means of engagement challenges us to create an environment that allows all students the opportunity to be connected to their learning. We seek to find balance between support and challenge, 
between novelty and familiarity, and aim to appeal to students who are at different places in their academic journey (Orkwis, 1998). It seems like an impossible undertaking. Yet, consider that in this type of learning community the same cohort of students is interacting with each other in three or more common classes. If the shared curriculum has provided space for cooperative dialogue, reflection, and process, the stage is set for engagement. Trust is also critical to flexible means of engagement.

In the multicultural learning community that I have described, sharing of oneself via writing, discussion, or performance is inherent to the experience. To share one's writing with peers is often as anxiety provoking as doing a presentation or performance. "To disclose one's reasoning and information, one must trust the other individuals involved in the situation to listen with respect. Trust is a central dynamic of promotive interaction" (Johnson, Johnson, \& Smith, 1991b, p. 36). In the learning community environment, trust plays a role in the encouragement of both flexible means of expression and engagement. Without feeling supported by peers and instructors alike, students are unlikely to take risks that encourage new learning and construction of knowledge. Thus, to arrive at a place where flexible means of engagement can be successful, we as instructors need to model the very behavior we seek from our students.
In presenting material, we need to consider the extent to which we might apply novel approaches to our own teaching.

In the multicultural learning community, the students were expected to write a creative, imaginative, historical short story about multicultural America. The assignment asked students to imagine what it might have been like to come to the United States, or to be here interacting with new immigrants. In the spirit of cooperation, students were invited to bring in copies of their story drafts to share with each other. This exercise required students to not only reveal their writing ability, but also to share a very personal perspective on the immigrant experience in America. I felt that it was important to model how challenging it can be to both share of oneself and also to take in constructive criticism. One way to provide a template for this activity was to do the assignment myself and allow students to critique my work. This was an attempt to normalize constructive criticism and provide an environment that was both supportive and challenging. Students also received feedback on this assignment through process and sharing, via individual meetings with peers and instructors, and in writing. Many students used some aspect of the short story as a theme in their performances for the arts course, thus linking their learning and finding new avenues to gain and express knowledge. 
All of the strategies addressed above can be applied to the individual classroom. However, the collaboration and planning that is critical to learning community design is well suited to the process students and instructors would naturally engage in when creating UID based classrooms.

\section{Faculty Collaboration}

Boyer argues that the "new American college" needs to reexamine its priorities, the most germane of which include clarifying the curriculum, creating a sense of community on campus, and connecting students to the real world beyond the walls of the academy (Coye, 1997). If classrooms are to provide extensions into the real world and shape citizenship and community, collaboration among instructors may be a sensible place to start. If it is fair to say that our students have been educated within an individualistic, competitive model of learning, the same can be said of those who teach. Both learning communities and Universal Instructional Design push us to think outside the parameters of our disciplines and the pedagogical structures inherent to them.

The process of being a participant in training for UID and collaborating with faculty within my learning community highlighted the connection between the two approaches:
1. Planning ahead: Teaching and learning in collaboration with others necessitates time for planning and process. Teaching cohorts must share their curriculum and also have time to discuss shared goals and vision for the learning community. This means that choosing textbooks and sharing syllabi and classroom activities can include attention to flexible means of representation, expression, and engagement. This type of preplanning allows for several instructional perspectives such that preparation for multiple means of testing or other forms of demonstrating knowledge, for presenting syllabi and text in alternate forms (e.g., books on tape) can be made available for prospective students early on.

2. Articulation of objectives and fit: UID encourages faculty to examine the essential components of their curriculum. The intent is to challenge us to pinpoint the critical objectives of the course and to examine the purpose behind the teaching activities we use. Do the teaching activities fully reflect the course objectives and do they serve the purpose they were intended for? Teaching in a learning community demands that faculty examine these very questions, but also provides a forum for shared learning and discussion with colleagues. This process involves specifying instructional objectives and examining the fit between the represented disciplines allowing for the incorporation of strategies and approaches 
to teaching that most benefit students. Instructors can then customize a curriculum that reflects both "academic and social skills objectives" (Johnson, Johnson, \& Smith, 1991 b, p. 60) with attention to the range of student abilities.

3. Examining student needs: Faculty who teach within learning communities report a much greater appreciation of the first year experience. Since each teacher has a personal and unique approach to students, each interacts with the students differently and experiences different aspects of a student's personality. Sharing these experiences provides each faculty member with valuable insights into the possible reasons for a student's behavior and academic performance. (Strommer, 1999)

Thus, faculty collaboration not only allows for multiple ways of evaluating student performance, but can also incorporate scaffolds like time-management activities that help students acclimate to a college workload. Learning community faculty may coordinate their assignment due dates to prevent excessive overlap. In addition, they may "reinforce the topics and expectations of each other's courses" (Goodsell Love \& Tokuno, 1999, p. 10). It can be helpful to have regular meetings to discuss student progress and brainstorm means of incorporating UID depending on student needs. Having a sense of students' learning styles can play a role when assigning students to small base groups for classroom activities. Faculty awareness of peer group dynamics can augment modeling social skills and supportive learning.

4. Practicing what we preach: Learning community collaboration creates collegial learning groups for faculty in the same way as their classes create communities of learning and being for their students. It is a place where cooperation builds trust and this allows for "coplanning, codesigning, copreparing, and coevaluating curricular material" (Johnson, Johnson, \& Smith, 1991b, p.117). Shared learning and teaching makes us more aware of our own learning preferences and how this may bias or shape our teaching pedagogy. The nature of collaboration and collective accountability may encourage faculty to try new UID approaches and examine the accessibility of each other's curriculum. "The commitment of physical and psychological energy to achieve the goals of improving one's instructional expertise is heavily influenced by the degree to which colleagues are supportive and encouraging" (Johnson, Johnson, \& Smith, p.116). A shared space for discussing problems and sharing successes can heighten our experiences as teachers and benefit all the students we serve. 
5. New directions: As with all new approaches, having a forum to discuss curriculum access is important. Although faculty collaboration within a learning community can provide space for ongoing incorporation of UID, it can also present opportunities to contribute and construct new knowledge on the subject-we sometimes call this research.

\section{Case Study}

I will conclude with a brief case study describing the experience of a student with a disability participating in a learning community. The case study does not address all types of disabilities, nor is the intent to segregate the experience of students with disabilities from that of other learners. Rather, I hope this example illuminates the benefits of a learning community as a vehicle for implementing UID principles.

When asked, David said that he felt that he was part of the deaf culture, but being in a hearing classroom he was also part of a hearing culture. Students who are non-native English speakers may be more tentative about their class participation. David's primary language is American Sign Language and he was less likely to participate in larger discussions. However, within his small collaborative group he was far more involved and even took on the role of lead presenter. In a reflective learning log, David had an opportunity to express his thoughts without an interpreter. Describing a discussion about race and identity issues, he wrote "I felt really good about the classes discussing why we go through this within our life. It did teach that I wasn't the only one who went through it, even though other students had different colors than me." Another multiracial student wrote of the same discussion "We were able to just express our own views and experiences regarding race. It surprised me that their [sic] were not limits put on how much we can get into detail. Traditionally, I don't think that this is common."

I chose this example to illustrate the extent to which a collaborative learning environment can create trust that is necessary for students to express themselves. Providing an opportunity to reflect on racial identity issues both in class and in a reflective writing assignment was beneficial to David, but also to other students who may or may not have been comfortable speaking up in class. In addition, the cohesive environment of three classes allowed students to feel a sense of belonging to the community and a willingness to take risks in their learning. This is true for students of multiple learning styles.

The last decade has seen a shift in approaches to social diversity on our campuses (Levine, 1991). Curricula have 
begun to reflect the various manifestations of power differentials and worldviews that affect our students and our teaching. As we make efforts to acknowledge, value, and celebrate the multiple means of knowing that are shaped by the race, culture, age, gender, and ethnicity of our students, we need to also take note of the extent to which a culture of ableism excludes not only students with disabilities, but also students from the aforementioned groups. Bowe (2000) urges us to become aware of our own "culture's teachings and how those affect you as an educator" (p.5). The same can be said of the teachings of your discipline. How have these models affected your approach to learning and teaching? Universal Design and the learning community design offer us models through which to examine these questions and also to view the classroom experience from the lens of others.

\section{References}

Anzaldúa, G. (2001). En rapport, In opposition: Cobrando cuentas a las nuetras. In P. Rothenberg (Ed.), Race, class, and gender in the United States: An integrated study (5th ed.) (pp. 595-601). New York: Worth.

Barr, R. B., \& Tagg, J. (1995). From teaching to learning-A new paradigm for undergraduate education. Change, 27(6), 12-25.
Bowe, F. (2000). Universal Design in education. Teaching nontraditional students. Westport, CT: Bergin and Garvey.

Coye, D. (1997). Ernest Boyer and the new American college: Connecting the disconnects. Change, 29(3), 20-30.

Elliot, J. L., \& Decker, E. (1999). Garnering the fundamental resources for learning communities. In J. Levine (Ed.), Learning communities: New structures, new partnerships for learning (pp.19-28). Columbia, SC: National Resource Center for The First-Year Experience and Students in Transition, University of South Carolina.

Evenbeck, S. E., Jackson, B., \& McGrew, J. (1999). Faculty development in learning communities: The role of reflection and reframing. In J. Levine (Ed.), Learning communities: New structures, new partnerships for learning (pp.51-58). Columbia, SC: National Resource Center for The First-Year Experience and Students in Transition, University of South Carolina. 
Goodsell Love, A. (1999). What are learning communities? In Levine, J. (Ed.). Learning communities: New structures, new partnerships for learning. (pp.1-8). Columbia, SC: National Resource Center for The First-Year Experience and Students in Transition. University of South Carolina.

Goodsell Love, A., \& Tokuno, K. A. (1999). Learning community models. In J. Levine, (Ed.), Learning communities: New structures, new partnerships for learning (pp. 9-17). Columbia, SC: National Resource Center for The First-Year Experience and Students in Transition, University of South Carolina.

Johnson, D. W., Johnson, R. T., \& Smith, K. A. (1991a). Active learning: Cooperation in the college classroom. Edina, MN: Interaction.

Johnson, D. W., Johnson, R. T., \& Smith, K. A. (1991b). Cooperative learning: Increasing college faculty instructional productivity. ASHE-ERIC Higher Education Report, 4. Washington D.C.: The George Washington School of Education and Human Development.
Lenning, O. T., \& Ebbers, L. H. (1999). The powerful potential of learning communities: Improving education for the future. ASHE-ERIC Higher Education Report, 26 (6). Washington D.C.: The George Washington School of Education and Human Development.

Levine, A. (1991). Editorial: The meaning of diversity. Change, 23(5), 4-5.

Orkwis, R. (1998). A curriculum every student can use: Design principles for student access. ERIC/OSEP Topical Brief. ERIC Clearinghouse on disabilities and gifted education. (ERIC/ OSEP \# E586). [Electronic version.] Available: http://ericec.org

Pascarella, E. T., \& Terenzini, P. T. (1991). How college affects students: Findings and insights from twenty years of research. San Francisco: Jossey-Bass.

Silver, P., Bourke, A., \& Strehorn, K. C. (1998). Universal Instructional Design in higher education: An approach for inclusion. Equity and Excellence in Education, 31(2), 47-51. 
CHAPTER $6 \mid 91$

Implementing Universal Design |

Stage, F. K., Muller, P. A., Kinzie, J., \& Simmons, A. (1998). Creating learning centered classrooms: What does learning theory have to say?

ASHE-ERIC Higher Education Report 26 (4). Washington D.C.: The George Washington School of Education and Human Development.

Strommer, D. W. (1999). Teaching and learning in a learning community. In J. Levine (Ed.), Learning communities: New structures, new partnerships for learning (pp. 39-49). Columbia, SC: National Resource Center for The First-Year Experience and Students in Transition, University of South Carolina.

Tinto, V. (1998). Colleges as communities: Taking research on student persistence seriously. Review of Higher Education, 21(2), 167-177. 
92 CHAPTER 6

Learning Communities 
CHAPTER $7 \mid 93$

Implementing Universal Design

\section{Interpreting and Implementing Universal Instructional Design in Basic Writing}

Patrick L. Bruch

University of Minnesota

This chapter offers an interpretation of Universal Instructional Design as an extension of recent political philosophy and critical theories of justice. It discusses the transformative implications of Universal Instructional Design for understandings of developmental writing instruction, describing the author's own efforts to implement a multi-modal approach to the teaching of writing.

$\mathrm{n}$ a society that values equality and diversity, the concept of a universally designed curriculum captures a broadly shared ideal. Indeed, education scholarship in the United States might be read as an ongoing debate about our successes and failures in creating neutral, universal curricular contexts in which different people can learn together. Ideals of universality have typically assumed that curricula can escape the relations of power and privilege that shape public life. Dominant strands of current social theory and political philosophy challenge this way of thinking about what we should be working for as we design curricula and policy. In this chapter, I offer an interpretation of Universal
Instructional Design (UID) informed by this contemporary thinking about justice. I then highlight the implications of this interpretation of UID for the teaching of writing, discussing my own effort to implement a writing curriculum compatible with UID.

\section{Contemporary Social Theory}

In her recent study of political philosophy, Iris Marion Young (1991) highlights transformations in ideas of justice that have resulted from the social theories and group movements that emerged in the 1960s and 1970s. For Young, feminist, anti-racist, gay rights, disability rights, and 
other movements drew attention to the shortcomings of those definitions of justice that were understood to be universal in the sense of being timeless and independent of specific contexts. As an alternative to pursuit of "a self-standing rational theory ... independent of actual social institutions and relations" (p. 4), the social group movements highlighted the need for understandings of justice that were able to recognize and address unintended consequences of seemingly or actually neutral policies and practices. As Young explains, rather than searching for a universality good for all people and all times, contemporary critical theories see justice as rooted in specific social and historical contexts. Here, rather than be an abstract principle that stands outside of experience, justice depends upon "hearing a cry of suffering or distress or feeling distress oneself' (p. 5). Where more traditional theories valued detachment and distance, current theories like Young's are participatory and process oriented.

Building on Young's arguments about the need for a more contextual and processual understanding of universal justice, Fraser (1997) has recently drawn attention to the dynamic relationship between two domains, the material and the cultural, in the current social and historical context. For Fraser, listening to the experiences and voices of marginalized social groups suggests that injustice operates in different ways on these two conceptually distinguishable, though overlapping planes. The first understanding of injustice is material. Here, attention to injustice focuses on unequal distribution of things like income, property ownership, access to paid work, education, health care, leisure time, and so on. The second understanding of injustice is cultural and symbolic. Here, injustice refers to "cultural domination ... nonrecognition ... and disrespect" (Fraser, p. 14). These forms of injustice often overlap. Physical disability, for instance, is often related to economic disenfranchisement. But the conceptual distinction is useful because it helps draw attention to the fact that economic enfranchisement may not, alone, remedy the unjust relations attached to disability in current institutions. Persons labeled as disabled may still be culturally marginalized, misrecognized, and disrespected.

What is useful about disentangling these overlapping planes of injustice, then, is that by doing so we are equipped with a more robust vocabulary for talking about injustice and suffering in our midst. Thus equipped, we are better able to recognize the need for multiple and perhaps seemingly contradictory remedies for injustice. For, as Fraser highlights, where emphasis on the material view leads people to appreciate injustices rooted in the political-economic 
structure of society and encourages them to advocate for material equality_remedying injustice by redistributing goods and abolishing group difference-the cultural view recognizes the injustice of misrecognition and disrespect and thus leads its proponents to advocate remedying injustice through recognition and revaluation of group specificity. Contending with both material and cultural obstacles to equal treatment within significant public contexts like schooling, an adequate conceptual foundation for transforming curriculum must bring together redistribution and recognition.

Summarizing the essential insight that these movements have helped to generate, Catherine Prendergast (1998) has recently argued that, in order to overcome injustices such as White privilege and male privilege, "it will not be simply enough to add women and people of color and stir. Without significant changes to the profession and pedagogy, women and people of color will continue to wind up on the bottom" (p. 50). What is needed are redefinitions of what it means to participate in social practices like work and schooling so that part of the purpose of participating in such practices is to change the practice itself. Within such a view, the universality and thus justness of our practices becomes participatory-they are always in the process of being redefined as we continuously learn more about how our practices relate to material or cultural injustice. Instead of creating a system that applies to any situation, universality means working within concrete contexts to enable more people to participate more fully in defining inequities and better alternatives.

Although Prendergast's (1998) recognition of the need for transformation of "the profession and pedagogy" (p. 50) usefully applies current thinking about justice to the educational context, she concludes her study by explicitly refusing to address classroom issues, pointing to the compromises that, within accepted educational discourses, such attention demands. She concludes that although "at this point articles dealing with composition generally incline toward some pedagogical imperatives," in order to be true to her evidence "[that] not only is an agenda of socialization insufficient for enfranchisement but that it might be detrimental to enfranchisement" (p. 50), she can only reemphasize that "we need to recognize that our rhetoric is one which continually inscribes our students as foreigners" (p. 51). If school curricula are to put into practice recent theories of multicultural justice, they must be transformed to provide marginalized groups meaningful opportunities to participate in and transform educational and other institutions. Our curricula will have to provide a means for expressing and valuing 
cultural difference in ways that make group difference one of the purposes of knowledge forms like literacy, rather than the foreign element that pollutes literacy. In the absence of such respect and recognition,

redistribution fails to fulfill its promise.

\section{Universal Instructional Design}

Fulfilling the promise of redistributive measures will involve more fully connecting such remedies to culturally oriented remedies. Growing out of architecture, a field of knowledge in which the connections between material and cultural issues are uniquely visible, Universal Design (UD), in its affirmation of critical revisionary feedback, potentially responds well to our need for new models of participating in knowledge. Universal Design as a professional movement grew out of emerging awareness within architecture of unintended consequences of design features that were thought to be impartial. Specifically, persons with disabilities made building designers aware that their designs were unjust both in terms of the material access they made available and in terms of the cultural and symbolic messages they sent to persons with disabilities and to those temporarily able bodied. Buildings with stairs at each entrance, with doorknobs or other mechanisms that require particular kinds of dexterity not possessed by all, or other features that make the buildings very difficult for some persons to use, materially obstruct equal access. Additionally, such structures send cultural messages about who is expected to participate in public life and who is capable of citizenship, messages that unjustly misrecognize and disrespect certain persons.

Universal Design holds great promise when translated to curriculum design if we remain aware of the central critical capacity that, in practice, UD has placed at the center of the design process-listening to the experiences of those who use the structure, observing the degree to which the structure facilitates equal participation, and continuously revising. In this sense, I see Universal Design as operationalizing a contingent understanding of the term "universal" consistent with the political philosphies I described in the previous section of this chapter. Universal names an ideal and a process rather than a realized outcome or a fixed state of affairs. Seeing universality as a process values participation and discourages those privileged by current structures from ignoring the obligation to listen, learn, and revise. That revisions responsive to particular undesirable effects of designs also enhance the usability of structures in unintended ways is a bonus effect that should help counter arguments against constant revision.

In my view, Universal Design offers educators a chance to design curricula from the position of listener rather than all 
knowing expert. As Young (1997) has argued, listening plays an important role in identifying and transforming injustice:

with careful listening able-bodied people can learn to understand important aspects of the lives and perspective of people with disabilities. This is a very different matter from imaginatively occupying their standpoint, however, and may require explicit acknowledgment of the impossibility of such a reversal. (p. 42)

The lesson here for me is that at its best, the design of structures aspires to universal access through listening and learning about how different people understand their experiences in them. With respect to this important process, it seems that curricular designers may have an advantage over building designers because our structures are much more flexible and easily revisable. Thus, there is no reason that curricula need to replicate the situation where buildings meet the letter of laws mandating access but fail to fulfill the spirit of equity.

\section{Connecting UID to Composition Studies: Redefining Writing as Literacy Work}

So far, I have offered an understanding of UID as a way of applying the insights of contemporary theories of justice to education. This connection provides a way to practically extend resources developed over the past 30 years within composition studies. It holds promise for addressing issues familiar to compositionists and for broadening attention to issues of access that compositionists have largely ignored. At the heart of the emerging attention to disability is a recognition on the part of composition scholars that assumptions about the physical, emotional, and cognitive norm have negatively impacted the structures we design - our curricula, our profession, and pedagogies.

But composition teachers have tended to separate issues of distribution from issues of recognition. Scholars have recently concentrated attention on the overall failure of redistributive pedagogies that narrowly conceived universality as universal access to a valued set of conventions. Prendergast's (1998) characterization of such efforts as potentially "detrimental to enfranchisement" (p. 50) and Fox's (1993) recent argument that "access through language pedagogy ... is an unqualifiable failure" (p. 42) both draw attention to the professional tendency to theorize about recognition while emphasizing assimilation in the classroom. The injustice of redistributive pedagogies is less about the limitations of a valued dialect to provide the economic access it promises, though there is that. Additionally, the emphasis on assimilating valued 
conventions creates an educational context of disrespect in which those who are the beneficiaries of conventions are able to go on without questioning the ways that the structures they are operating within unjustly privilege them. Transforming the teaching of writing in ways that implement the kind of UID I have discussed holds promise for better serving students with disabilities as well as all others, because all are, ultimately, underserved by curricula that concentrate solely on either issues of distribution or issues of recognition.

Applying UID to the teaching of writing means transforming the curriculum to ameliorate cultural and material obstacles to educational equity. Materially, I am speaking of how the class itself operatesthe physical layout of activities, the material design of handouts, texts, the environment of the classroom, how much time is spent in different ways, and so on. Culturally, I am referring to questions about the identities students are assumed to have or expected to inhabit by the curricula of the class. As a conceptual framework, UID draws attention to the interrelation of these cultural and material issues. They both become the focus of critical reflection and potential revision in pursuit of the goal of equity.

The practice of UID has resulted in changes in the way that I understand what I want students to learn, in the assignments that I give, and in the classroom activities through which we work on assignments. UID provides a framework for shifting our attention from literacy as a stable skill that we want to impart to a more participatory formulation of writing as a matter of simultaneously doing and shaping in pursuit of equality and difference. A term that, for me, names this understanding of what students learn in writing classes is literacy work. In writing classes students learn to participate in and reflect on the various kinds of work that literacy does. They learn to appreciate that language use is a practice of relating to others and to reflectively navigate those relationships.

Applying the insights of UID to writing classes, the idea of literacy work defines writing as a reflective and revisionary practice. That is, when one writes one simultaneously accomplishes the immediate concrete goal of communicating in a particular context and at the same time, one expresses ideas about communication in that context. As one student, Asante, phrased this insight in a paper for a recent class, "by me writing this paper in this way, I am communicating my thoughts about communication to you, but yet a lot of people may not see it this way at first." In other words, writing includes both participation according to current conventions and reflection on those conventions and the relations of equality and difference they are part of. 
As mentioned earlier, a key principle that UID offers to writing teachers is critical participation and revision. The material and cultural issues faced when serving any group are so multifaceted and complex, and the ways that students receive and interpret teachers' messages are so unpredictable, that no design for a class can address all issues and concerns beforehand. Instead, the message of UID is multiple formats supplemented by participatory feedback and redefinition. No single curricular mode can achieve universality and serve all students equally, so classes must be built to work towards contingent universality of serving the students that are actually there.

The role of student feedback is essential here. In one recent class, for example, I learned an important lesson about my practices for introducing new assignments. My method was to extensively describe the new essay assignment on paper, including a discussion of the rhetorical practices I wanted students to recognize and work on, why, and how. My introduction to the summary assignment read like this:

Academic writing is a set of practices for participating in conversation with others. One of the most important of these practices is summarizing. This first project is focused on reading carefully and writing good, strong, summaries. Strong summaries tell your readers what others in the "conversation" you are joining have been saying. Strong summaries convince readers that your view of the conversation has some merit. A strong summary convinces readers that you should be listened to and creates a context for you to add your piece to the conversation.

In an effort to appeal to a broad audience, I contextualized the assignment by linking something I thought students would identify with, conversation, to academic writing. I also offered an in-class overview and provided students with examples to use as models of successful responses that could inspire them in thinking about how they might respond to the assignment. When I asked students for questions, there were none.

When I requested feedback from students on their progress after about a week, one student reported that she had been stuck because she wasn't sure if she understood the assignment "correctly." Although concerns with "giving the teacher what he wants" influence all students, the fact that this student had a learning disability that required a very direct and linear understanding of tasks like writing had made the situation paralyzing for her. In our discussion, I asked her what she thought about the assignment and she said that she 
thought she could take the authors one at a time and tell readers what they say. We discussed what she thought each of the authors was trying to say and made notes about why she understood them as she did. When I assured her that her understanding was fine she was relieved and said that she was thrown off by my introductory discussion.

I responded to this problem by redesigning the way I introduce new assignments to be much more focused on how the students understand the assignment rather than how I understand it. I now include much more student-generated discussion of how they understand what they are being asked to do and how they anticipate getting to work. One activity that has been very helpful in this regard is simply taking five minutes to let students write the assignment in their own words and then share them. Because I want students to think about the cultural work involved in writing as well as the practical work, I have broken down this process so that students begin by sharing their versions of the assignment in a small group with two or three others. I ask them to share their versions and to talk not so much about who's right or wrong, but about the different kinds of cultural work done by the different kinds of writing that each in the group imagine doing. My role as teacher while these conversations are happening evolves over the course of the term. Early on in the semester I circulate in the groups helping students develop a vocabulary for talking about the work writing does, the consequences of writing in different ways. As students develop confidence in addressing this issue, my role shifts towards helping groups maintain focus and work out difficulties that arise. As a classroom practice, the exercise teaches that rather than being right or wrong, different kinds of writing do different kinds of work. Some of these kinds of work, such as stating and defending an opinion, are more highly valued in some contexts than others.

In addition to operating as material transformations that provide broader and fuller access, such curricular redesigns that evolve from student participation in the design of the class raise and contend with cultural obstacles to equitable access as well. On one level, an activity like the one described above creates a context of greater recognition for students like the one who inspired the change, but also for many others. It creates an opportunity for each student to make an understanding of the assignment that recognizes their needs. Further, it creates a context for beginning to grapple with the cultural work that writing does. For example, in one of the groups I sat in on as students were discussing their understandings of the "strong summary" assignment, two students began to disagree 
CHAPTER $7 \mid 101$

Implementing Universal Design

when one African American student compared her understanding of the assignment to another, White, student's understanding by saying that she wanted to make her opinion "plain rather than hidden." The other student responded that a summary shouldn't have an opinion at all. To which the first responded that, for her, a summary is "my view of how I see them." At this point, I intervened to remind the students that the object of sharing was not to decide who in the group was right or wrong, but to try and clarify different understandings and the different kinds of work they do. This encouraged the two students to share their views of the work that their own and each others' interpretations do. Martha explained that she believed her way of understanding a summary would let readers decide how to understand the texts she discussed, using her opinion or not. Mary explained that she believed her way would let readers decide by leaving herself out and just saying what the authors said. Another student here joined in to add that Mary's would, then, be what Mary believed the authors said, which both Mary and Martha agreed to. The value that I hope comes of such exchanges is making each of the students more familiar with how two fundamentally different ways of understanding writing understand themselves and each other. It clarified that one kind of work writing strives to do is to help readers make informed decisions for themselves and that there are different opinions of how best to facilitate this. It provided a basis for each of the students to read and write in a more informed way.

An unexpected outcome of this new activity was that allowing students to take a significant hand in interpreting the assignment required that I clarify for myself the learning objectives and acceptable parameters of responses. In other words, the activity made me more fully reflect on multiple ways of demonstrating learning. In a writing class, flexibility is restricted by the fact that students must write. But the form of that writing is a point of negotiation with profound material and cultural implications. Sarah was most comfortable using writing to communicate stable meanings. Other students I have encountered find that trying to limit themselves to one way of understanding what are invariably complex texts or issues is constraining and demands they limit their writing to acceptable partial versions. In negotiating with students about the range of fully credible responses to the summary assignment, I have had to think about what abilities I want students to work on and demonstrate. For me, what matters is that students learn to read carefully and to help readers see both how they interpret texts and why they think their interpretations are credible in an academic setting. This means linking their summaries directly to what authors say. I think that if students do that, their writing will serve them well in 
many academic and public situations. As I have learned from student suggestions of how they understand and approach the assignment, this does not demand a thesis based, paragraph oriented, linear, traditional school essay.

An option that one student suggested for herself has become a formal alternative on my assignment sheet. This student was uncomfortable with the idea that she was being asked to be an expert on the various positions making up a conversation that she was previously unfamiliar with. She decided to write out a conversation between the authors that would show readers how she understood their positions. For her, the imaginary context would tell her readers that she was offering one, tentative interpretation of how the authors' opinions related to each other. My assignment sheet now suggests two broad options for completing the assignment as follows:

Option 1: Find a common thread that emerges across the conversation we've been reading and write an essay in which you present and discuss this common thread by summarizing how at least 3 of the sources relate to it. Feel free to bring in your own experiences or your own senses of the issues, but be sure to concentrate on offering a substantial review of the perspectives offered by each of the authors you discuss, explaining how they each relate to the common thread.

Option 2: Write a dialogue between four of the authors we've read in which they continue the conversation that their essays are a part of. Incorporate into what each author says your understanding of their view of the issues. Have each speaker use some direct quotes from their pieces to explain what they mean. In the dialogue, each person should talk at least three times, each time speaking at least 85 words. Try to capture some of the voice and style of each of the speakers in what you have them say.

Overall, these curricular transformations shift the emphasis from simple assimilation of conventions to a participatory recognition of the contingency of those conventions and their effects. I say "participatory" in order to call attention to the essential insight of Universal Design that those who inhabit structures have important roles to play in remaking those structures. In terms of a writing class that implements this concept in its instructional design, students are expected to learn that part of the purpose of writing is to call attention to aspects of the structure of writing that "many people may not see" as Asante, my previously quoted student, phrased it. They are learning as well 
that as writers part of their job is to participate in creating alternative designs for texts. Students in such a class are learning about literacy work by doing the work of literacy. They are interanimating redistributive and recognition-oriented remedies to educational injustice.

\section{References}

Fox, T. (1993). Standards and access.

Journal of Basic Writing, 12 (1), 37-45.

Fraser, N. (1997). Justice interruptus: Critical reflections on the "postsocialist" condition. New York: Routledge.

Prendergast, C. (1998). Race: The absent presence in composition studies.

College Composition and Communication, 50 (3), 36-53.

Young, I. M. (1991). Justice and the politics of difference. Princeton, NJ: Princeton University Press.

Young, I. M. (1997). Intersecting voices: Dilemmas of gender, political philosophy, and policy. Princeton, NJ: Princeton University Press. 
104 CHAPTER 7

UID in Basic Writing 
CHAPTER $8 \mid 105$

Implementing Universal Design

\title{
Using Principles of Universal Design in College Composition Courses
}

\author{
Patricia J. McAlexander \\ The University of Georgia
}

While debates rage over the best way to teach college composition, Universal Instructional Design principles suggest that there is in fact no single best way; students' individual learning strengths and motivation require individual approaches, whether or not students have learning or physical disabilities. This article suggests some ways that composition teachers can adapt their teaching to individual learners while following a mandated curriculum and engaging students in common classroom activities.

A s a college composition teacher, I know that first-year students often dread freshman composition and, even more, the "developmental" composition courses that are often also required for "underprepared" writers. Both types of composition course have fairly standard content. A typical description, this one of a developmental composition course, reads, "Covers elements of effective style, careful proofreading, logical organization, and convincing development of expository and persuasive essays" (The University of Georgia Undergraduate Bulletin 2001-2002, p. 425). Nevertheless, debates have raged in composition journals about the best ways to teach this material. Should assigned writing topics be personal or political? Should the reading on which the student essays are based be creative and literary or analytical? Should the organization of student essays be tightly structured or at least sometimes creatively "loose"? Should the class include formal grammar lessons, or should grammar instruction be mainly through commentary on student essays? Most articles dealing with such questions suggest that there is only one "right" answer - the author's, of course.

Yet the right answer is "all of the above." As more students attend college, diversitynot only of races and ethnic groups, but also of learning styles and motivation-is now 
more than ever the norm. And as composition instructors become increasingly used to modifying their teaching methods for students with disabilities, they realize the general truth that a single method of teaching will not suit all students. It is not surprising, then, that we find a growing advocacy of individual approaches to students as embodied in the concept of Universal Instructional Design (UID).

For several years now, researchers have investigated individual learning strengths and motivation. One influential study, for example, identified seven specific perceptual modalities, preferred senses that an individual uses in the process of learning. Common modalities described were "print" (i.e., learning through reading and writing), "visual" (learning through observation with emphasis upon pictures or visual patterns), "interactive" (learning through participation in groups), and "auditory" (learning through listening, for example, to lectures or tapes) (Galbraith \& James, 1985). We also find studies of motivation. Part of motivation is based on students' sense of what they can achieve. As Cross (2001) has often pointed out, "Students must believe that, with appropriate effort, they can succeed" (p. 7). Another aspect of motivation is based on a student's goals or values-what he or she thinks is the point of the learning process. Biggs (1988) reviewed three different learning approaches based on this element in motivation - surface (found in students who emphasize the pragmatic-i.e., getting the degree), deep (found in students who have an intrinsic interest in the task), and achieving (which may be found in conjunction with either of the other two approaches in students who want to make the highest possible grade) (pp. 186-187).

Students have often been advised to be aware of both their individual learning strengths and the nature of their motivation. For example, in the textbook Lifeskills for the University (2000), Ginter and Glauser provide an inventory to help students analyze their learning styles (p. 67) and recommend that they "take advantage of [their strong] modalities and strengthen the weaker ones" (p. 59). As for motivation, Biggs argues that students should be aware not only of their specific "cognitive resources" but also of their "intentions" ( $p$. 187). A bulletin board outside one university learning center gives students representative advice relating to both aspects of motivation-"Think positively"; "Consider the benefits of completing the task"; "Set specific goals"-while Ginter and Glauser's textbook emphasizes that "students ... are responsible for maintaining [their] motivation" (p. 31).

But if college students are often advised to take responsibility for their own learning, federal legislation on disabilities has been a major force that stresses the responsibility of teachers and institutions as well. Teachers 
and institutions are legally bound to modify instructional procedures to compensate for various disabilities. At the college level, for instance, institutions are to provide specified students with educational aids normally not available or permitted, such as tape recorders to record lectures, taped textbooks, and word processors for essay exams. The students might also be provided with tutors, note takers, proofreaders, private rooms for tests, and special counselors. Teachers of these students are often required to modify testing techniques for these students. Depending upon their disability, the students are allowed extra time on tests or given alternate types of tests (e.g., oral instead of written). Specific teaching strategies are often suggested as well. For example, a letter from a learning disabilities specialist to a composition teacher concerning one of the teacher's students who has a learning disability (LD) states, "Whenever possible, verbal information should be supplemented visually, e.g. with graphs, diagrams, and/or illustrations" (personal communication, December 10, 1999). Thus, under the influence of federal law, the educational process has become more and more tailored to the individual learning abilities and needs of a particular population of students.

However, such modifications, when given to students with the "invisible" problem of learning disabilities, are not always considered fair. Indeed, many critics of the American educational system charge that it is mainly the children of middle class parents who are diagnosed with learning disabilities; their parents have the money and incentive to have them tested. One such critic is Gerald Coles (1987), who argues that LD legislation serves the interests of the status quo - the government, schools, middle class parents - any agency with an interest in preserving the social (i.e., class) order.

The debate over the fairness of modifications for students with learning disabilities has been particularly heated in the field of postsecondary developmental composition, where questions have arisen about the relationship between LD writers and non-LD but "underprepared" writers. The characteristics of the two groups are often similar. Both types of students may have spelling and grammar errors, confusing organization, sparse development, and lack of audience awareness, along with problems of motivation and attention. Yet, no matter how similar the problems of these students, the legislation on learning disabilities creates an either-or situation: either a student has learning disabilities and is legally entitled to certain modifications, or the student does not, and is not.

How can a student be identified as having learning disabilities in a subject area rather than a theoretically more easily improved "weakness"? In Errors and 
Expectations (Shaughnessy, 1977), the groundbreaking study of students she called "basic writers," Shaughnessy suggests that the writing problems of the students in her remedial program at the City College of New York (CCNY) could be explained simply by their background:

Certainly were such errors to appear in the papers of academically advantaged students, ... there would be good reason to explore the possibility of an underlying disorder. But where students have had limited experience in reading and writing, they cannot be expected to make visual discriminations of the sort most people learn to make only after years of practice and instruction. (p. 174)

In the years following, however, writing teachers have become less certain of that position. Today, Jeff Elliott, Assistant Director of Stephen F. Austin State University's Academic Assistance and Resource Center, expresses the thoughts of many in a posting on a Basic Writing Listserv: he questions how one can distinguish "between students who have never had an opportunity to develop critical thinking and writing skills ... and those students who have some disability which makes the development of those skills difficult" (April 5, 2001).
I believe that it is right to give modifications to students who have been tested and diagnosed with disabilities (McAlexander, 1997). However, I also recognize that doing so for them and not for others may discriminate against those others. Thus it seems not only just but also logical that the concept of Universal Instructional Design has arisen, encouraging teachers to adjust their teaching strategies, where possible, to the learning styles, interests, and abilities not just of students with disabilities, but of every student.

With specific content usually mandated for a composition course and common activities needed to engage the class as a whole, how can a composition teacher adapt his/her teaching to each individual learner? As the Universal Design of Learning (UDL) website points out, teachers can provide material that is personally relevant to individual students, offer a flexible curriculum that appropriately challenges each student, and give students individualized feedback (Center for Applied Special Technology, 1999-2000). Here are some ways that college composition teachers may employ this advice.

\section{Providing Personally Relevant Material}

1. As much as possible, assign readings that engage student interests. I think we all 
agree that the best kind of motivation springs from intrinsic interest in the subject (Biggs, 1988, p. 218), and that students will be more motivated to write if they are responsive to the readings on which composition topics are based. Appealing to student interests does not mean that a teacher must assign a hodgepodge of individual reading assignments; students in most classes turn out to have interests in common. As educator-psychologist Hamachek (1995) states, "It doesn't take long for a classroom to develop its own unique personality," depending in part "on the students and how ... their particular mix of backgrounds and experiences blend together" (p. 545). Thus, instead of rigidly planning all reading assignments for a class before even meeting it, teachers might wait to see what interests their students have in common and how the class personality develops. Then they can select readings from a textbook accordingly - or order a special book. When I had a class that included many athletes, I assigned the brief novel A Short Season, the story of football player Brian Piccolo (the movie Brian's Song is based on this book). Because the novel was not read until mid-term, I was able to order it once the class had begun. The students really enjoyed this book.

2. Give a variety of topics on the readings. Through conferences, student discussions, and questionnaires, determine the direction of individual student interests within the group. Then, for each writing assignment based on a reading unit, offer a variety of topics that appeal to these interests. For example, A Short Season deals not only with sports, but also with race relationships, illness, and family conflicts; topics can focus on these different themes. All the students in the class assigned this novel selected one of the suggested topics to write on. However, if a student does not find a topic that works for him or her, the teacher and student can discuss the problem and together develop a new topic.

3. Use the Internet for material. Traditional hard texts are not the only sources for material on which writing can be based. Now the Internet provides an infinite source of information, allowing a teacher to broaden the range of sources a student might draw from and to do so more spontaneously. A popular comparison-contrast topic I have given asks students to describe travel plans to two places they want to go and then select the preferable plan, using the Internet for information. Students who wrote on this topic found detailed information on modes of travel, places to stay, and available activities in the two possible locations, as well as on the cost for the two trips. Their interest in the topic and their enjoyment of Internet research led them to find solid, detailed information. 
4. Use popular television shows and articles in current newspapers and magazines as material. Often such sources (as well as the Internet) can be used for the most timely and controversial topics. Topics on television shows that young people watch (e.g., "Boston Public," "Dawson's Creek," "Everwood," "Felicity," "Gilmore Girls," "The Real World," "Road Rules," "Seventh Heaven"), on new technologies (e.g., the advantages and disadvantages of cell phones), or local and state issues that affect students (e.g., raising the driving age, imposing curfews), often arouse strong student feeling and interest.

\section{Offering an Appropriate Level of Challenge}

1. Give students a choice of writing topics with varying levels of difficulty. As Cross (2001) points out, students must feel that they can succeed, at least to some degree. Thus it is important for composition teachers to offer topics that relate not only to a variety of interests, but also to a variety of abilities. For students who prefer the usually "easier" personal topics to topics involving reading analysis, offer topics that combine both approaches, such as "Compare your grandmother to the grandmother in Mary Hood's 'How Far She Went'." For students who have problems with essay structure, provide some topics that set up an organization plan (e.g., give specific points on which to compare the two grandmothers); for more creative or advanced students, offer more analytical topics and leave the structure open. Teachers may need to guide students in their selection of an appropriately challenging (as well as interesting) topic.

2. When possible, offer alternative essay formats. This is particularly appropriate if the composition course is oriented to business or technical writing. In such courses, students might use graphs, charts, and other illustrations as a supplement to the written text. Those who prefer the visual mode do very well with such figures, indeed sometimes creating more and better illustrations than print-oriented students. (However, in one such class, I had to remind a young woman who felt insecure with grammar and mechanics that she needed more "sentences" along with her excellent charts and graphs!) Also, the use of headings and bulleted lists gives students with organizational weaknesses more options for making their writing plan clear to the reader.

3. Use teaching strategies that appeal to various learning styles. For example, while traditional lectures appeal to the auditory modality, charts, diagrams, and outlines on overheads appeal to the visual modality, handouts to the "print" modality, and group discussions or peer review to the interactive modality. 


\section{Accept varying writing styles as long} as the communication is appropriate and effective. To show that writing styles can vary, teachers might give samples of different types of writing and discuss how different styles can be effective in varying situations. There are stories of teachers who recognize and reward just one style of writing, often to the detriment of their students. A colleague of mine was criticized in her freshman composition class for her direct, to-the-point writing style. A high achiever, she never got over this experience. She went on to earn a doctorate in educational psychology, but always felt inadequate as a writer.

5. If a student needs extra time to complete the often departmentally-required in-class essay, let the student finish the essay outside of class. Only students diagnosed with learning disabilities are eligible to take tests and write in-class essays in our university's LD Center, where they can have extended time. I let other students who need more time come to my office to finish that last body paragraph and conclusion. On some campuses the opportunity to complete papers beyond the limits of a 50 minute class period is made available through the learning center.

6. If a student finds writing in the classroom distracting, try to find another place where the student can write. One of my students would sit staring at her almost blank sheet of paper all period, writing only one or two sentences. A deep thinker, she told me that she just could not concentrate on her ideas in the classroom, yet she did not qualify for modifications that would allow her to use a private room in our university's LD Center. I found an office down the hall from the classroom where she could write her essays, and she proved herself one of my best writers. (Luckily the office was available, and luckily not many of my students have had this problem!)

7. Allow all students to use word processors, even for in-class essays. Whatever the level of the student's writing development, word processors help greatly with writing; they are particularly useful to students with poor handwriting and spelling. Yet when writing in-class essays in noncomputer composition courses, students who have not been diagnosed with a learning disability generally must write by hand. When possible, I send non-LD students who wish to compose on the computer to nearby university computer labs to write their inclass essays. But when this is not possible, I have students write by hand in class; then after I check the often messy, crossed out, arrowed-about handwritten versions, students type the essay at home. They turn the handwritten essay in with the typed version so that I can see that the typed essay is basically the same essay as the one 
written in class, and I ask them not to change grammar and mechanics except for spelling, so that I can see areas in which they need instruction. This way, I have the required "in-class" essay, and all students use a word processor. Not only are the essays more legible, but also the word processor file version can be used if the students revise the essay.

It is interesting to note that when I apply these methods to in-class essays, many students eligible to write on the computers in the university's LD center choose to write their essays in the classroom with the other students.

\section{Giving Individualized Feedback}

1. Be available to consult with students as they write. Some students prefer to write without asking the teacher any questions. Others, however, need the teacher's encouragement and advice, whether with individual sentences or with organization or content. It is helpful for such students, when writing in class, to be able to consult as they write, while those doing out-of-class essays may want to drop in to the instructor's office to ask questions. Such in-progress consultation provides an excellent, if often brief, individualized teaching opportunity. The Socratic method—asking students questions about their content-can evoke better specific details as well as a clearer organization plan. Student questions on the grammar and mechanics of individual sentences give the teacher an opportunity to present a quick individual grammar lesson to supplement the more formal lessons often given in composition classes. And working on problems with organization with the teacher provides models of the thought processes involved in setting up essay structure.

2. After grading an essay, schedule oneon-one conferences to discuss each student's essay and specific strategies for revision. Such "conferencing," which generally involves a longer encounter, further individualizes instruction while giving the teacher an opportunity to learn a student's interests, abilities, and background. There are many good books and articles on the art of conferencing, but basically I find it a conversation in which a student collaborates with a teacher on an essay revision and thereby learns more about writing techniques. Part of this collaboration involves the teacher playing the role of reader in order to increase the student's audience awareness; part of it involves the teacher offering specific advice. The focus of this advice will vary greatly from student to student: for a more advanced writer, the conference may focus on style; for a weaker writer, it may focus on such basic elements of writing as setting up a thesis. A teacher might also employ specialized teaching 
techniques in a conference. In one case, I had a student whose written sentences were incoherent. I asked her to read her paper out loud, recorded her so that she herself could literally hear the incoherence, and then had her record, in more informal language, what she meant. I gave her the tape, and she revised the sentences more as she had actually spoken them into the recorder. At the college level, teachers might cancel one or two class meetings to give time for such personal conferences.

3. Encourage individual tutoring sessions and, if a learning or writing center is available, advise students to go there also for tutoring. These tutoring sessions will be much like the conferences described above, but may not deal with the revision of an essay. Rather, they may simply give individual lessons on such specific writing problems as dangling modifiers, comma splices, or wordiness.

4. In some situations, offer peer review sessions as part of the class. If the class has an appropriate level of writing ability, selfconcept, motivation, and social interaction, peer review sessions can be an excellent source of individualized response to essays (McAlexander, 2000). Having fellow students respond to one's writing, along with responding to the writing of fellow students, develops greater awareness of the reader as well as of one's own writing weaknesses and strengths. Peer review will be particularly effective for students with interactive learning styles.

\section{Conclusion}

Although some of these teaching techniques may involve changes in the overall structure of the composition curriculum, most of them, I think, work well within the framework of standard composition courses. Some teachers may fear that such individualization in teaching will undermine student responsibility for learning or lower standards. These fears are ungrounded. After all, students still need to do their part; further, many of the described individualizing techniques have been used for years, and even when they are not used, students still achieve at different rates and levels. In my mind there is no doubt that the application of Universal Instructional Design principles to the teaching of composition will result in more studentsgifted, average, weak, "disabled"improving their writing while enjoying the process.

\section{References}

Biggs, J. (1988). Approaches to learning and to essay writing. In R. R. Schmeck (Ed.), Learning strategies and learning styles (pp. 185-228). New York: Plenum. 
Center for Applied Special Technology (CAST) Website (1999-2000). Retrieved on May 30, 2001 from http:// www.cast.org

Coles, G. (1987). The learning mystique: A critical look at learning disabilities. New York: Pantheon.

Cross, K. P. (2001). Motivation: Er . . will that be on the test? [The Cross Papers Number 5]. Mission Viejo, CA: League for Innovation in the Community College and the Educational Testing Service.

Galbraith, J., \& James, W. (1985).

Perceptual learning styles: Implications and techniques for the practitioner. Lifelong Learning, 8, 2-23.

Ginter, E. J., \& Glauser, A. S. (2000). Lifeskills for the university and beyond. ( $2^{\text {nd }}$ ed.). Dubuque, IA: Kendall-Hunt.

Hamachek, D. (1995). Psychology in teaching, learning, and growth $\left(5^{\text {th }} \mathrm{ed}.\right)$. Boston: Allyn and Bacon.

McAlexander, P. J. (1997). Learning disabilities and faculty skepticism.

Research and Teaching in Developmental Education, 13(2), 123-129.
McAlexander, P. J. (2000) Developmental classroom personality and response to peer review. Research and Teaching in Developmental Education, 17(1), 5-12.

Shaughnessy, M. P. (1977). Errors and expectations: A guide for the teacher of basic writing. New York: Oxford University Press.

The University of Georgia undergraduate bulletin 2001-2001 (2001). Athens, GA: The University of Georgia. 
CHAPTER $9 \mid 115$

Implementing Universal Design

\title{
Computer-mediated Learning in Mathematics and Universal Instructional Design
}

\author{
D. Patrick Kinney \\ Wisconsin Indianhead Technical College \\ Laura Smith Kinney \\ Northland College
}

Interactive multimedia software is creating new opportunities for mathematics educators to implement Universal Instructional Design to meet the needs of all students. The software delivers the course content, provides immediate feedback, and allows students to work at their own pace and from remote locations. The instructor is freed up from lecturing and is available to work with students individually or in small groups as needed. Instruction of this type, referred to as computer-mediated learning, allows students of varying ability levels to meet the course standards in a way that provides flexibility in terms of pace, modes of learning, and location.

This work was supported in part by the National Science Foundation (DUE 9972445).

S tudents in introductory college mathematics courses are increasingly becoming a diverse group of learners. Historically, most introductory postsecondary mathematics courses have been taught using the lecture format, in which the instructor provides direct instruction. Rosenshine and Meister (1987) noted that direct instruction usually includes (a) presenting new material in small steps, (b) modeling of the procedure by the teacher, (c) thinking aloud by the teacher, (d) guiding initial student practice, (e) providing systematic corrections and feedback, and (f) providing expert models of the completed task. Instructors may also engage students in discussions and use some form of collaborative or group work.

For many students, however, lecture classes do not adequately meet their needs for a variety of reasons. For example, 
listening to lecture may not be the preferred learning style for a particular student. There is evidence that instruction that allows students to learn using their preferred learning styles can lead to improved student outcomes (Higbee, Ginter, \& Taylor, 1991; Lemire, 1998). Also, traditional lecture classes often fail to fully meet the needs of students with disabilities, even when instructors do their best to provide appropriate accommodations.

\section{Computer-mediated Learning}

In recent years, computer-mediated mathematics courses incorporating interactive multimedia software have increasingly been used to offer students an alternative to lecture courses. Gifford (1996) defines computer-mediated learning as a learner-centered model of technology-mediated instruction. The computer-mediated courses discussed in this chapter incorporated software from

Academic Systems (AcademicOnline 2000, 2000) and reflect the implementation model used at the General College at the University of Minnesota. The software: (a) presents the concepts and skills using interactive multimedia; (b) embeds items requiring student interaction within the instruction; (c) includes provisions for the development of skills; (d) provides immediate feedback, including detailed solutions after the second attempt on an item; (e) offers online quizzes; and (f) includes a course management system that tracks students' progress and time on task.

In a computer-mediated classroom the instructor, who does not lecture, is able to move about the room during the entire class period to provide individual or small group assistance to all students as needed. Because the instructor does not lecture, the instructor can work with individual students for longer periods of time than is usually possible in lecture classes. When interacting with students, the instructor may clarify an explanation of a concept provided by the software, aid in troubleshooting errors in the development of procedural skills, and discuss with students their progress so that they remain on track. The course management system provides detailed information about each student's progress. This enables instructors to quickly identify the students most in need of assistance.

The reviews of research on technology-mediated instruction have consistently found that instruction of this type can have positive effects on student learning (Becker, 1992; Khalili \& Shashaani, 1994; Kulik \& Kulik, 1991; Niemiec, Samson, Weinstein, \& Walberg, 1987). In mathematics courses from prealgebra through college algebra, the technology of choice is interactive multimedia software. Software that is interactive allows students to control both 
the pace of their learning and the navigation path. Najjar (1996) reviewed the research related to interactivity by Bosco (1986), Fletcher (1989, 1990), and Verano (1987) and concluded, "Interactivity appears to have a strong positive effect on learning" (p. 131). Multimedia is the use of text, graphics, animation, pictures, video, and sound to present information (Najjar).

In computer-mediated classes, students control the pace that they move through the software, although they are expected to complete lessons according to a schedule. The ability to control the pace benefits students who only need a brief review or who acquire the material quickly because it allows them to proceed through the instruction and assignments more rapidly than in a lecture class. For other students, considerably more time may be needed to process the material than is usually provided in a lecture course. The computer-mediated student can spend as much time as desired to study the mathematics on each screen, to navigate backwards to review previous material, and to take notes. Characteristics of mediated learning such as these are particularly important to students with learning disabilities.

Immediate feedback is another important component of interactive multimedia software. The research related to feedback indicates that feedback is important to the development of student self-regulation and self-efficacy (Hattie, Biggs, \& Purdie, 1996; Kluger \& DeNisi, 1996). Kluger and DeNisi found that feedback should be specific to the task, corrective, and done in a familiar context that shapes learning. In the mediated learning model, students receive feedback that is specific to each task that they attempt when using the software. If a student answers incorrectly on the first attempt, the software provides feedback that points the student in the right direction. This allows students to review their work and reattempt the item. If a second incorrect response is entered, the software provides a detailed explanation. In addition to the feedback provided by the software, students often receive feedback from classmates when they work together informally, as well as from the instructional staff.

\section{Student's Selection of Computer-mediated or Lecture Instruction}

Students' responses to surveys, questionnaires, and focus groups (Kinney, 2000 ) indicate that they enroll in computer-mediated and lecture courses for a variety of reasons such as (a) they prefer to learn through multimedia rather than watching and listening to an instructor; (b) they find multimedia more visual than what instructors can typically write on the board; (c) they prefer to learn independently, rather 
than having another person show them everything; (d) they can control the pace of the instruction and receive individual assistance as requested (Kinney, 2000); and (e) they find that multimedia, with its interactivity and immediate feedback, holds their attention better than a lecturer. Many of these students discussed negative experiences in high school with lecture instructors, citing poor explanations of the material, ineffective classroom management skills, and not treating students in a respectful manner. For some students, computer-mediated instruction is attractive simply because it allows them to avoid the possibility of another negative experience in a lecture mathematics class.

Students who enroll in lecture classes consistently expressed several reasons for preferring lecture (Kinney, 2000). They prefer to learn by watching an instructor present the material and being able to ask questions during the presentation of the material; they valued the human interaction. They also pointed out that they frequently benefit when another student asks the instructor a question and they are able to listen to the instructor's response. Students in lecture courses prefer these types of interactions over the opportunity for more individual attention in a computer-mediated course.

It is clear from offering both computer-mediated and lecture mathematics courses that both instructional formats contribute to meeting the needs of mathematics students. In a recent semester, student's performance in the computermediated and lecture courses showed no significant difference on common final exams (Kinney, 2001a). What is important, especially in traditionally "high risk" courses like mathematics, is to provides students with a variety of options.

\section{Universal Instructional Design}

The concept of Universal Instructional Design (UID) suggests that as instructional design decisions are made to meet the needs of any particular student, it is worth looking for a solution that may benefit all students. The mathematics program at the University of Minnesota General College offers both computer-mediated and lecture mathematics courses in Introductory Algebra and Intermediate Algebra. Students are allowed to self-select into the instructional format that they believe will best meet their learning preferences. To assist them in their decision, students take an inventory containing items related to computer-mediated and lecture instruction and discuss their options with their advisor.

In an attempt to provide students with the widest range of instructional materials and access to those materials, all students are provided with the textbook and software from Academic Systems (AcademicOnline 
$2000,2000)$ and a study guide. The study guide, developed by faculty and staff, contains (a) the objectives for each section, (b) the location of the instruction related to each objective in the textbook, (c) instructional supplements to add to or clarify those in the textbook, (d) exercises in the homework set related to each objective, and (e) the answers to each problem. All students, whether enrolled in computer-mediated or lecture classes, are able to use the software in the mathematics learning center and where they live if they have a personal computer (PC) and Internet access.

The use of these instructional materials benefits students in several ways. First, if students miss a class for any reason, they can study the material for that class using the software in the mathematics learning center or possibly at home. This may be important to students who are ill for extended periods of time, have work or family conflicts, or have a disability that at times makes it difficult to physically get to class or interferes with their ability to learn, perhaps due to the effects of medication while in class. Second, students enrolled in lecture courses may be able to access the software for an additional presentation of the material, which may be useful if they did not fully understand the presentation provided by the lecturer or if they would like to work some additional problems where they receive immediate detailed feedback. This opportunity can be particularly helpful to students with acquired brain injuries (ABI) and other disabilities that impede retention of knowledge. Third, the study guide allows students to concentrate on learning the content, rather than spending time trying to figure out what they are expected to learn and identifying where to find the relevant instruction. The time saved can be particularly important to students with learning disabilities because they often require more time to process the material than other students.

This approach also benefits students with Attention Deficit Disorder (ADD) and Attention Deficit Hyperactivity Disorder (ADHD) who may easily be distracted and have difficulty making complex connections. Using this method, these students can focus their attention on the mathematics.

\section{The Principles of UID as an Assessment Tool}

On instructor evaluations in a recent pilot study, students were asked to evaluate their learning experiences by answering eight items based on the principles of UID (Kinney, 2001b). Traditional instructor evaluation items do not always apply to computer-mediated instruction and they may 
not address topics that contribute to successful and positive learning experiences for students. The goal of the General College mathematics program is to provide students with an opportunity to study mathematics that is consistent with the principles of UID, whether in computer-mediated or lecture courses. Overall, student responses in the pilot study were favorable and provided useful suggestions for identifying areas in the mathematics program that can be improved. Next, the eight items administered to students are provided along with a short discussion of how we are attempting to incorporate each principle into the mathematics program.

1. "The instructional staff created a classroom climate that fostered trust and respect." Establishing good communication with students contributes to students feeling respected, and establishes trust between students and faculty. Communication includes verbal interactions between instructors and students and written information such as the course syllabus. Instructors communicate more than mathematics when presenting lessons or working with students individually. They often implicitly communicate their own attitudes towards mathematics, what it means to learn mathematics, and their expectations about the pace and level of mastery that their students should achieve. Thus, it is important that what is communicated to students encourages them to continue attending class and working to be successful, even when they may dislike mathematics or are struggling. A classroom that fosters trust and respect may encourage students with disabilities to let the instructor know what facilitates their learning. The classroom should also encourage students to ask questions, share potential solutions, seek assistance as needed, including using office hours, and contribute to students viewing attending class as a positive experience.

2. "The instructor clearly identified the knowledge and skills students must attain to complete the course successfully." The study guide was written in part to identify the knowledge and skills that students must attain. In many textbooks, the author includes a heading called "objectives" and then simply lists the topics to be covered in that section rather than actual objectives. Few students actually read these so-called objectives, let alone know how to use them to guide their studying. The objectives in the study guide, and links to the relevant instruction and related problems, are intended to make the instructor's expectations clear to the students. Instructors are expected to provide instruction that assists students in achieving these objectives and students are informed that the quizzes and exams are linked directly to these objectives. This approach can be particularly helpful to students with learning disabilities, ADD, ADHD, and ABI, 
who often need more time than other students to process the material, because it allows them to focus on learning the material rather than determining the instructor's expectations and where to access useful materials.

3. "The instructor provided clear expectations and feedback." The expectations for the course are contained in the study guide, which includes a detailed course syllabus, assignment schedule, and due dates for all assignments, quizzes, and exams. Another mechanism for providing clear expectations is daily reminders written on the board at the beginning of class. Instructors may also communicate their expectations when working with students individually in class, during office hours, and by e-mail.

Feedback is provided to students on all assignments, which includes homework, checkpoint questions, quizzes, and exams. Daily checkpoint questions are a single item on a recently covered concept or skill and are given in class for group work. Students are encouraged to communicate with classmates about their strategies and solutions when completing checkpoint questions, which enable them to receive peer feedback. The instructor is also available to provide feedback to students as they complete checkpoint questions. Students also receive feedback on two mid-semester reports. These reports are sent to the student and advisor and provide information about the student's progress in the course. An instructor may request that the advisor intervene if the student is not performing up to expectations academically, needs assistance in developing better study skills, or is aware of other issues that may be adversely affecting the student. For students who are reluctant to ask questions in a lecture class, such as students who have missed classes due to their disabilities and do not want to feel like they are "holding up the class" by asking questions, the computer-mediated courses offer the opportunity for extended periods of individual assistance and feedback from the instructor.

4. "The course materials (software, book, study guide, handouts, etc.), the instructional staff, and the course design were effective in supporting your learning." Students are able to select the primary mode, computer-mediated or lecture, in which they prefer to learn mathematics. For students in the lecture courses, the software acts as an ancillary resource that supports their learning in the event they missed class, were not clear about the content covered that day, or simply find that an interactive multimedia presentation of the material aids their learning. The software can be used by all students in the mathematics learning center and where they live by students with a personal computer (PC) and Internet access. The study guide supports student learning 
by providing all of the course objectives, references to the instruction in the textbook and corresponding problems in the exercise set for each objective, and includes answers to all problems. This supports students' learning by making clear what they are expected to learn and enabling them to quickly and easily access the desired material. All students may receive one-on-one tutoring in the mathematics learning center during regular business hours.

5. "The course materials and design provided opportunities to learn in a way(s) that fit your learning style." Students may enroll in either a computer-based or lecture course and take an inventory to assist them in making their decision. All students are provided with an interactive multimedia software package, a textbook, and a study guide. Lecture instructors make frequent use of various representations-words, algebraic, tables, graphs, and pictures - to assist students in understanding the concepts and skills. In the computer-mediated courses, students receive a multimedia presentation of the concepts and skills in various modes of representation. The animation and graphics, along with students' ability to control the pace and navigation path, provide students with a learning experience that is very different than lecture.

6. "There were enough different ways to demonstrate your knowledge of the subject and earn that grade that you deserved." Traditionally, students have been asked to demonstrate their knowledge through homework exercises, quizzes, and exams. The resources and time available to students varies for each of these categories. Homework assignments, for example, encourage students to use any available resource, including working with classmates and tutorial assistance, and usually have no time limits other than that they are to be completed by a set date. Exams have time limits, unless a student with a disability has appropriate documentation, and often the only resource that students may use is a calculator. A mastery approach on exams, which we currently do not use but are considering if the current software is modified, would allow students more than one opportunity to demonstrate their knowledge. Furthermore, when using computer-mediated instruction, the teacher can opt to give extended time on tests to all students.

Students may also demonstrate their knowledge through innovative approaches such as checkpoint questions and learning logs. Checkpoint questions, as discussed earlier, are currently incorporated into the program. An additional approach under consideration involves learning logs, which give students further opportunities to express their ideas and demonstrate their understanding through writing. General guiding questions are given to students to 
help them organize their work for a particular problem in the format "introduction-main body-reflection." Learning logs encourage students to explore, question, and clarify their own mathematical thinking and reasoning and facilitate writing across the curriculum. A rubric focusing on the mathematical process can be designed for evaluating learning logs.

7. "The technology used in this class helped me learn the subject matter." By making interactive multimedia software available to all students, students no longer are reliant on the instructor for a presentation of the content. For some students, the most important aspect of the software is the multimedia presentation, interactivity, and control of pace. For other students, it is simply that they have control over their learning rather than the instructor. Students also have greater flexibility in terms of time and location of their learning because the software can be used in computer-mediated classrooms, the mathematics learning center, and at home.

The mathematics faculty and staff are in the process of incorporating the web platform WebCT into the regular day classes and distance education classes as a means to facilitate communication. Chatrooms, for example, allow students to ask classmates questions about the mathematics covered in each lesson and the homework assignments. For students with disabilities, a variety of technology products are available, including a software program called Zoomtext that aids visually impaired students when using the course software.

8. "The course design and instructional staff encouraged student-instructional staff contact." In the computer-based courses the instructor provides individual or small group assistance to students throughout the class, thus providing more individual facultystudent contact than generally is possible in lecture courses. E-mail and office hours, along with a classroom that fosters trust and respect, also encourage faculty-student contact.

\section{Summary}

The availability of interactive multimedia software, for use in computermediated courses and as additional resource for students in lecture courses, is providing new opportunities for redesigning introductory mathematics courses and programs. The principles of UID are worth reflecting on as programs change to meet the needs of all learners to the greatest extent possible. For many students, including students with disabilities, computer-mediated learning provides students with greater control over the pace and navigation of their learning, a more visual and interactive approach to learning, and more flexible times and locations for learning than lecture. The principles of UID, 
however, do not suggest that programs eliminate lecture classes because many students still prefer to learn mathematics through lecture. UID does suggest that solutions for some students, such as providing opportunities to learn through interactive multimedia software, be incorporated into a program so that it may support all students.

\section{References}

AcademicOnline 2000 [computer software]. (2000). Mountain View, CA.: Academic Systems Corporation.

Becker, H. J. (1992). Computer-based integrated learning systems in the elementary and middle schools: A critical review and synthesis of evaluation reports. Journal of Educational Computing Research, 8, $1-41$.

Bosco, J. (1986). An analysis of evaluations of interactive video. Educational Technology, 25, 7-16.

Developmental Interactive Multimedia Mathematics (DIMM). Funded by the National Science Foundation (DUE 9972445).

Fletcher, D. (1989). The effectiveness and cost of interactive videodisc instruction. Machine-mediated Learning, 3, 361-385.
Fletcher, D. (1990). The effectiveness and cost of interactive videodisc instruction in defense training and education (IDA Paper P-2372). Alexandria, VA: Institute for Defense Analyses.

Gifford, B. R. (1996). Mediated learning: A new model of technology-mediated instruction and learning. Mountain View, CA: Academic Systems.

Hattie, J., Biggs, J., \& Purdie, N. (1996). Effects of learning skills interventions on student learning: A meta-analysis. Review of Educational Research, 66, 99-136.

Higbee, J. L., Ginter E. J., \& Taylor W. D. (1991). Enhancing academic performance: Seven perceptual styles of learning. Research and Teaching in Developmental Education, 7(2), 5-10.

Khalili, A., \& Shashaani, L. (1994). The effectiveness of computer applications: A meta-analysis. Journal of Research on Computing in Education, 27, 48-61.

Kinney, D. P. (2000). [Student responses to survey, questionnaire, and focus group questions identifying reasons for students' enrollment in computermediated and lecture courses]. Unpublished raw data. Minneapolis, MN: University of Minnesota. 
Kinney, D. P. (2001a). A comparison of computer-mediated and lecture classes in developmental mathematics.

Research and Teaching in Developmental Education, 18 (1), 32-40.

Kinney, D. P. (2001b). [Instructor evaluations based on the principles of Universal Instructional Design]. Unpublished raw data. Minneapolis, MN: University of Minnesota.

Kluger, A., \& DeNisis, A. (1996). The effects of feedback interventions on performance: A historical review, a meta-analysis, and a preliminary feedback intervention theory. Psychological Bulletin, 119, 254-284.

Kulik, C., \& Kulik, J. (1991). Effectiveness of computer-based instruction: An updated analysis. Computers in Human Behavior, 7, 75-94.

Lemire, D. S. (1998). Three learning styles models: Research and recommendations for developmental education. The Learning Assistance Review, 3(2), 26-40.

Najjar, L. J. (1996). Multimedia information and learning. Journal of Educational Multimedia and Hypermedia 5(2), 129-150.
Niemiec, R., Samson, G., Weinstein, T., Walberg, H. (1987). The effects of computer-based instruction in elementary schools: A qualitative synthesis. Journal of Research on Computing in Education, 20, 85-103.

Rosenshine, B., \& Meister, C. (1987). Direct instruction. In M. J. Dunkin (Ed.), The International Encyclopedia of Teaching and Teacher Education. Oxford, UK: Pergamon.

Verano, M. (1987). Achievement and retention of Spanish presented via videodisc in linear, segmented and interactive modes. Unpublished doctoral dissertation, University of Texas, Austin, TX.

Zoomtext [computer software]. (2001). Manchester Center, VT: Ai Squared. 
126|CHAPTER 9

Computer-Mediated Learning 
CHAPTER $10 \mid 127$

Implementing Universal Design

\section{Universal Instructional Design in a Computer-Based Psychology Course}

Thomas Brothen and Cathrine Wambach

University of Minnesota

In this chapter we describe a general psychology course that is consistent with Universal Instructional Design principles and illustrate it with several case studies of students with disabilities. We show how all students' needs are met with the normal interventions of our personalized system of instruction (PSI) model. We conclude that PSI courses can effectively accommodate the needs of students with disabilities and make "accommodation" simply part of what occurs in class on a regular basis.

$\mathrm{n}$ a series of articles, Twigg (1994a,

1994b, 1994c) suggested that the

traditional lecture classroom is a learning technology that is simply out of date. Twigg advocated a new national learning infrastructure in which students learn more independently, test and enhance their learning with each other in cooperative learning communities, and work without the rigid time constraints of the traditional academic term. Twigg's description of higher education today as a "teaching infrastructure" rather than a "learning infrastructure" applies most clearly to the traditional classroom. The viability of a teacher centered educational system is even more problematic since passage of the
Americans with Disabilities Act of 1990 (1991). That act requires educational institutions to develop policies for accommodating students with disabilities. Accommodations typically are expected to be consistent with a definition of disability that encourages individuals with disabilities to "seek adaptations to their needs and aspirations rather than simply adjusting themselves to the demands of a predominantly nondisabled society" (Hahn, 1985, p. 101). This expectation complicates matters for educational institutions, which have adapted to it in various ways (c.f., Fairweather \& Shaver, 1990; Hodge \& Preston-Sabin, 1997). 
Most commonly, larger institutions have a disability services office that mediates relationships between faculty and students with disabilities. That office works with students to certify that their need for accommodation is legitimate and helps students decide what instructional features are necessary to facilitate their academic performance. Then the office sends official requests to faculty to provide the suggested accommodations. A study of 485 faculty members' actions to provide accommodations (Bourke, Strehorn, \& Silver, 1997) showed that the more difficult the accommodation was for faculty to implement, the less likely it was to be delivered. There are also indications that requests for accommodations, especially difficult ones, cause skepticism and concerns about fairness among instructors (Williams \& Ceci, 1999), especially when it comes to disabilities less "obvious" than vision, hearing, or mobility impairments (McAlexander, 1997).

Part of the problem is that instructors do not know how to respond to requests for accommodations. Writers offering guidance (e.g., Chang, Richards, \& Jackson, 1996; Knox, Higbee, Kalivoda, \& Totty, 2000; Lissner, 1997) are working to fill this gap with practical suggestions about working with students, applying technology to traditional classes, and dealing with the legal issues that sometimes arise. But for instructors, the letter they are likely to get from the disability services office might simply say "Extended time on tests (time and one half is recommended)" and little else. This might be an easy accommodation to make but may not adequately address the student's problem and may evoke concerns about fairness to other students. If the goal is to facilitate student learning, often much more needs to be done and it is not readily clear just what that might be.

Silver, Bourke, and Strehorn (1998) address accommodation in a new way with the concept of Universal Instructional Design (UID). They advocate placing "accessibility issues as an integral component of all instructional planning" ( $p$. 47) and suggest that faculty adopt instructional practices such as those described in Chickering and Gamson (1987) and McKeachie (1999) as a way to provide accommodations. To us, this implies making some basic changes in the enterprise of higher education. But first college instructors need new models of instruction that meet the needs of students with disabilities and also benefit other students.

In this chapter we describe our UID model and present case studies of students with disabilities in a general psychology course we designed to meet the needs of developmental students (Brothen \& Wambach, 2000a). Our purpose here is to show how a course specifically designed to improve students' academic performance 
CHAPTER $10 \mid 129$

Implementing Universal Design

may be consistent with Universal Instructional Design principles to accommodate the needs of students with disabilities effectively. We teach our class in the General College, the "open-access," developmental education unit of the University of Minnesota, and currently deliver the course via the Internet with WebCT courseware (see Landon, Bruce, \& Harby, 2001 for a description and comparison of WebCT with other courseware packages).

\section{The Personalized System of Instruction}

Bloom's (1976) formulation of the mastery learning model requires students to achieve mastery over subject matter before progressing to a new unit. A highly developed and researched version of the mastery learning teaching method from the field of learning psychology is Keller's (1968) Personalized System of Instruction (PSI). Several reviews and meta-analyses over the years (Keller, 1974; Kulik, Kulik, \& Bangert-Drowns, 1990; Kulik, Kulik, \& Cohen, 1979; Robin, 1976; Ryan, 1974) have found superior student learning in PSI compared to traditional forms of instruction. Our UID model is based on PSI.

\section{Written Materials}

PSI emphasizes written materials rather than lecture as the major teaching activity.
Instead of presenting information to students orally, instructors select and create appropriate reading materials, create behavioral objectives and study questions, and prepare multiple forms of tests that measure student progress and provide feedback. Lectures are sometimes used in PSI but the conclusion of numerous research studies is that they add little to student learning (Brothen \& Wambach, 1999; Semb, 1995).

We base all assignments in our course on the structure of the 18 chapter textbook. Before they read each chapter, students complete an "electronic flashcard" psychology vocabulary development computer exercise. This exercise requires exact typing of terms or key words missing from 20 randomly selected definitions taken from those printed in the study guide. Students get two points for all 20 correct, and can repeat the exercise unlimited times, getting a new set of items each time they repeat any exercise or quiz. Then they read their text, guided by study questions that they write answers to and turn in for two points. Next they do a 10 item computerized completion exercise that requires them to fill in a key word for a "main point" phrase randomly selected from the textbook chapter. Students are to use their books and can do this exercise unlimited times. They receive three points for getting all 10 correct, two for nine correct and one for eight correct. They must get a mastery score 
of at least eight correct to be able to take quizzes. Their last task for each chapter is to take a 10 item proctored multiple choice chapter quiz. The items are randomly selected from a pool of over 100 that vary from easy to very difficult. Their best score of five tries counts toward their grade. To help them determine if they are ready for the quiz they can take practice quizzes also selected randomly from a large pool of items. They get two bonus points for getting all 10 correct and one for nine correct. Immediately after they finish all exercises and quizzes, WebCT presents students with information about what material they need to study further before they try again. Our research shows that over the term, students improve their ability to be successful on quizzes (Brothen \& Wambach, 2000b).

\section{Small Unit Mastery}

PSI courses are broken down into manageable units that students are to master before they move on. Mastery is determined by successful completion of short unit tests that provide feedback to unsuccessful students so they may review the appropriate material before trying again. We measure learning by students' final performance on a number of small, repeatable exercises on small (i.e., one chapter) units. We encourage mastery in two ways. First, students must get 8 of 10 correct on the challenging completion exercise before continuing the chapter. Students cannot successfully complete this exercise in a reasonable time without having studied the chapter. Second, to make mastery more likely, students receive feedback on their performance and have the option to repeat exercises and quizzes.

Our exercises and quizzes deliver feedback consistent with Kluger and DeNisi's (1996) Feedback Intervention Theory (FIT). FIT describes how feedback should be structured and defines feedback interventions as "actions taken by (an) external agent(s) to provide information regarding some aspect(s) of one's task performance" (p. 255). The FIT approach demands that feedback must be (a) specific to the task, (b) corrective, and (c) done in a familiar context that shapes learning. First, general, nonspecific feedback (e.g., "You got $70 \%$ correct.") is much less performance enhancing than task information feedback (e.g., "You got an item incorrect on the differences between classical and operant conditioning, see page 312"). Second, corrective feedback should be tailored to help the individual student improve. This implies that the feedback must be delivered by a responsive person who knows the student or by "intelligent" computers that can judge and track the student's responses. Third, the task feedback should be embedded in course activities. That is, as students do coursework they should be 
CHAPTER $10 \mid 131$

Implementing Universal Design

receiving feedback on it. Our students receive feedback on all their exercises and quizzes as soon as they finish them.

\section{Self-Pacing}

In PSI courses, students pace themselves through the material, finishing assignments as they are able. Flexibility is a cornerstone of the method and is based on the realization that students have many other obligations and learn at different rates. This is especially true for adult students with careers and families and the increasing number of traditional undergraduates with heavy outside work schedules as well as for students with disabilities.

\section{Personalized but not Individualized Instruction}

Finally, undergraduate tutors have typically scored tests and helped students understand what their deficiencies are and what they need to do to deal with them. Tutors help to personalize PSI. This is different from individualized instruction in which each student pursues a different learning plan (Semb, 1995). In typical PSI courses all students have the same body of content to learn; tutors are available to help them learn it. Our teaching assistants work with students individually and our research (Brothen \& Wambach, in press) shows that our computer assisted model can fulfill most of tutoring's many dimensions. Our staff is central to the operation of our instructional model. It consists of two professors assigned part time to the course, a full time course coordinator, and several undergraduate teaching assistants who completed the course in a previous semester with A grades.

Elsewhere (Brothen \& Wambach, 2000a) we describe the research program we have carried out with our computer assisted PSI model. We describe below two studies over two semesters in which we have explored how students with disabilities respond to our model. In this chapter our report of these investigations is descriptive rather than experimental; we believe it illustrates the advantages of PSI in meeting the goals of UID.

\section{Study I}

We conducted the first case studies in an earlier version of the course model (Brothen, Hansen, \& Wambach, 2001). Participants consisted of students enrolled in six sections of the course that met three days each week with two other days reserved for open lab during a 15 week spring semester. Students did all their computer work in a computer classroom containing 35 workstations and six quiz computers located at the back of the room (Brothen, 1992). Out of 210 initially enrolled students, a total of 187 finished the course by taking the final examination. 


\section{Methodology}

We told students the first day of class that we would be studying their course progress. All read and signed an informed consent form giving us permission for the confidential use of their course data and academic progress data on file at the university. On the first day of class students completed a Big 5 personality questionnaire (John, Donahue, \& Kantle, 1991) as part of a course assignment. We recorded students' scores on the Big 5 traits of agreeableness, conscientiousness, extraversion, openness to new experience, and neuroticism along with each student's cumulative completed credits and cumulative grade point average (GPA) for this study.

For each chapter students did three computer exercises (i.e., vocabulary exercise, completion exercise, progress quiz) that were self-paced with no time limits. They accessed them with a course delivery system (Brothen, 1995) that randomly selected items from chapter databases, recorded scores, and recorded time spent on each exercise in log files for subsequent analysis. We used this information to monitor student progress during the semester. Because completing exercises and amassing points is most strongly related to course success, time spent working is crucial. We selected for intervention both students spending too little time working and those spending a great deal of time but not accomplishing much.

In this study we present student progress data and other observations to detail the progress of the three students we will call Ralph, Terry, and Rene, who were identified by the university's Office of Disabilities Services as requiring accommodations during the academic term of this study. These students brought letters to us during the first week of classes requesting specific accommodations. We describe how they negotiated the course and how they illustrate our UID model.

\section{The Students}

Students registering for the course had completed from zero to 106 semester credits $(\underline{\mathrm{M}}=20.24, \underline{\mathrm{SD}}=17.19)$ with cumulative GPAs ranging from zero to $4.0(\underline{\mathrm{M}}=2.81$, $\underline{\mathrm{SD}}=.72)$. There were 57 computer exercises to complete in the course, 3 for each of 19 textbook chapters. The 187 students who took the final exam completed from 6 to 57 exercises $(\underline{\mathrm{M}}=50.76, \underline{\mathrm{SD}}=$ 10.82) and they spent from 176 to 3,209 total minutes completing these exercises ( $\underline{\mathrm{M}}$ $=1,326, \underline{\mathrm{SD}}=501)$. Our three students with disabilities completed all 57 exercises in from 787 to 2,319 $\mathrm{min}$. The corresponding completion times for the other 77 students who completed all 57 exercises ranged from 669 to 2,277 minutes $(\underline{\mathrm{M}}=1,433, \underline{\mathrm{SD}}=$ 
CHAPTER $10 \mid 133$

Implementing Universal Design

400). Students completing the final examination received scores ranging from 37 to $96(\underline{M}=66.59, \underline{S D}=11.32)$. We present comparison data and case descriptions for our three students subsequently.

Student \#1. Ralph was a large, friendly, and vocal student whom everyone on the staff came to know in a short time. His scores on the Big 5 all fell within one standard deviation of the class means. The letter from his Disabilities Services counselor said very little about him specifically. The first, third, and fourth paragraphs simply identified him and provided general information about whom to contact for further information. The second paragraph read:

Accommodations for students with disabilities are individually determined with input from the student, instructor, and the Disability specialist. Your input in this process is important, as the accommodations should in no way compromise the essential elements or objectives of your curriculum. [Ralph] and I are anticipating that the following accommodations would be reasonable: Extended time on tests (time and one half is recommended).

The lack of specific information in this letter is not unusual given that students have input into how much they are willing to disclose about their disability. Perhaps Ralph's experience in previous courses showed that extra time was all that he required. Perhaps it was the only accommodation possible in his previous courses. Or, perhaps it was the only thing he would "admit" to needing. Our approach to Ralph was no different than for any other of our students; we monitored how he handled the work and responded accordingly.

Of our three students with disabilities, Ralph spent the longest time working on computer exercises-2,319 min for the semester. Although this was a high total, it was far from the highest of all our students. The staff did notice very early in the term that Ralph was spending a lot of time on and having difficulty with his computer exercises (see Table 1). However, at this point early in the term Ralph was apparently preparing adequately outside of class because even though he struggled on his first quiz attempts, his final quiz scores for both Chapter 1 and the Appendix were 9 out of 10 . He did spend more time than the average student on quizzes. The Chapter 1 quiz on which he received a 9 took him 12 min. The Appendix quiz on which he received a 9 took him 20 min. Most students finish quizzes in 8 min or less. From this data it appeared that our built-in extra time accommodation was working well for Ralph. 
But even though he was attending class regularly and ultimately doing well on quizzes, Ralph began falling behind early in the semester, often because he was spending so much time completing exercises, particularly completion exercises, which require students to fill in key words. We noticed this and assigned one of our undergraduate teaching assistants to work with him. While working with Ralph, our assistant soon noticed that he seemed to know the material, but had difficulty reading computer exercise items and finding answers for items in the text. He often struggled with individual words and mumbled them when reading a phrase out loud to the assistant. This led us to suspect that his disability was related to reading and affected his out of class work as well as his computer exercises. We called his Disabilities Services counselor to report that the extra time was only part of what Ralph needed and that help with reading items was crucial. The counselor revealed that Ralph had what she described as one of the most severe cases of dyslexia her office had ever encountered.

For the first 6 weeks of the course, Ralph basically did the exercises the way we recommended, completing vocabulary and completion exercises and quizzes before moving on to the next chapter in the text. However, about the 6th week, Ralph took a quiz for Chapter 4, and then did not take a quiz again for over a month, concentrating on doing the other chapter exercises. The opinion of the assistant working with Ralph was that he was no longer reading and preparing outside of class, and was trying to do the pre-quiz exercises without carefully reading the book. For this reason, he was spending even more time on completion exercises than he was previously.

With about a month left in the course, Ralph realized that he only had a few weeks to finish quizzes for 14 chapters. Because he had completed nearly all of the vocabulary and completion exercises, most of his day in the classroom was spent reviewing for quizzes with one of our assistants, taking quizzes, studying feedback, and retaking quizzes. In general, his goal was to receive a minimum score of 7 , which is a C. To finish this many quizzes in a month would be a very difficult for any student, much less for a student with a reading disability.

After discovering that Ralph's request for additional time was due to a reading disability, we regularly provided a reader for his quizzes. He would often become "stuck" on a word in a question, or he would just skip words that he could not read, and try to fill in the blank using the context of the question, a survival skill that had probably served him well in the past. However, for our multiple choice quizzes that ask students to make some very fine discriminations, that 
CHAPTER $10 \mid 135$

Implementing Universal Design

strategy does not work. We discovered that simply providing Ralph with more time to complete quizzes would not help. If he did not recognize a word, it did not matter how long he looked at the question. Providing him with a reader was by far the more effective strategy.

In addition, we wanted to induce Ralph to practice the exercises to develop fluency (cf., Johnson \& Layng, 1992). Because it took him so much longer to complete vocabulary exercises where he had to search for a word and type it correctly, we told him that if he received two 19s on a vocabulary exercise, we would give him full points, just as if he had received a 20. As we expected, Ralph became faster at doing them. He completed his last nine chapter vocabulary exercises in an average of $13.1 \mathrm{~min}$ compared to an average of 28.8 min over the first 10 chapters. Ralph received a B- final grade for the course.

Student \#2. Terry was an older returning student who appeared anxious enough on the first day of classes for us to notice. His scores on the Big 5 fell within one standard deviation of the class means on agreeableness, conscientiousness, and extraversion. But he scored nearly two standard deviations above the mean on openness and more than two on neuroticism. His letter from Disabilities Services was much the same as Ralph's except that it mentioned the nature of his disability as well as requesting an accommodation. The letter stated, "He is being treated for a chronic illness that limits his ability to manage anxiety and maintain concentration." It requested that he "be allowed to take a break during class if necessary to manage his anxiety."

Because students can enter and leave our classroom at any time, Terry did not require an accommodation to take breaks. Terry's letter also indicated that he needed a nondistracting test taking environment. We discovered that although Terry may have been anxious, he was actually not easily distracted, but incredibly focused in the environment we created for our students. Terry spent the least time completing computer exercises of our three students with disabilities and received the most points. He followed our recommended study technique to the letter, doing the exercises in the sequence noted above, restudying before repeating an exercise, and repeating earlier chapter exercises if he was having trouble on later ones. When asked at the end of the semester about following our recommendations, he said that he did not set out to follow them but simply did them in a manner he thought was logical.

From the beginning, Terry used the completion exercises to build fluency. On the difficult neuropsychology chapter he did 
six of them before taking a quiz, and received 10s on five of the quizzes, in as little as two min each. He took three quizzes, restudying his text after the first two, and the highest score he received was a nine. After the third try he did another completion exercise for Chapter 2, and then took another quiz and received a 10 . This became a pattern for Terry. If he did not get a 10 on his first quiz attempt, he would do more completion exercises and then retake the quiz. Even though Terry took several completion exercises for each chapter, he did not spend a great deal of time on them. By the last chapters he took only one or two before achieving the maximum quiz score.

Our strategy for Terry was to stay out of his way because it appeared that the PSI structure was working fine for him without any special intervention. We tried to be encouraging and asked if he had any questions; he rarely did. We noticed fairly early that he had a strategy that was working well for him, and we let him work on his own. It became a game for Terry to see if he could get a 10 on his first try on each quiz, and we joined in by asking him if it was his first try when we would see that he received a 10. Out of 19 chapters, Terry scored 10 on his first try on 11 . The only points Terry missed all semester were four points on his final exam and he received an A final grade for the course.
Student \#3. Rene was a small, fragile, shy individual who could easily go unnoticed in a large class. Her scores on the Big 5 fell within one standard deviation of the class means on agreeableness, conscientiousness, extraversion and openness. But she scored two standard deviations above the mean on neuroticism. The reason for her appearance and demeanor was only hinted at in her letter from Disabilities Services. It contained basically the same "boilerplate" as the other two and described her disability as one "which impacts concentration and speed of thought." The letter requested " 1.5 test time and a non-distracting test environment."

Rene spent 2200 min working on the computer exercises in the classroom, missing $4 \frac{1}{2}$ weeks of class time due to serious illness. Throughout the semester she was in and out of the hospital for what was apparently highly invasive medical treatment. She was very test anxious and for the first few chapters did an enormous number of completion exercises before taking quizzes. After doing fairly well on the first quiz she took for Chapter 1, a score of seven, she did nine more completion exercises before taking another quiz. She had very high expectations and when she was unhappy with a quiz score, she continued to practice to the point of using her time inefficiently. 
CHAPTER $10 \mid 137$

Implementing Universal Design

After Rene missed 3 consecutive weeks of class early in the semester due to her illness, she contacted us via e-mail and asked for help. This gave us an opportunity to work with her on more efficient strategies, which was necessary due to the amount of time she missed. We recommended that she resume her work on Chapter 8 because the reading and study guide assignments were current for that chapter. She did only two completion exercises, both with scores of 10 , in $42 \mathrm{~min}$. She then took all five of her quizzes, studying feedback and asking questions between each time she took one. Her final score on this chapter was an eight (the equivalent of a B letter grade).

Rene continued this pattern for the rest of the semester, doing a few completion exercises for each chapter, taking quizzes, studying feedback, and taking quizzes again. She worked on chapters as they were assigned and on earlier chapters as she had time. She was not afraid to ask for help, and if she struggled on a chapter she would ask one of the staff to ask her questions about the material between her quiz attempts. She finished with only two quizzes below a score of eight - those chapters she took after her last episode in the hospital when she was still on heavy medication. She told us that she was having trouble organizing her thoughts the same way as she could when she was not medicated, but she also was behind and knew that she needed to catch up.

We provided a lot of support to Rene and tried not to add to the severe stress she appeared to be undergoing. We encouraged her when she was in the classroom, were available to answer her questions, and when she received a low score we offered to work with her. She used open lab times frequently when we could spend more time with her one-on-one. We allowed her to turn in her study questions late for no penalty during the time she was in the hospital and simply tried to maintain an environment in which she could be as relaxed as possible and perform her best. Rene received an A final grade for the course.

\section{Discussion}

The three students described above all performed well in the course. The PSI format allowed the instructors and staff considerable flexibility in meeting their learning needs. In a traditionally taught psychology course, one that was based on lectures, two midterms, and a final examination, it would have been more difficult to discover and respond appropriately to their needs. For example, Ralph would have been given more time to take tests, but that would not have addressed his underlying reading issue. Recording the 
examinations on audiotape might have worked for Ralph, but this was not requested by him or his disabilities counselor and would have been very difficult to implement. Because we had the opportunity to watch Ralph work, we could design accommodations that were more effective than those requested. Many sympathetic instructors would have recognized Rene's health problems and given her opportunities to make up missed examinations. In fact, university policy requires faculty to make alternative arrangements for students who have legitimate reasons for missing class. Our class did not have scheduled dates for tests so Rene did not require a special accommodation to complete her work. Terry's problem with anxiety would have been more perplexing to many instructors. Although psychology teachers would likely view an anxiety disorder as a legitimate disability, many instructors would be skeptical, and resist the notion that a separate exam should be scheduled for this reason. The need to accommodate psychological disabilities is the most controversial part of the American's with Disabilities Act (Higbee, Kalivoda, \& Hunt, 1993). And, in our PSI course, Terry did not require anything from us. The issue of accommodating vaguely defined disabilities is further illustrated in the next study.

\section{Study II}

In this study we focus on the performance of a student we will refer to by the pseudonym of Jerry. To highlight issues we encountered with Jerry, we will also describe a student who approached our sense of the ideal, whom we will call Ben. The students were enrolled during the spring of 2001. The course was offered using the WebCT course delivery system. WebCT allowed students to complete many of the course exercises outside the classroom, which was not possible with the previous courseware. WebCT also allowed us to place time limits on some exercises. Time limits encourage students to be better prepared before they attempt exercises. When students spend less time on each exercise they are likely to attempt more exercises, consistent with our goal of encouraging more practice and opportunities for feedback.

\section{The Students}

Jerry is a student athlete. The Office of Athletic Academic Counseling carefully monitors the performance of student athletes. That office also provides a variety of learning assistance services, and supervises mandatory study sessions for student athletes. The learning specialists in the office have long term contact with 
CHAPTER $10 \mid 139$

Implementing Universal Design

individual athletes and develop a deep understanding of them as students and persons. The Athletic Department counselors and learning specialists seek feedback from instructors about student progress that they use to create interventions for these students. Many students now have learning disabilities identified at earlier stages of schooling, so more student athletes arrive on campus with disability diagnoses. Also, as more schools have developed sophisticated athlete support services, more learning disability issues among student athletes are being identified at the college level. It was through Jerry's Athletic Department learning specialist that we learned that Jerry has a learning disability and we should expect to receive a letter requesting an accommodation. That was as much information as the Learning Specialist could tell us without breaching confidentiality.

It took Jerry several weeks into the semester to bring us his letter from the Office of Disabilities Services. In the meantime we noticed that he was not making good use of his time in class. Instead of focusing on computer exercises, he would sit next to fellow athletes and whisper. When approached he would giggle and pretend to get back to work. He was accomplishing little, and quickly falling behind.
In contrast to Jerry, Ben, our ideal student, stayed focused in class. He worked quietly at the exercises and steadily completed work with close to $100 \%$ accuracy. He appeared each day at the beginning of his scheduled class period and left at the end having accomplished all he needed to do while in class. He did no computer exercises outside of class, but came to class obviously having done his reading and studying. We spoke with Ben occasionally about his accomplishments and about information from the class he found interesting, but at no point did we need to give him advice on how to become more successful. He knew what to do.

Several weeks into the semester, Jerry gave the staff a letter from disability services. The letter requested that Jerry take tests in a nondistracting environment and be given extra time to complete them. Our first hypothesis was that Jerry has a reading disability. To pursue this hypothesis, one of our staff members began talking with Jerry as he completed exercises. She observed that Jerry mispronounced many words and did not know the meaning of common words. We came to suspect that Jerry had a very weak general vocabulary and poor prior knowledge, which made it difficult for him to comprehend what he read, much less retain it. Unlike Ralph, who had trouble decoding words, Jerry could decode words, but did not understand them. 
In contrast, Ben appeared to have an excellent vocabulary and good prior knowledge. We discovered that he had an ACT Composite score of 26, suggesting he had a good mastery of the high school curriculum and good general intelligence. His ability and prior knowledge allowed him to complete the work of the course efficiently.

As we worked with Jerry it became more apparent that he was an intelligent young man who was capable of learning when he expended the effort. As he mastered more vocabulary he was able to use it appropriately and generate original examples of course concepts. We discovered that he was faced with several serious decisions in his life, and was demonstrating effective problem solving as he made these decisions. We began to wonder if Jerry's learning disability was actually a deficit in prior educational background combined with lack of effort in the past. As Jerry began to experience more success in the course he responded by spending more time both in the classroom and outside of class working on computer activities.

\section{Students' Performance}

First, Jerry did more completion exercises (83) and spent more time on them $(\underline{\mathrm{M}}=27.2 \mathrm{~min})$ than Ben $(43, \underline{\mathrm{M}}=13.0$ $\min )$. The difference in number was primarily because Jerry was getting lower scores $(\underline{M}=6.25$ out of 10 possible $)$ than Ben $(M=9.72)$ and had to repeat them to reach the mastery level of 8 correct. It would be reasonable to argue that Jerry's need for more time caused his low scores because many times he reached the 30 minute time limit before answering all 10 questions. However, in our experience, students typically take longer if they do not prepare well and we see the same pattern in many of our students without disabilities. Jerry eventually did what most of those students do; he put in more time and did the exercises more times, completing all 19 chapters successfully. His distractibility could also have played a role in that we often observed him talking to other students when he should have been working to finish within the time limit. He solved this problem on his own by doing more than half of his completion exercises during nonclass hours, many of them late at night.

Second, Jerry took fewer progress quizzes (46), scored lower on them $(\underline{\mathrm{M}}=$ 5.65), and spent more time on them $(\underline{\mathrm{M}}=$ $23.4 \mathrm{~min})$ than $\operatorname{Ben}(65, \underline{\mathrm{Ms}}=8.62 ; 4.5$ $\mathrm{min})$. The difference is primarily that Ben repeated quizzes until he got the highest score he could, getting 17 high scores of 10 and 2 of 9 on the 19 chapters. Jerry often quit when he got what seemed to him a decent grade. He got 13 high scores of 7, 5 of 8,1 of 9, and no 10s even though he had attempts left on most of the chapters. Ben 
CHAPTER $10 \mid 141$

Implementing Universal Design

was generally better prepared for progress quizzes, getting no scores below 6 (i.e., passing) while one third of Jerry's scores were below 6 .

Third, Ben's and Jerry's completion and quiz scores differed in another way. Jerry's scores were higher when he spent more time, while Ben's were lower. We correlated time spent with score on each exercise and quiz. The correlations for Jerry's completion and quiz scores were +.414 and +.356 respectively while Ben's were -.422 and -.369 (all were significant beyond the .05 level). Apparently, Ben spent more time when he was trying unsuccessfully to find or remember some material. Jerry began to spend more time on quizzes when we persuaded him that it would be helpful for an assistant to read quiz items to him. We did this to keep him focused. For example, we did not allow him to bring his cell phone to the quiz computers. It also allowed us to deal with vocabulary as we did for Ralph in our earlier study and define words that were critical to his understanding of the question but not key psychological terms on which his mastery was being tested.

Figure 1. Completion Quiz Comparison Student 1 and Student 2.

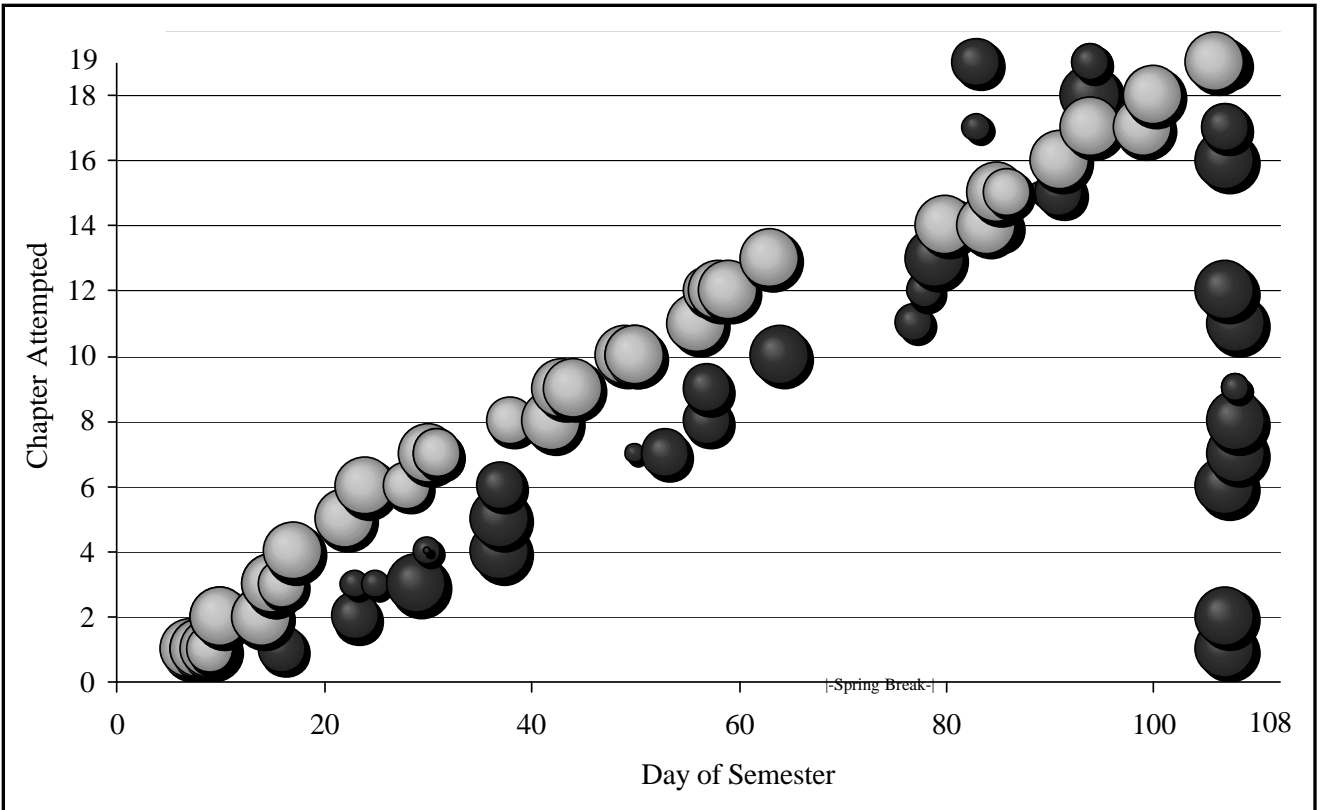


Finally, Ben and Jerry differed in the way they approached the course. Ben was almost "machine like" in his approach. He proceeded exactly as we suggested and worked steadily on task. Jerry delayed getting started and fell behind early. He stayed behind for most of the semester but caught up to Ben after Spring break. Figures 1 (Completion Exercises) and 2 (Progress Quizzes) show both student's progress graphically. The size of the "bubbles" correspond to students' scores squared to show differentiation better. Dots represent quizzes below the threshold for points. The bubbles are arrayed on a matrix of chapters and days of the semester.

Ben's progress is basically linear with one gap early in the semester and one at Spring Break. Smaller bubbles precede larger ones on the chapter axis showing that his scores generally improved on subsequent attempts. His progress is consistent with that of the highest performers in our classes over the years such as Terry's in Study 1. Jerry's progress is more erratic. His chapter scores sometimes decreased on subsequent attempts due probably to inadequate restudy.

Figure 2. Progress Quiz Comparison Student 1 and Student 2.

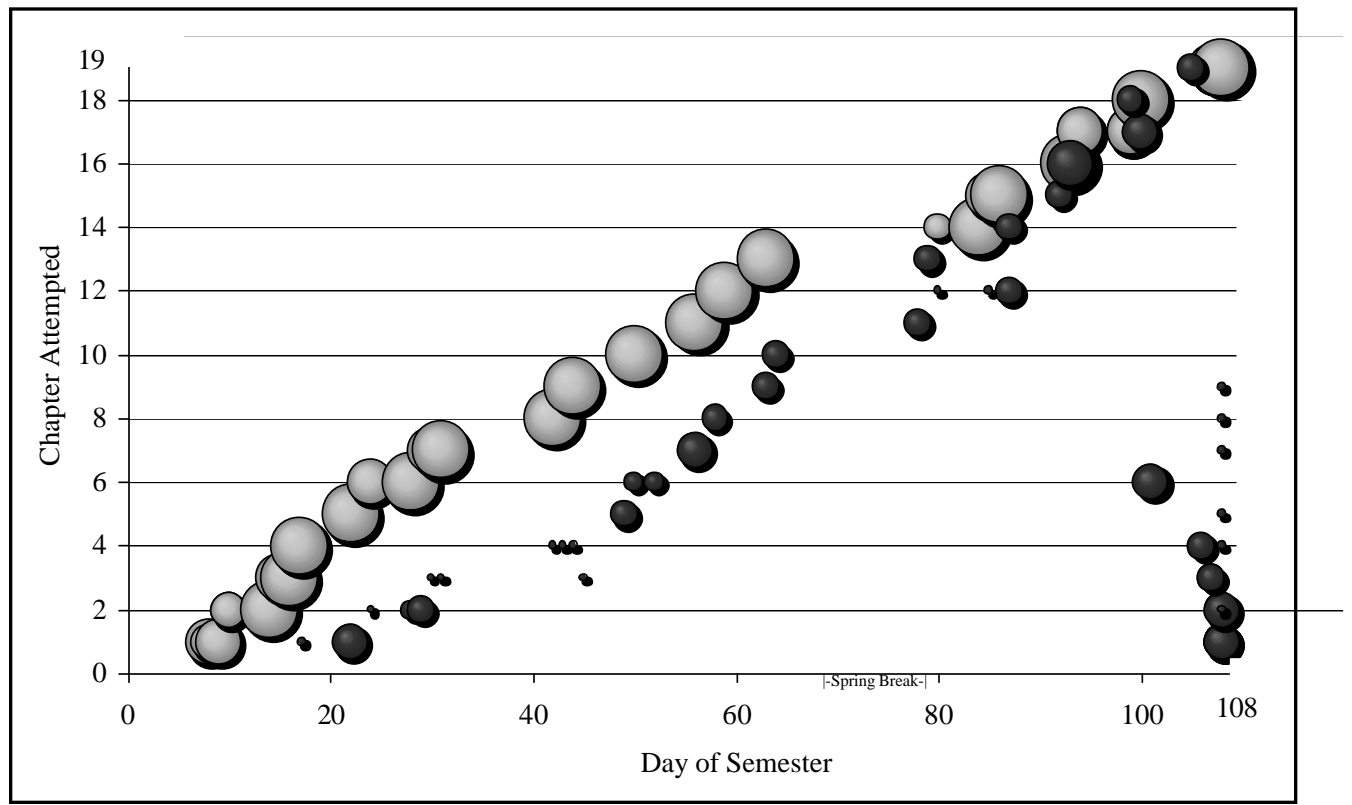


CHAPTER $10 \mid 143$

Implementing Universal Design |

He sometimes completed completion exercises for more than one chapter on the same day before taking a progress quiz, thereby losing focus on the earlier chapter. And he attempted numerous chapter exercises and quizzes on the last few days of classes in an attempt to improve earlier low scores as shown on the bottom right of the figures.

In a traditional psychology class, Ben would have earned good grades on his examinations. Jerry would have been given the extra time requested to complete the examinations, but time and a half is probably an underestimate of the time he required. It often took Jerry $20 \mathrm{~min}$ to complete 10 items. At this rate it would have taken him $100 \mathrm{~min}$ to complete 50 items, a common number of items for a mid-semester test. Typically an instructor would allow 50 min for a test of this length, and most students would be done in $30 \mathrm{~min}$ or less. Time and a half would be $75 \mathrm{~min}$, far short of what Jerry would need.

Taking a test in a less distracting environment, the second accommodation requested for Jerry, might have allowed him to complete the exams more quickly. However, it would not have addressed Jerry's more serious problem of being distracted during class and while studying. Because our teaching method allows the instructor to observe students' work habits, we could intervene during class to help Jerry stay focused and learn to use his time more effectively.

Figure 1 says volumes about the differences between Ben and Jerry. Ben had the attitudes and skills he needed to perform well immediately, Jerry had to acquire those attitudes and skills as he gained experience with the course. Multiple attempts at exercises allowed Ben to achieve a high level of mastery of the course material. Multiple attempts at exercises and attention from the staff gave Jerry the motivation to put in the long hours he needed to spend to pass. By the end of the term, Jerry knew what was needed to succeed and he earned a grade of B in the course.

\section{Conclusions}

PSI is a mastery learning model that fosters superior student learning compared to traditional forms of instruction. We believe that one of the reasons it is effective is that it is responsive to student needs, providing important progress feedback to them and their instructor (cf., Wambach, Brothen, \& Dikel, 2000). Our computer-assisted model (Brothen \& Wambach, 2000a) allows us to monitor students quickly and efficiently so that we can make appropriate interventions.

The flexibility of our method allows most students with disabilities to complete 
the course without special treatment. Students with disabilities can receive assistance within the classroom setting in the same environment in which other students receive assistance. For example, any student could request help reviewing a chapter, or discuss quiz-taking strategies. Although our students with disabilities received more consistent and intense assistance, the type of help was available to all. For example, a teaching assistant reading test items to Ralph or Jerry was not at all unusual. Nearly every class day saw a staff member sitting with students taking quizzes who had been having trouble with quizzes. We did this for second language students as well as for those underperforming on quizzes because they made the typical strategic errors students make on exams (e.g., rushing, "second-guessing" themselves, or picking the first alternative that seems reasonable without reading further). Staff sitting and working with students was a common sight as was our talking to them about their progress and how they were approaching their work.

Nothing in our classroom activities themselves distinguishes students with disabilities from any other student. Although two of the students in Study 1 scored high on the Big 5 neuroticism scale, which was consistent with the accommodations they requested, other students were unlikely to notice anything different about them. They did not take their exams in a different place, they did not require a student volunteer to take notes for them, or require any of the special technological interventions described by Knox et al. (2000). Of course, new circumstances might require something more. We have, for example, had individuals provided in the past by Disability Services to read screens for students who are blind and we have had to configure the room for wheelchairs and Seeing Eye dogs. But our experience over the past several years has been exactly the same as the one described here. Students with disabilities have worked along with other students, albeit taking longer and so on, with similar results. We conclude from this that most students with disabilities can adapt to course requirements and that our PSI model for Universal Instructional Design gives them the opportunity to do that quickly and effectively.

Instructors utilizing PSI will find, as we have, that this form of Universal Instructional Design makes "accommodation" simply part of what they do on a regular basis. We believe PSI has been good for us and for all of our students.

\section{References}

Americans With Disabilities Act of 1990, Pub. L. No. 101-336, § 2, 104 Stat. 328 (1991). 
CHAPTER $10 \mid 145$

Implementing Universal Design |

Bloom, B. (1976). Human characteristics and school learning. New York: McGraw-Hill.

Bourke, A., Strehorn, K. C., \& Silver, P. (1997, March). Tracing the links in the chain of accommodation: A study of University of Massachusetts' faculty members' provision of accommodations to students with learning disabilities. Paper presented at the annual conference of the American Educational Research Association, Chicago, IL. [ERIC Reproduction Service No. ED 408 764]

Brothen, T. (1992). A developmental education approach to computer assisted content instruction. Journal of Developmental Education, 15(3), 32-35.

Brothen, T. (1995). Using a new text-based authoring system to create a computerassisted introductory psychology course. In T. Sechrest, M. Thomas, \& N. Estes (Eds.), Leadership for creating educational change: Integrating the power of technology, Vol. 1 (pp. 308-310). Austin, TX: University of Texas.

Brothen, T., Hansen, G., \& Wambach, C. (2001). Accommodating students with disabilities: Three case studies that illustrate Universal Instructional Design. Unpublished manuscript, University of Minnesota.
Brothen, T., \& Wambach, C. (1999). An evaluation of lectures in a computerbased, PSI introductory psychology course. Journal of Educational Technology Systems, 27, 147-155.

Brothen, T., \& Wambach, C. (2000a). A research based approach to developing a computer-assisted course for developmental students. In J. L. Higbee \& P. L. Dwinell (Eds.), The many faces of developmental education (pp. 59-72). Warrensburg, MO: National Association for Developmental Education.

Brothen, T., \& Wambach, C. (2000b), The effectiveness of computer-based quizzes in a PSI introductory psychology course. Journal of Educational Technology Systems, 28, 253-261.

Brothen, T., \& Wambach, C. (in press). Computer and human tutors in a mastery learning general psychology course. Journal of Tutoring.

Chang, M. K., Richards, S. J., \& Jackson, A. (1996). Accommodating students with disabilities: A practical guide for faculty. [ERIC Document Reproduction Service No. ED 404 827].

Chickering, A. W., \& Gamson, Z. F. (1987, March). Seven principles for good practice in undergraduate education. AAHE Bulletin, 3-7. 
Fairweather, J. S., \& Shaver, D. M. (1990). A troubled future? Participation in education by youths with disabilities. Journal of Higher Education, 61, 332348.

Hahn, H. (1985). Toward a politics of disability: Definitions, disciplines, and policies. The Social Science Journal, 22, 87-105.

Higbee, J. L., Kalivoda, K. S., \& Hunt, P. (1993). Serving students with psychological disabilities. In P. Malinowski (Ed.), Perspectives in practice in developmental education (pp. 90-92). Canandaigua, NY: New York College Learning Skills Association.

Hodge, B. M., \& Preston-Sabin, J. (Eds.). (1997). Accommodations-Or just good teaching? Westport, CT: Praeger.

John, O. P., Donahue, E. M., \& Kantle, R. (1991). The "Big Five" InventoryVersions 4a and 54. (University of California Technical Report). Berkeley, CA: Institute of Personality and Social Psychology.

Johnson, K., \& Layng, J. (1992). Breaking the structuralist barrier: Literacy and numeracy with fluency. American Psychologist, 47, 1475-1490.
Keller, F. (1968). "Goodbye teacher. . ." Journal of Applied Behavior Analysis, 1, 79-89.

Keller, F. (1974). Ten years of personalized instruction. Teaching of Psychology, 1, 4-9.

Kluger, A., \& DeNisi, A. (1996). The effects of feedback interventions on performance: A historical review, a meta-analysis, and a preliminary feedback intervention theory. Psychological Bulletin, 119, 254-284.

Knox, D. K., Higbee, J. L., Kalivoda, K. S., \& Totty, M. C. (2000). Serving the diverse needs of students with disabilities through technology. Journal of College Reading and Learning, 30, 144-157.

Kulik, C., Kulik, J., \& Bangert-Drowns, R. (1990). Effectiveness of mastery learning programs: A meta-analysis. Review of Educational Research, 60, 265-299.

Kulik, C., Kulik, J., \& Cohen, P. (1979). A meta-analysis of outcome studies on Keller's personalized system of instruction. American Psychologist, 34, 307-318. 
Landon, B., Bruce, R., \& Harby, A. (2001). Online educational delivery applications: A web tool for comparative analysis. Retrieved July 2 , 2001 from the World Wide Web: http:// www.ctt.bc.ca/landonline/

Lissner, L. S. (1997). Legal issues concerning all faculty in higher education. In B. M. Hodge \& J. PrestonSabin (Eds.), Accommodations-Orjust good teaching? (pp. 5-22). Westport, CT: Praeger.

McAlexander, P. J. (1997). Learning disabilities and faculty skepticism. Research and Teaching in Developmental Education, 13, 1-5.

McKeachie, W. (1999). McKeachie's teaching tips: Strategies, research, and theory for college and university teachers $\left(10^{\text {th }}\right.$ ed.). Boston, MA: Houghton Mifflin.

Robin, A. (1976). Behavioral instruction in the college classroom. Review of Educational Research, 46, 313-354.

Ryan, B. (1974). PSI, Keller's personalized system of instruction. Washington, DC: American Psychological Association.

Semb, G. (1995). The personalized system of instruction (PSI): A quarter century report. Revista Mexicana De Psicologia, 12, 145-160.
Silver, P., Bourke, A., \& Strehorn, K. C. (1998). Universal Instructional Design in higher education: An approach for inclusion. Equity \& Excellence in Education, 31, 47-51.

Twigg, C. (1994a). The changing definition of learning. Educom Review, 29(1), 2-25.

Twigg, C. (1994b). The need for a national learning structure. Educom Review, 29(2), 16-20.

Twigg, C. (1994c). Navigating the transition. Educom Review, 29(3), 20-24.

Wambach, C., Brothen, T., \& Dikel, T. N. (2000). Toward a developmental theory for developmental educators. Journal of Developmental Education, 24(1), 2-4, 6, 8, 10, 29.

Williams, W. M., \& Ceci, S. J. (1999, August 6). Accommodating learning disabilities can bestow unfair advantages. The Chronicle of Higher Education, B4-B5. 
$148 \mid$ CHAPTER 10

Computer-Based Psychology Course 
CHAPTER $11 \mid 149$

Implementing Universal Design

\title{
Best Practices and Students with Disabilities: Experiences in a College History Course
}

\author{
David L. Ghere \\ University of Minnesota
}

This chapter describes a variety of teaching techniques, modes of presentation, and methods of evaluation utilized to implement Universal Instructional Design in a college history class. The use of classroom simulations is explained in detail. Examples of different types of simulations are provided and their educational benefits discussed. Four disability groups are discussed, merging the author's experience with recent research on learning disabilities, impaired hearing, visual impairment, and physical disabilities.

$\mathrm{T}$ hirty years ago, when I was an undergraduate preparing for a career in education, I was introduced to the Inquiry Method for teaching social studies. One of my instructors emphasized the various benefits of the pregnant pause after asking a question. Calling on the first student to volunteer allows the other students to ignore the question and remain uninvolved in the class discussion while they await the correct answer from one of the stars of the class. However, the instructor could wait to see who has volunteered and then decide whether to choose one of them or to involve another student who has not volunteered. All students in the class must consider the question and be mentally involved in the discussion, because they may be called upon to answer it. The student thought process during the pregnant pause will tend to heighten the curiosity and enhance the comprehension of all students in the class. It also maintains attention to class material and enhances the students' retention of that information. If the question is worth asking, then it is worth the time for students to think about the question and consider their answer. 
These long pauses after questions also benefit students with disabilities. Students with various learning disabilities need time to consider their answer or summon the courage to volunteer. Students with augmentative communication devices need time to volunteer and type in their answers. The pause after questions also accommodates the delay in the transmission of sign language to students with hearing impairments. One student who was deaf repeatedly seized the opportunity to display her understanding and knowledge of class material because she was conscious of misperceptions about her intelligence in other classes. Other students with hearing impairments have been more restrained while still benefiting from an enhanced thought process and greater involvement in class discussion. Students who are blind or have learning disabilities have shared with me that this questioning technique allowed them to be more active in the class discussion and kept them interested in class material. The key is that this questioning technique benefits all students and allows the classroom involvement of students with disabilities to be nearly equivalent to that of other students.

\section{Universal Instructional Design in a History Class}

The Inquiry Method is but one of many teaching strategies that can engage students in the learning process. However, it is important to recognize that any one method for the presentation of content material that promotes learning for some students will present barriers for others. Similarly, any one method of expression or teacher assessment of student knowledge and comprehension will advantage some students and disadvantage others. Students are best served when a variety of teaching techniques, modes of presentation, and methods of evaluation are utilized. This serves to address the differences between students in learning style, skill level, and disability by providing alternative means of accessing information and demonstrating competencies. A multifaceted approach limits the advantage or disadvantage that any one student experiences with any one method, providing all students with a better understanding of the material and a fairer evaluation of their knowledge.

\section{Dissemination of Knowledge}

Historical material can be conveyed in a variety of means: textually through published books, historical documents, and handouts; visually through maps, charts, graphs, and diagrams; and orally through lecture, class discussion, and small group interaction. Presenting the material in a variety of means accommodates the learning styles of all students as well as providing alternate means for students with disabilities to access the knowledge. Also, students, through lack of interest or understanding, 
CHAPTER $11 \mid 151$

Implementing Universal Design

may not recognize significant aspects of a map, chart, or diagram, which are obvious to the instructor. If instructors explain the key points in detail, they focus the attention and increase the understanding of all the students in the class. In addition, the information is provided to the student who is sight impaired or to the student who needs information presented in multiple sensory channels.

Placing course materials on a website makes them more accessible to all students while facilitating the use of appropriate technology (e.g., text readers, enlarged print) by students with disabilities. Syllabi, course calendars, assignment guidelines, review sheets, topic outlines, and discussion questions can all be placed on the website as well as the documents, quotations, maps, charts, graphs or diagrams that will be distributed as handouts or displayed on the overhead projector. Background material for class activities could be online, enabling all students, but particularly those with disabilities, to be better prepared and more involved in those class activities. Establishing a chat room on the website facilitates student-to-student and student-to-teacher communication and could be the mechanism for collaboration on group assignments, conducting peer assessments, or promoting study groups. Access to instructors is further improved for all students through the use of e-mail. Commonly, students are less nervous than in face-to-face meetings, they have time to consider what questions to ask, and they can communicate when it is most convenient for them.

\section{Assessment of Knowledge}

History exams traditionally consist of multiple choice questions and timed essays, which favor some students and disadvantage others based on the student's learning style, skill development, or disability. Removing unnecessary constraints to the students' ability to demonstrate their knowledge and understanding is beneficial to all students and enables the instructor to more accurately assess both their effort and relative success in mastering the course content. Essay exams with generous time limits would allow all writers to more fully express their ideas, whether they are thoughtful, nervous, meticulous, or gifted writers, or have a disability. Providing review sheets and announcing the essay topic in advance allows all students to focus their study efforts, greatly reduces test anxiety, and enables the instructor to demand work of higher quality. When quality work is not produced, the reason for the failure, lack of ability or lack of effort, is more clearly apparent and the appropriate solutions more obvious to both instructor and student.

The student's historical knowledge and understanding can be evaluated using various methods and techniques. In addition 
to the traditional multiple choice and essay tests, instructors could assess student knowledge and understanding through a variety of other means: oral presentations, class discussion, targeted questions, peer assessments, free writing, journaling, and involvement in class activities. Utilizing multiple methods of evaluation provides each student with a variety of different opportunities to demonstrate their knowledge and understanding of the topic. These broadly based assessments provide a more accurate evaluation of the students' mastery of the course content than their skill level in a particular type of examination.

\section{Simulations: Combining Dissemination and Assessment of Knowledge}

Classroom simulations add flexibility to the curriculum that facilitates access for all students. Simulations provide an active learning alternative to other methods of presentation and create a variety of opportunities for student expression and teacher assessment. Within the simulation, content is provided in a textual format through handouts; verbally through teacher presentations, small group negotiations, and class discussion; and visually through maps, charts, and diagrams on handouts, overheads, and power point presentations. Students can express their ideas verbally in small group or class discussions, by writing in short reaction papers or journaling assignments, or visually through graphs, charts, or maps.

Many teachers assume that students with disabilities would be both academically disadvantaged and socially embarrassed in the active and cooperative learning situations created by simulations. Yet, research indicates that active learning methods increase student involvement in the class and provide more opportunities for student contributions to class discussion (Christenson, Ysseldyke, \& Thurlow, 1989; Greenwood, Delquadri, \& Hall, 1984). This results in higher academic achievement while directly addressing many of the barriers cited above for students with disabilities. These conclusions are supported by research during the past two decades assessing the effectiveness of cooperative learning methods in teaching students with disabilities (Foster, Long, \& Snell, 1999; Johnson \& Johnson, 1982, 1984; Scott, 1990; Martino \& Johnson, 1979). These studies have demonstrated that cooperative learning activities promote communication, mutual understanding, and friendships between students with disabilities and those without, and that both groups achieve higher academic achievement through cooperative learning experiences. In my own experience, the student with the most challenging array of disabilities frequently emerged as the 
CHAPTER $11 \mid 153$

Implementing Universal Design

class star in the cooperative learning situations provided by classroom simulations.

\section{Types of Simulations}

Classroom simulations can be designed to achieve various educational goals by incorporating a variety of teaching strategies. All simulations involve the students in active learning situations requiring some level of role playing. These roles can be very specific as an historical individual; more general as a representative of a country, region, or state; or very generic as a decision maker assessing the historical options. Simulations provide the background material necessary for each student to evaluate the various decision options in the historical situation, and to play the role assigned. Sometimes a reward system is utilized to create a situation, which fosters competition between groups and cooperation within each group. In these "game" simulations, students must articulate their position, negotiate with other students, and compromise when necessary to reach a consensus decision or political bargain that achieves their goals. Other simulations employ maps to convey information to the students, to designate various territorial options, and to ultimately display student decisions. Three specific examples of simulations and their integration into a history class are summarized below.
Farming is a role playing simulation in which pairs of students decide which crops to plant and livestock to raise on their 160 acre farm for a three year period from 1872 to 1874 . All students start with the same amount of cash, but they have three different economic arrangements that greatly affect their ability to be successful over the three year period. One third of the students are homesteaders on the Great Plains, one third are tenant farmers in the Ohio valley, and one third are sharecroppers in the South. At the end of each year, the teacher announces the return on investment for each type of crop or livestock and the student teams calculate how much profit they have to invest in the following year. This simulation acquaints students with the basic economics of farming, the vagaries of farming "success," and the farmer's dependence on weather and national markets. The comparison of the relative success of homesteaders, tenant farmers, and sharecroppers in the simulation stimulates a class discussion of the social effects of these differing economic arrangements.

The Slavery Issue: 1848 is a game simulation addressing the political options concerning the issue of slavery in the years preceding the American Civil War. Five positions were advanced by various political leaders to resolve the issue of slavery in the territories: total abolition, the Wilmot Proviso, Popular Sovereignty, extension of 
the Missouri Compromise line, and the Common Property doctrine. Students, playing the role of senators from particular states, must negotiate with each other to reach a group decision. Student senators are awarded points based on the popularity of that group decision in the state or region they represent. Students become familiar with the diverse positions and arguments concerning the issue of slavery, providing background knowledge for a better understanding of the Compromise of 1850 , Bleeding Kansas, and the Dred Scott case.

The Congress of Vienna is a map simulation focusing on that conference, which established the political and diplomatic situation in Europe for the half century following the Napoleonic Wars, 1815 to 1871 . Utilizing an outline map depicting major provinces and principalities in central Europe, student triads decide how to reestablish the balance of power in Europe; what territorial rewards will be given to each victorious country; and what factors must be considered in making those decisions. This process acquaints students with the conservative goals and decisions of the diplomats at the Congress of Vienna, while familiarizing them with the locations of the series of subsequent liberal and nationalist revolutions that attempted to overturn these decisions. Students also develop an understanding of the diplomatic relationships and knowledge of the geographic locations relevant to the diplomacy and wars involved in the unification of Italy and Germany.

\section{Benefits of Simulations}

Research has identified major benefits to the utilization of simulations and interactive games in an educational context, which relate directly to the difficulties experienced by students with disabilities. Druckman (1995) found that simulations and interactive games fostered student interest in the specific topic and historical circumstances associated with the simulation. Additionally, involvement in the simulation stimulated student curiosity about related subject matter. Students developed more positive attitudes toward the general subject matter than with more conventional methods. Furthermore, students' retention of course material increased significantly as a result of their increased involvement in the activity. Other research studies confirm the increased level of interest, greater student involvement, and longer retention of course material (Bredemeier \& Greenblat, 1981; Randel, Morris, Welzel, \& Whitehall., 1992; Sharan, 1980).

The very nature of classroom simulations and interactive games requires communication, but in an enjoyable and relatively nonstressful situation. The resulting increase in student interactions can facilitate the development of interpersonal 
CHAPTER $11 \mid 155$

Implementing Universal Design

skills in all students while directly addressing some of the social needs of students with disabilities. Sharan (1980) determined that team learning methods fostered relationships with group members, promoted student involvement, increased cognitive learning, and promoted the construction of meaning. Students are more willing to communicate while involved in these classroom activities than in more traditional situations (Bredemeier \& Greenblat, 1981). Druckman (1995) found simulations "effective as vehicles for team-building," encouraging participation in a social learning process that conveys new concepts and ideas to students while exposing them to teamwork activities ( $\mathrm{p}$. 184).

Simulations provide students with greater opportunities to display their various talents and abilities, whether in the context of the simulation or through the multitude of possible assignments and projects associated with the simulation. They prompt lively class discussion and require critical thinking skills as students reconsider prevailing assumptions and adopt new perspectives. Simulations can serve as an opening activity to introduce a unit or as a closing exercise for students to demonstrate their knowledge and understanding of course material. They can provide the stimulus for a number of individual student or group research projects such as investigating the historical background of the situation, identifying the factors that promote or inhibit a resolution, contrasting the simulation with actual decisions, or assessing the influence of particular individuals or groups in the final outcome.

Classroom simulations involve students in active learning situations that facilitate a variety of cooperative learning methods and are well suited for students with disabilities Simulations are often utilized to provide students with an experiential knowledge of concepts that are not easily or fully comprehended through traditional teaching methods. They are most effective when the activity is relatively short (e.g., 20 to 35 minutes) and immediately followed by a discussion of the knowledge and understanding conveyed by the simulation. They are most beneficial when designed to focus on a narrow range of educational goals "where very specific content can be targeted and objectives precisely defined" (Randel et al., 1992, p. 269). Role playing activities can be designed to "involve students in an active learning situation that may teach them specific skills" (Glenn, Gregg, \& Tipple, 1982, p. 209).

\section{Students with Learning Disabilities}

Students with learning disabilities constitute the largest group of students with disabilities at the college level. Resnick and Klopfer (1989) suggested the need for new 
teaching methods and instructional materials to develop students' thinking ability, increase their motivation, and assess their learning. They argued that students must play an active role in generating knowledge by integrating new information into their existing knowledge base, which students then employ to think, reason, and learn in future situations. Harris and Pressley (1991) warned that this constructivist approach may be less appropriate to students with learning disabilities who are typically passive and unmotivated learners who, without guidance, may be more prone to misunderstand concepts and construct inaccurate knowledge. Simulations provide a structured method for constructivist learning by providing historical background, an organized learning process, decision making options, and teacher direction.

Carnine (1991) and Ellis (1993) advocated focusing teaching strategies and instructional materials for all students on developing higher order thinking processes. They argued that an emphasis on the acquisition of factual knowledge inhibits innovative teaching techniques, cooperative learning methods, and metacognitive strategy training. They observed that developing higher order thinking ability in students with disabilities was as important as the acquisition of basic content knowledge. Rieth and Polsgrove (1994) discussed three models for creating a curriculum for students with learning disabilities. Their goals included enabling students to better process information, improving their coping and problem-solving skills, developing their interpersonal skills, and enabling them to establish social support networks. Classroom simulations promote all four of these goals and could be effectively utilized in any of the three models discussed.

Writing is often a particular challenge to college students with learning disabilities and a multi-stage process approach is most effective for teaching that group of students (Schnapp, 1997). The experiential learning involved in a simulation is conducive to a variety of writing assignments ranging from journals to reaction papers to summaries to peer evaluations. Collaborative groups can be used very effectively in the drafting process, enabling students to exchange viewpoints, organize their ideas, and present them in coherent sentences and paragraphs. This method is designed to improve student interpersonal skills, enhance student interest in the topic, and reduce student anxiety about the assignment (Schnapp). The shared experience of the simulation also provides each student an expertise with which to critique a journal, reaction paper, or summary of other group members.

\section{Students with Impaired Hearing}

Reviewing recent research, Foster et al. (1999) concluded that despite 
CHAPTER $11 \mid 157$

Implementing Universal Design

comprehensive support services, students with hearing deficits faced a unique challenge in accessing classroom communication. First, there is a delay of 5 to 10 seconds between when the teacher stops speaking and the interpreter finishes signing. Typically, the instructor has called on another student before the student with impaired hearing has an opportunity to respond to a question. Second, students utilizing speech reading are disadvantaged whenever visual contact is broken by the instructor, such as when writing on the board or moving about the room. Third, when the instructor is displaying objects, performing tasks on a projected screen, or referring to a map, chart or diagram, students often must choose whether to watch the interpreter for the words being spoken or to watch the instructor and screen for the visual information. Finally, "deaf students are rarely included in informal exchanges among hearing students regarding instructor expectations, study tips, and unspoken rules for class behavior and organization" ( $p$. 226).

The results of Foster et al.'s (1999) research with students at Rochester Institute of Technology revealed the similarities between the educational needs and desires of hearing students and those who are deaf. Based on quantitative and qualitative analyses, both groups of students had very similar perceptions about educational environments, course materials, and class participation. They listed very similar feelings, positive and negative, about class communication, and their assessment of the ease of communication in the classroom. Differences in perceptions about class communication focused on the ability of the interpreter or the mannerisms of the specific instructor. Both groups also reported being actively engaged in learning, but students with hearing impairments felt less a part of the campus community. Both groups thought they benefited from a slower instructor pace and active teaching methods that prompted more involvement in the class and facilitated ease of communication. However, students with a hearing disability were less inclined to think that the teacher's pace in presenting information was appropriate and facilitated their understanding.

Many of the recommendations from this study correspond closely with the concept of Universal Instructional Design, the accommodations in the history class, and the use of classroom simulations. First, the similarities between the educational needs of hearing students and those with hearing impairments should be emphasized. Second, teaching practices should be identified that address the needs of students with hearing disabilities while enhancing the learning of all students. Third, the selection of instructors should focus on their willingness to adapt their teaching style and methods to 
promote the inclusion of all students. Several other recommendations addressed practical procedures and strategies for accommodating deaf students, improving student access to communication, and disseminating course materials. Simulations address the needs of students with impaired hearing and promote their interaction with other students, while enhancing the interest, active involvement, and learning of all students.

\section{Students with Visual Impairments}

Participation in the classroom and understanding of course material is limited for many college students with a visual disability "by a lack of correspondence between visual and auditory modes of presentation" (Waksler, 1996, p. 99). Instructors often make short references or incomplete commentary to material presented visually, making it extremely difficult for students with visual impairments to follow the discussion and understand the teaching points. Sighted students suffer similar confusion, if they are not looking at the visual representation, or cannot see important details clearly, or do not understand what details are being referenced by the instructor. Teaching techniques designed to provide a barrier-free classroom presentation for a student who is visually impaired promote clarity in presentations for all students (Waksler).
Students with visual impairments have the most difficulty in fully accessing all aspects of the presentation of history material. A student who is blind can listen to class lecture and discussion, but misses the material written on the board or displayed on the overhead as well as any meaningful gestures or facial expressions of the instructor. Textbooks can be ordered in Braille, but the student who is blind misses the content conveyed through maps, pictures, graphs, charts, and diagrams unless provided with raised renderings of these materials. Limited visual impairment may be accommodated through image magnification or printing materials with an enlarged font. Providing copies of handouts or overhead transparencies prior to their use in class enables visually impaired students to become familiar with these materials. Then when the instructor refers to these materials, the student will better understand the instructor's key points and the relevance of those materials.

\section{Students with Mobility Impairments}

Physical disabilities are frequently the most obvious and often the easiest to accommodate. With rare exceptions, classrooms, laboratories, libraries, and study areas are accessible to students using wheelchairs and the placement and design of door handles, elevator buttons, drinking fountains, and so on are gradually changing 
CHAPTER $11 \mid 159$

Implementing Universal Design

to facilitate access by students with other mobility impairments. Depending upon the student's specific impairment, accommodations may be as simple as seating placement in the classroom, modification of the student's desk, typed answers rather than handwritten ones, computer assisted diagrams rather than hand drawn, and alternatives to "fill in the circle" answer sheets. Many students who have difficulty manipulating their hands and fingers request extra time for taking exams. Although this accommodation seems very appropriate to the situation, it would be unnecessary if all students enjoyed the benefit of exams without time limits. The speed with which the student identifies the answer is irrelevant in a history course and timed exams serve only to distort the evaluation of the student's knowledge and understanding.

Mobility is typically not an issue in using simulations except for the initial seating arrangements (i.e., assigning groups and moving desks). Simulations are usually designed to create small group dynamics (e.g., discussion, negotiation, and resolution) between two to six students in close proximity to each other. Some simulations involve the entire class and require some interaction between student work groups in different parts of the classroom. The movement required in these instances may disadvantage a student with impaired mobility, but this situation can usually be accommodated easily. Having the student sit centrally in the classroom would facilitate direct communication with other groups as well as ease their movement when quiet negotiations are preferable. The student could be assigned a role in the simulation that does not require movement, but that might limit the learning opportunity and would be less beneficial than an accommodation that allows the student to experience all aspects of the simulation.

Some students with mobility impairments, as well as those with learning disabilities or sight impairments, are more adept at spoken than written language. In classroom simulations, students generally express their ideas orally in the small group activities and class discussion, providing teachers with additional opportunities to evaluate their knowledge and comprehension. Students could also serve as the spokesperson for the simulation group, accommodating students with written language limitations while providing much needed and rarely offered opportunities for public speaking to all students.

\section{Conclusion}

Many scholars investigating various disabilities have called for the development of teaching methods and techniques that address the needs of students with disabilities while benefiting the learning of all students. Resourceful history teachers 
can design their courses to maximize the access to learning of all students, thereby minimizing the need for individual accommodations. By using the pregnant pause, posting materials on the course web site, and implementing collaborative experiences like class simulations, history teachers can engage all students actively in the learning process. Classroom simulations provide numerous opportunities for interaction and cooperative learning activities to support this Universal Instructional Design. Simulations address many of the needs of students with disabilities while enhancing the learning of all students.

\section{References}

Bredemeier, M. E., \& Greenblat, C. S. (1981). The educational effectiveness of simulation games: A synthesis of findings. Simulation \& Gaming: An International Journal, 12, 307-332.

Carnine, D. (1991). Curricular interventions for teaching higher order thinking to all students: Introduction to special series. Journal of Learning Disabilities, 24, 261-269.

Christenson, S. L., Ysseldyke, J. E., \& Thurlow, M. L. (1989). Critical instruction factors for students with mild handicaps: An integrative review. Remedial and Special Education, 10(5), 21-31.
Druckman, D. (1995). The educational effectiveness of interactive games. In D. Crookall \& K. Arai (Eds.), Simulation and gaming across disciplines and cultures (pp. 178-187). London: Sage.

Ellis, E. S. (1993). Integrative strategy instruction: A potential model for teaching content area subjects to adolescents with learning disabilities. Journal of Learning Disabilities, 26, 358-383.

Foster, S., Long, G., \& Snell, K. (1999). Inclusive instruction and learning for deaf students in postsecondary education. Journal of Deaf Studies and Deaf Education,4(3), 225-235.

Glenn, A. D., Gregg, D., \& Tipple, B. (1982). Using role-playing activities to teach problem solving: Three teaching strategies. Simulation \& Gaming: An International Journal, 13, 199-209.

Greenwood, C. R., Delquadri, J., \& Hall, R. V. (1984). Opportunity to respond and student academic performance. In W. Heward, T. Heron, D. Hill, \& J. TrapPorter (Eds.), Focus on behavior analysis in education (pp. 58-88). Columbus, $\mathrm{OH}$ : Merrill.

Harris, K. R., \& Pressley, M. (1991). The nature of cognitive strategy instruction: Interactive strategy construction. Exceptional Children, 57, 392-404. 
CHAPTER $11 \mid 161$

Implementing Universal Design

Johnson, D. W., \& Johnson, R. T. (1982).

The effects of cooperative and individualistic instruction on handicapped and nonhandicapped students. Journal of Social Psychology, 118, 257-268.

Johnson, D. W., \& Johnson, R. T. (1984). Building acceptance of differences between handicapped and nonhandicapped students: The effects of cooperative and individualistic instruction. Journal of Social Psychology, 122, 257-267.

Martino, L., \& Johnson, D. W. (1979). Cooperative and individualistic experiences among disabled and normal children. Journal of Social Psychology, 107, 177-183.

Randel, J. M., Morris, B. A., Welzel, C. D., \& Whitehall, B. V. (1992). The effectiveness of games for educational purposes: A review of recent research. Simulation \& Gaming: An International Journal, 23, 261-276.

Resnick, L. B., \& Klopfer, L. E. (1989). Toward the thinking curriculum: An overview. In L. B. Resnick \& L. E. Klopfer (Eds.), Toward the thinking curriculum: Current cognitive research (pp. 1-18). Pittsburgh, PA: Association for Supervision and Curriculum Development.
Rieth, H. J., \& Polsgrove, L. (1994). Curriculum and instructional issues in teaching secondary students with learning disabilities. Learning Disabilities Research \& Practice, 9(2), 118-126.

Schnapp, L. (1997). Writing success for the postsecondary student with learning Disabilities. National Association for Developmental Education Selected Conference Papers, 3, 41-43.

Scott, T. J. (1989). The effects of cooperative learning team $v s$. traditional classroom/resource room instruction on handicapped student self esteem and academic achievement. Unpublished doctoral dissertation, Boston College, Boston, MA.

Dissertation Abstracts International, 50(10), 3145-A.

Sharan, S. (1980). Cooperative learning in small groups: Recent methods and effects on achievement, attitudes, and other ethnic relations. Review of Educational Research, 50, 241-272.

Waksler, R. (1996). Teaching strategies for a barrier-free classroom. Journal of Excellence in College Teaching, 7(2), 99-111. 
162 CHAPTER 11

Teaching History 
CHAPTER $12 \mid 163$

Implementing Universal Design

\title{
Universal Instructional Design in a Legal Studies Classroom
}

\author{
Karen L. Miksch \\ University of Minnesota
}

This chapter was generated after the author attended the Curriculum Transformation and Disability (CTAD) workshop and implemented Universal Instructional Design (UID) principles in her Law in Society course. The chapter begins by describing an accessible web page. The author then discusses the use of mock trials in which students can play a variety of roles that fit their individual learning styles. The chapter concludes with a discussion of how to broaden course and student service content to include disability rights.

had the opportunity to attend the first

Curriculum Transformation and

Disability (CTAD) workshop in January 2000. It helped me to reflect on how I could make my courses and services more accessible. I teach legal studies classes to first and second year undergraduate students in a developmental education program. I also act as a pre-law advisor. This chapter was generated from my experiences implementing Universal Instructional Design (UID) in my courses and advising.

Designing a course and pre-law web page was my first step in implementing a "learning support" and will be discussed in the initial section of this chapter. I will then discuss how I redesigned my participation assessment and how I utilize mock trials so that students can play a variety of roles that fit their individual learning styles. The chapter concludes with a discussion of how to broaden course and student service content to include disability rights.

\section{Designing and Incorporating a Web Page to Provide a UID Learning Support}

After attending the CTAD training, I decided that I wanted to create a universally designed course web page (Miksch, 2001). In order to create an accessible web page I first went to the Bobby web site. Bobby is a free service provided by the Center for Applied Special Technology (CAST, 2001) to help Web page authors identify and repair significant barriers to access by individuals with disabilities. Bobby will run a 
diagnostic program on your web page and give you tips to make it more accessible. It will also "approve" your web site if you incorporate UID principles.

Next, I thought about the purpose of having a course web page. I realized that the disability accommodations that I have made for students in the past are also just good teaching practices. In the past, I have made copies of my power point lecture slides as a reasonable accommodation for a student with a disability. In universally designing my web page, I decided to include copies of my power point lecture slides on my web page so all students could access my notes. I post the notes weekly and many students have told me they use my lecture slides in order to check their notes for completeness, clarification, and spelling errors. Students no longer miss the big picture because they are madly trying to write down definitions and details.

I have started posting my assignments, a plagiarism and proper documentation guide, and other helpful handouts on public speaking and how to read cases on the web page, in addition to giving students a paper copy. This assists all students, including students with learning and psychological disabilities. If students need to start an assignment early, they can do so. Tutors in the Writing Center also have access to the assignment guides and find them useful in understanding what I expect of my students.
Posting a course syllabus to a web page not only assists students currently enrolled, it also provides helpful information to advisors and prospective students about course content, goals, and the instructor's teaching style. After I realized that other staff and prospective students benefited from the increased information, I added a section for students interested in attending law school. The new section provides links to online information as a way to supplement the pre-law workshops that I conduct. As my web page has grown, I continue to go back to the Bobby web site for design suggestions to make sure the information is readily accessible by all prospective users.

\section{Assessment of Participation That Respects Divergent Learning Styles}

An important goal of Law in Society is for students to gain better oral communication skills and hone their ability to think critically. When I implemented UID I wanted to make sure that I was taking into account diverse learning styles when assessing participation. I have learned a lot from my students and colleagues about how to teach legal concepts in a first year developmental education course. As Higbee, Ginter, and Taylor (1991) advocate, I present the information utilizing methods that are congruent with my students' 
CHAPTER $12 \mid 165$

Implementing Universal Design

learning styles. Reading cases, hearing lectures, and reading and listening to Supreme Court oral arguments complements print and aural learning styles. Debates, mock hearings, and trials are excellent methods for interactive learners. Visual learners' comprehension of material is enhanced by timelines, maps, videotapes, and power point slides. Finally, performative movement during the mock trial reaches kinesthetic learning styles.

Prior to attending the CTAD training, I assessed classroom participation mainly via debates, small group presentations to the entire class, and large group discussions. Although I want to maintain participation as a requirement for the course, I also want to recognize that there are a variety of ways for students to engage with the material and provide their unique perspective to all of us involved in the course. My syllabus now reads:

Your participation in class is highly valued. Our class will be a collective effort in which our efforts to understand law and society will depend on the exploration of a number of perspectives and viewpoints. I recognize that not all students feel comfortable speaking in front of large groups of people. Class participation therefore includes a variety of ways to contribute to the course development, including: meaningful contribution to class discussions, small group work, debates, presentations, e-mail communication, office hour discussions, reviewing drafts of other student's work and providing useful written and/or oral comments.

I assign a mock trial in my classes and participation is a major portion of the grade. For the assignment, I write a fact pattern and witness statements based on a current U.S. Supreme Court case. Students choose whether they want to play the role of an attorney or a witness. Working together in six to eight person teams, students spend three weeks preparing the trial and then conduct a jury trial in class. In rethinking the mock trial to make sure it is universally designed, I have developed the assignment so students can play a variety of roles that fit their individual learning styles. For example, visual learners can create charts and power point slides for use as visual aids during the trial. This also enables jury members who are print and visual learners to better follow the case. Visual aids also assist students playing the role of an attorney to organize opening statements and to remember important case names. Witnesses, especially those who must remember a key dollar figure, also may use visual aids. In the past I made accommodations for students with a learning disability and allowed the use of 
notes. Now, all witnesses can use visual aids if they want help remembering a key fact.

Mock trial is an effective way to learn about the U.S. legal system, work on oral communication, and enhance critical thinking. The majority of students rate the mock trial as the assignment that best helped them meet course goals on end of semester evaluations. Interactive and kinesthetic learners excel in the mock trials and often gain confidence that enhances their large group participation and written work. Print learners also provide a key skill by digesting the written information in the case packet. Aural learners follow the mini-lectures that I conduct on argumentative strategies and provide constructive feedback to team members on delivery of opening and closing statements and witness testimony. In their peer assessment forms of their own and each other's participation, many students remark that each team member played a different, yet key role in preparing the case.

I continue to work on designing the mock trials so that different forms of participation are assessed and valued. Students are assessed by me and by each other on how well they work with other team members and not just on the actual trial performance. I have noticed that students who are initially nervous about the public speaking component of the course are much more successful and report a more positive experience now that I have incorporated more UID principles into both the assignment and assessment of the mock trial.

\section{Broadening Content to Include Disability Rights}

I also assessed the content of my classes to ensure they are universally designed. As James Banks (1993) and Ronald Takaki (1993) have advocated, integrating multicultural education into course content is an effective way to make courses more inclusive. I want to integrate disability rights into my courses and agree with Geneva Gay (1995) that there are multiple appropriate ways to teach in a multicultural manner. Initially I incorporated a separate section on disability rights and am now rethinking the way in which I teach to incorporate UID principles.

When students see themselves reflected in the curriculum, they are more engaged with the underlying subject matter of the course (Takaki, 1993). To this end, I have incorporated more information on people with disabilities in all of the social science classes that I teach. The legislative history, major federal laws, and seminal cases surrounding disability rights are part of Civil Rights content of the Law in Society class. However, now rather than segregating disability rights to a separate section of the 
CHAPTER $12 \mid 167$

Implementing Universal Design

course, we discuss the emergence of equal protection and evolving definitions of legal equality. Within this discussion, disability is discussed and analyzed along with race and ethnicity, gender, class, age, and sexual orientation. Disability is not relegated to a separate "ism, "but seen within the context of a major Civil Rights issue.

I also decided to incorporate disability, race, class, sexual orientation, and gender issues as they relate to education law. I have found that education law and policy is an issue that all students relate to and offers a way for them to engage with course content. Students read a number of cases, including Brown v. Board of Education (1954), and learn about laws, such as the Americans with Disabilities Act of 1990 (ADA, 1994/ 1997), that govern education. For example, when we discuss education law, we read the provisions in Section 504 of the Rehabilitation Act of 1973 (1994) and Title II and III of the ADA that apply to higher education and prohibit discrimination on the basis of disability. There are a number of articles and publications that provide detailed information on Section 504 and the ADA that assisted in my curriculum development (Blanck, 1998; Council on Law in Higher Education [CLHE], 2000; Rothstein, 2000; Tucker, 1996).

Including disability rights content also reinforces my syllabus statement regarding disability accommodations. Furthermore, students who may have misinformation about psychiatric or learning disabilities learn important information and together we shatter some of the stereotypes about accommodations (e.g., students are faking it, makes course too easy, etc.). Perhaps most importantly, we discuss the Individuals with Disabilities Education Act (IDEA) of 1994 and how it differs from the ADA. Students who had IDEA accommodations when they were in high school need to know that, unlike in primary and secondary schools, when they enter higher education the onus is on them to register with the college or university disability services office and contact individual instructors to obtain reasonable accommodations. Without understanding this distinction, and that testing may no longer be free, many students may incorrectly believe they are automatically eligible for accommodations received in high school.

Discussions about disability culture and the movement for disability rights have led to a number of benefits. My perception is that students are more willing to selfdisclose learning and psychiatric disabilities to me during office hours than they were when disability issues were not integrated into my courses. Hopefully this change is also due to less stigma being attached to being labeled "learning disabled" or having a psychiatric disability. In past course 
offerings where I focused primarily on issues of equality surrounding race, class, and gender, some students dismissed the issue as "discrimination that used to happen, but doesn't anymore." With the inclusion of disability and sexual orientation integrated into our discussion of equality, it is more difficult to dismiss inequality as just a historical problem. Students are also able to see more of a link between themselves as individuals and the legal system, a major goal of Law in Society.

\section{Conclusion}

Since incorporating UID principles in my classes, I have had several students bring me letters detailing the accommodations they require. The students notice that the most common accommodations (i.e., copies of lecture notes and additional time on assignments) have already been incorporated into the course design to benefit all students. I explain that I have attempted to incorporate more learning supports into the course with the goal of inclusive pedagogy. The mock trial, which is the best way I have found to teach students about the U.S. legal system, seems to increase course retention now that I have incorporated multiple ways to participate. Most importantly, integrating disability rights issues into the Civil Rights and education law sections of the course content has provided a valuable learning experience.
In attempting to meet Sonia Nieto's (1994) challenge to move from tolerance to acceptance in multicultural education, hopefully more students are seeing themselves reflected, respected, and affirmed in the curriculum.

\section{References}

The Americans with Disabilities Act of 1990, 42 U.S.C. $\S \S 12101$ to 12132 (West 1994 \& Supp. 1997).

Banks, J. (1993). Multicultural education as an academic discipline: Goals for the $21^{\text {st }}$ century. Multicultural Education, 1(3), 8-11, 39.

Blanck, P. (1998). Civil rights, learning disability, and academic standards. Journal of Gender, Race \& Justice, 2, 33-58.

Brown v. Board of Education, 347 U.S. 483 (1954).

Center for Applied Special Technology (CAST) (2001). Bobby home page, [Online], Available: http://www.cast.org/ bobby/

Council on Law in Higher Education (CLHE) (2000). Disability law for campus administrators: Meeting the needs of students. [Online] Available: www.clhe.org 
CHAPTER $12 \mid 169$

Implementing Universal Design

Gay, G. (1995). Bridging multicultural theory and practice. Multicultural Education, 3(1), 4-9.

Higbee, J. L., Ginter, E. J., \& Taylor, W. D. (1991). Enhancing academic performance: Seven perceptual styles of learning. Research and Teaching in Developmental Education, 7(2), 5-9.

Individuals with Disabilities Education Act, 20 U.S.C. $\S \S 1400-1485$ (1994), as amended by 20 U.S.C.A. $\S \S 1400-1487$ (West 1997).

Miksch, K. Home page for Karen Miksch. [Online]. Available: http:// www.gen.umn.edu/faculty_staff/miksch/

Nieto, S. (1994). Moving beyond tolerance in multicultural education. Multicultural Education, 1(4), 9-12, 35-38.

Rehabilitation Act of 1973, 29 U.S.C. $§ 701$ (1994).

Rothstein, L. (2000). Higher education and the future of disability policy. Alabama Law Review, 52, 241-270.

Takaki, R. (1993). A different mirror: A history of multicultural America. Boston: Little, Brown.
Tucker, B. (1996). Application of the Americans with Disabilities Act (ADA) and Section 504 to colleges and universities: An overview and discussion of special issues relating to students. Journal of College \& University Law, 23, 1-41. 
170| CHAPTER 12

UID in Legal Studies 
CHAPTER $13 \mid 171$

Implementing Universal Design

\title{
Empowering Students with Severe Disabilities: A Case Study
}

\author{
Jay T. Hatch, David L. Ghere, and Katrina Jirik \\ University of Minnesota
}

This chapter provides a case study of the empowerment of a student with multiple and severe disabilities. We outline accommodations provided in three college courses, describe classroom events that contributed to the student's success, and provide the student's own insights into her situation. We conclude that instructors must be thoughtful about what constitutes the essential elements of their courses and creative about how students can acquire and demonstrate knowledge in order to remove the instructional barriers that prevent students with disabilities from being successful in college coursework. Removing these barriers empowers students with disabilities to achieve their academic potential by building self-confidence and developing a realization that the responsibility for success is shared by the students, the instructors, and the institution.

$\mathrm{D}$ ata suggest seriously disproportionate barriers both to access and to success in higher education for persons with disabilities (U.S. Census Bureau, 2001). That the disproportionate success results in large part from inadequately designed curricula and skeptical or hostile attitudes of faculty is no longer a matter of conjecture (Foster, Long, \& Snell, 1999; Hill, 1996; Kalivoda \& Higbee, 1998; Seymour \& Hunter, 1998; West, Kregel, Getzel, \& Zhu, 1993). In this chapter we present a case study of Kate, a student who, because of her severe and multiple disabilities, easily could have been pushed to the edge of the classroom and the entire college experience. We show instead how Kate became fully integrated into three courses (one in world history taught by David Ghere and two in biological science taught by Jay Hatch), won the respect of her teachers and peers, and gained a strong sense of self-confidence and empowerment that resulted in her becoming an outstanding student. We also describe how she helped us to recognize the elements of Universal Instructional Design (UID) that are crucial to the academic advancement of students with severe disabilities (Bowe, 2000; Higbee, 2001; Silver, Bourke, \& Strehorn, 1998). Some of these elements already existed in our courses, while others had to 
be invented to accommodate Kate and are now available to every student.

We begin by describing Kate's array of disabilities, followed by separate case accounts of the world history course and the biological science courses. In these case accounts, we describe what accommodations each of us made, how these accommodations and other course practices facilitated Kate's integration into each course, and how Kate responded to the integration. We conclude with a brief analysis of what we believe to be crucial elements of curricular modification that will empower students with severe disabilities to successfully achieve their academic potential.

This case study is unusual in that its subject, Kate, is also one of its authors. We strongly believe that the advancements made here and the knowledge gained resulted from intellectual contributions involving all three of us. Kate's participation as an author also brought a level of accuracy and authenticity to the writing that would not have existed otherwise. Finally, Kate thought it important to be identified both as subject and as author; hence, we do not employ a subject pseudonym.

\section{Kate's Challenge}

Kate was a challenge, a delightful challenge. In our combined 35 years of teaching, we have never encountered a more daunting prospect or a more successful conclusion. Both of us have had personal experiences with friends or acquaintances who have disabilities, and these experiences preconditioned us to view the potential of students with disabilities very positively. We each have had a number of successful experiences accommodating such students in our classes. Yet, confronted with the array of Kate's disabilities, each of us wondered if we could have any positive impact on her learning.

Kate has severe and multiple disabilities that affected motor control, sensory perception, communication, and learning. She is unable to walk or have complete control over her head and arm movements. Her motor disabilities cause her speech to be virtually unrecognizable. She speaks by typing words into an augmentative communication device with a synthetic voice output. Weak muscles make it necessary for an assistant to support her arm while she swings it slowly but deliberately to strike the keys. Typing is a very slow and arduous task; thus, real-time conversation is a very slow and sometimes frustrating process. Kate also is legally blind. She has limited short-range vision but a form of dyslexia affects even that capability by sometimes rearranging and distorting those things that she can see. The combination of untrustworthy vision and weak muscles 
CHAPTER $13 \mid 173$

Implementing Universal Design

means that Kate cannot control the movement of her wheelchair physically or electronically and has to rely on an assistant to move anywhere. Poor muscle control also results in uncontrollable drooling and a variety of guttural noises made during attempts to swallow excessive saliva. Often these noises exacerbate communication problems and initiate a level of irritability in classmates, some of whom interpret the noises as discourteous, juvenile giggling.

Finally, Kate has a "central processing difficulty" that interferes with word finding and retrieval, which makes it appear that she has memory problems and causes her to go about problem solving in an unusual way. Kate explains it this way.

I'm beginning to realize that I think differently than a lot of people. I think in associative webs. I do not memorize well. I have to have lots of information and a thorough understanding of the concept or theory in order to remember it. I need to know much more than other students just so I can remember the required information. The typical teaching method of simplifying things is a disaster for me. When I don't understand something, I need more information not less.

Despite our doubts concerning our abilities to adequately address Kate's needs, we both were determined to make our courses positive educational experiences for Kate. We each met with Kate to discuss what specific accommodations would be effective and set out to determine how we could implement those accommodations in our courses. We hoped Kate would learn from her experiences in our courses; we had little notion of how profound the experience would be for all three of us.

\section{The World History Course}

Kate enrolled in a ten-week freshman world history class covering the period from 1750 to the present. One simple accommodation was to have exams administered by the staff at the University's Office of Disability Services so that Kate could use their magnification equipment and have questions read out loud if necessary. I also provided Kate with copies of class notes and map transparencies so that she could review them prior to class, and thus be better prepared to understand class presentations and be more involved in class discussions. The world history class included four classroom simulations, active learning exercises that require students to assess the options available to historical figures, reach some decisions, and then explain or critique those decisions. I provided Kate with simulation materials in advance so that she could prepare and save voice messages on her communication 
device for possible use during the simulation. These materials are now posted on a course website for the benefit of all students in the course.

Kate's presence prompted me to make greater use of techniques and methods that I already attempted to practice in the classroom. I routinely contrast opposing views or evidence by writing them on opposite ends of the blackboard, and I vary my tone of voice and speech patterns to emphasize different points. Also, I try to verbally provide detailed explanations of the important aspects of material being presented visually. The physical movement, the voice changes, and the detailed explanations helped all students to follow the logic of class lecture and discussion, but it was particularly beneficial for Kate due to her limited vision. Also, my questions in class are followed by long pauses before I select the person to answer the question. This allows all students to consider the question, facilitates involving more students in the discussion, and provides broader indications of student comprehension of the material. In this instance, it also provided Kate with the time necessary for her to answer questions.

Long before ever learning of the concept of UID, my teaching goals included promoting the widest and deepest acquisition of course material and providing students with the greatest opportunity to demonstrate their knowledge and understanding. Detailed review sheets were provided and essay topics were announced a week before each exam. This had the dual benefit of enabling students to focus their thoughts and energies while increasing the quality of work that could be expected by the instructor. In addition, when demonstrating their mastery of course content through written essays, students were given generous amounts of time, thus promoting and rewarding thoughtful analysis rather than writing speed. These practices enhance student learning while enabling instructors to evaluate each student's effort, knowledge, and understanding with more precision. While they were implemented to benefit all the students, these practices contributed to Kate's success in the course and limited the need for special accommodations.

A significant breakthrough was achieved during the first classroom simulation that occurred at the end of the second week of classes. In this simulation, Congress of Vienna, students were divided into groups of three and provided with outline maps of central Europe depicting the boundaries of France, Prussia, Austria, and Russia as well as smaller countries and principalities in central Europe. Each group had to decide how to reward the victorious countries with territory, reestablish the balance of power 
CHAPTER $13 \mid 175$

Implementing Universal Design

between the major powers, and reinstall autocratic governments following the Napoleonic Wars. The two students grouped with Kate were friendly, but seemed uncomfortable and uncertain about how to include Kate in the simulation. As they were discussing a possible territorial decision, Kate selected a prerecorded message and the mechanical voice from her communication device said, "Austria would not like that." Her two startled partners waited for Kate to type a further comment and were rewarded with a clear explanation of the dilemma posed by the simulation. Kate quickly emerged as the leader of the discussion group for the rest of the class period.

The simulations allowed Kate to demonstrate her capabilities in ways that would never have happened in a typical lecture-style classroom. Kate's high scores on exams and papers would have been largely unknown to her classmates, and her severe physical disabilities would have greatly limited her involvement in most classes. Yet, in the context of the simulation, the 'tinny' voice of Kate's communication device caught students' attention throughout the classroom. They were aware of her active involvement in her group and her contributions were evident in the class discussion that followed the simulation. Kate was paired with a different set of students in each of the three subsequent simulations. Having observed Kate in that first simulation, these new partners immediately involved her in the discussions and waited eagerly for her contributions. In each case, Kate participated fully in the activities and her active involvement could be heard by others in the classroom. By the end of the quarter, everyone knew that the student with the most "medical" disabilities was also the most intellectually capable student in the class.

Kate is a unique student, possessing a truly gifted intellect and a determination to succeed. However, her success in the world history course was also dependent upon a body of class procedures, course assignments, and teaching methods that enabled her to demonstrate her ability. Throughout most of her previous educational experience, she had not had the opportunity to display her capabilities.

Many teachers, staff, and administrators had assumed an intellectual deficit based upon Kate's physical disabilities and her inability to participate in typical class interaction. When Kate had done well on standard tests and papers, many had assumed that others must have written the papers and answered the test questions for Kate. In this world history class, Kate's acquisition of knowledge was promoted, her active involvement was fostered, and her mastery of the content was accurately evaluated. Kate achieved success because the instructional design barriers were removed 
that had previously prevented her from demonstrating her ability. All students regardless of their intellectual or physical abilities should be allowed to demonstrate that ability without having to overcome needless barriers created by instructional design.

\section{The Biological Science Courses}

Kate enrolled in two biological science courses one year apart. The first was a small-enrollment (i.e., 35 students) environmental science course and the second was a larger enrollment (i.e., 100 students) general principles course that included a laboratory component. For the environmental science course I made several of the same accommodations that Dave did in the world history course. All students received a detailed study guide at the beginning of the course. This guide included all of the exercises and study questions that were worked on and discussed in class, as well as examples of tests from previous quarters. I made the additional lecture information (tables, graphs and other illustrations) available to Kate at least one week in advance. This way Kate could formulate responses and her own questions ahead of time, program them into her computer, and participate in class much as other students did. I had already made in-class tests only $20 \%$ of the grade, with a variety of formal and informal writing assignments and a group project making up the remaining $80 \%$. As an accommodation to Kate, I gave all students the option of taking in-class tests similar to those in the study guide (i.e., a mix of short-essay and objective questions) or completing overnight take-home essay exams. Both exam types tested exactly the same learning objectives. These were the accommodations that Kate said ahead of time were the most important. She needed to know in detail from the start what was expected of her so that she could set up her support system and lay out a work schedule that would allow her to stay up to date in the course. She needed to know that there was at least the possibility that she could meet each course requirement, one of which was class participation. In retrospect, this seems only fair and reasonable for any student.

There was one course requirement that Kate thought she might have trouble meeting: the group project. Because of her real-time communication difficulties, Kate was not accustomed to working in a group, especially during class time. To help facilitate the initial group work, I assigned Kate to a group with an older, experienced student who had done a great deal of group work inside and outside of academia. I also suggested to the group members that, as they discussed project issues, they might periodically pose "yes" or "no" questions to allow Kate to participate in a timely way. As the group work proceeded, fellow students realized that Kate possessed considerable 
CHAPTER $13 \mid 177$

Implementing Universal Design

intellect and that she brought an unusually focused clarity to what she wrote. Both my concerns and Kate's about her ability to successfully complete the project work faded quickly. Still, there was the vexing problem of the final class presentation of the project's outcome. No one, including me, expected Kate to present before the class. It was not a requirement for anyone. The requirement was that each member of the group had to contribute to the project in a meaningful way that was acceptable to everyone in the group. Nevertheless, when the day for presentations arrived, Kate was at the front of the room with the rest of her group. They presented a Jeopardy quiz show on the Siberian tiger. While other members of the group read the answers, Kate used the variety of voices available on her voice synthesizer, like Bubbly Betty and Freaky Frederick, to supply the question, "What is the Siberian tiger?" The entire presentation was superb and it received the only standing ovation in memory.

Not quite one year later, Kate asked me if I would help her with a course requirement issue. The University of Minnesota requires all students to complete a foundation course in biological science that has a significant laboratory component. Kate was eager to take the general principles course, but she thought the laboratory component might be inappropriate for her. After all, she reasoned, the purpose of a lab is to get students to manipulate things with their hands and make direct observations, and "I cannot do that." My immediate reaction was, "Not so, you've already proven that you can do science as well as anyone, better than most." However, as I thought about exactly what we required our students to do in the laboratory, I began to think that Kate might be right. In the past we had had students with sight impairments, students with hearing impairments, students with motor impairments, and students with a variety of learning disabilities truly engaged in our laboratory exercises. But we had never attempted to engage someone with Kate's array of impairments.

I thought the question of Kate's involvement was complicated enough that I arranged for a meeting with Kate, her mother, her personal assistant, her counselor at the University's Office of Disabilities Services, a representative from the state's Services for the Blind and Visually Impaired, and our college's laboratory coordinator. After brief introductions, the meeting began with a prepared statement from Kate delivered via her voice synthesizer. Kate made it clear that she did not expect to "slide by" in any course; on the contrary, she wanted to have the same chance as any other student to learn about biology. Her concern, based on previous experiences in science labs, was that:

I would be expected to do everything everyone else did in the same way 
they did it and it would not work. In the past, I always felt like I failed rather than the system failed. I need to have clear learning objectives and clear expectations of what I have to do, and those expectations should not change later on. Jay's environmental science class was one of the first times in science when I got to participate with what I could [emphasis added] do. Having had that class with Jay, I know we can work out the lecture part, but I am still worried about lab because I don't see well and I don't move well; and if the lab is based on those skills, I'm in trouble because I can't do them.

By the end of her statement, I realized how far askew my thinking had been. The real purpose of an introductory level laboratory experience is not to have students manipulate things with their hands or even to have them make direct observations. Its real purpose is to impart to each student a strong sense of how the process of science works; a student gains insight into how scientists discover knowledge. All at the meeting agreed that Kate could achieve such an insight and that she should participate fully in the laboratory exercises. The laboratory coordinator and I would work with Kate to determine exactly how she would engage in the process.
That day I gave Kate a copy of the laboratory manual and asked her erstwhile reader, her mother, to go through it with her and write out a list of accommodations that Kate thought would be necessary for each lab. The overall accommodations included (a) time outside of lab to write out answers to questions on the worksheets (we now offer this option to all students), (b) someone to do the physical manipulations of the experiments and someone to record data (the lab is collaborative and students work in pairs anyway), (c) large versions of some of the visual materials (most of the materials were available electronically and could be enlarged; all materials are now), (d) availability of some of the computer software we use in the lab for home use (we obtained permission to do so), and (e) a quiz format other than multiple choice (we worked out a way for Kate to do multiple choice by allowing her to answer a question with a short essay if she could not retrieve the information in the multiple choice format).

Kate also told us how she could participate in virtually every lab. Her strength was in understanding concepts, making connections, and making predictions. She could come to lab prepared to make contributions based on her knowledge. For example, in the mitosis (cell division) lab, she suggested she could come to lab prepared to explain to others how to 
CHAPTER $13 \mid 179$

Implementing Universal Design

obtain a representative sample of dividing cells and why it was important to have a representative (i.e., random) sample. As I read through the five pages of how she would participate, I realized that Kate was already deeply engaged in the lab experience. She was well on her way to meeting the central learning outcome of a laboratory experience: having insight into the process of doing science.

I was confident that Kate could be an integral part of the lab and that her experiences there would be true learning experiences. I also concluded that, even though Kate would be working with a lab partner, she would need a personal laboratory assistant. This assistant would verbalize to Kate exactly what her lab partner was doing and would record measurements and observations into the computer when it was Kate's turn to do so. Kate made it clear that she also needed to have agreed-upon alternatives for demonstrating accomplishment of certain objectives in the event that she could not meet them in the same way as other students. The laboratory coordinator and I wrote out these alternatives and provided them for Kate one to two weeks in advance of each lab exercise. For example, instead of viewing a life stage and identifying it in the life cycles lab, the task became "be able to ask the 'appropriate question' about a life cycle that would permit a sighted person to discover what stage was being viewed."
Sometimes Kate used these alternatives, sometimes not, but having them available put her at ease in the laboratory so that she could concentrate on doing what she knew she could do. Lastly, I provided additional background information about various concepts being learned or applied in the laboratory. This last accommodation helped meet Kate's associative learning needs.

Of course, not everything went smoothly in the laboratory. It took time for Kate's personal laboratory assistant to work out a reasonable system for communication and to get over "trying to help too much." The time taken for communication tended to put Kate out of synchrony with the other students, thus segregating her from the rest of the class. Ultimately, we discovered it was best to keep up with the other students and let the communication lag. Kate was processing far more than she could let us know while lab was in session. The proof came in her written responses on the take-home worksheets and in her oral (voice-synthesized) presentation about life cycles.

Kate's analysis of her laboratory experience was very informative and encouraging. She acknowledged having learned a variety of things about biology and about how science works, but more importantly she learned a great deal about herself. She wrote: 
Most of what I learned was that it [my lab work] was a partnership with everybody working toward the same goal, my successful completion of the lab. I learned that if we tried something and it didn't work, that everybody, not just me, was responsible and it was a system failure not a personal failure. I learned I could use my strengths and do the same activities but in a somewhat different manner, like in identifying the life cycles. And if I have the data, I' $m$ good at analyzing it. I also learned some things about socializing with other people. I even learned to feel safe enough to share my sense of humor.

Here are some things I think are important. I never tried to use my disabilities to get out of hard work. I expected to work hard. I expected to try things that would stretch my capabilities. As long as I was trying, I didn't expect to be blamed when things didn't work. That gave me a lot of freedom to try new things that I didn't know beforehand if they would work out. Sharing responsibility for a failure was very new to me and a very remarkable concept. I didn't expect everything to be perfect and it wasn't, but it wasn't solely my responsibility to make things work.
Constructing a learning environment with shared responsibilities for success was the most important accommodation we made, and it was not until I read Kate's evaluation of her experience that I even realized we had made it.

\section{The Take-Home Messages}

We do not know how many students with multiple severe disabilities have had the kinds of discouraging and disenfranchising experiences that Kate did in her high school and early college tenure, but we suspect it is a high percentage. Such experiences erect their own barriers to seeking further education. For the few who press onward to pursue higher education (32.6\%), very few find the will and the opportunity to complete a college degree $(9.4 \%)$ (U.S. Census Bureau, 2001). Our case study of Kate shows that such an outcome need not prevail. True, Kate is highly intelligent and a very hard worker, but even in sum these attributes were insufficient to overcome the barriers erected by curricula that were designed by and for those with few or no medically recognized disabilities. Thus, it is reasonable and prudent to conclude that college curricula must be modified in ways that will be inclusive of and invitational to students with severe disabilities. We also conclude that the modifications must go beyond simple accommodations, like alternative testing modes or conditions, 
CHAPTER $13 \mid 181$

Implementing Universal Design

multiple modes of access to course materials, adequate time for all to complete assignments, and so on.

As we have since discovered, the principles of Universal Instructional Design can guide us in making the kinds of modifications that will be truly inclusive of students with severe disabilities (Bowe, 2000). As Higbee (2001) points out, the first step in developing a universally accessible curriculum is to determine its "essential elements." We need to ask ourselves:

1. What is it that our students must be able to do by the conclusion of this course and what is it that they must know?

2. Why must they be able to do it or know it? Here we have to be very critical of our answer.

3. In what ways can a student demonstrate that she or he knows the information or can do the task? Here is where we have to rely on our creativity and the creativity of others. For most learning objectives, there is more than one valid means of demonstrating what one knows or can do. Often, as illustrated by Kate, the student can be the best resource for determining these alternative ways.

This is exactly what we did in part as we attempted to discover what Kate should be expected to do in our courses. For example, the study of history generally includes memorization of many dates, important personages, and events. But what is the real importance of knowing these things? What is the essential element here? The history teacher hopes that the student ultimately will be able to understand how and why events unfolded the way they did. In the world history course, students moved on to this level when they worked through the simulations. They demonstrated what they knew factually and, at the same time, learned to refine their ability to critically analyze history. In Kate's case, the opportunity to demonstrate her knowledge and analytical abilities in this way was crucial. It not only provided the instructor with an additional way of evaluating her achievement, it provided a means by which Kate became an integral part of the class. The same thing happened with the group project in the environmental science course and with the collaborative laboratory experience in the general biology principles course.

Kate had the opportunity to capitalize on her strengths and so was not faced with having to do things that she could not do (an important tactic, see Preston-Sabin, 1997). This approach allowed her to take part in all of the essential elements of the courses. Thus, Kate felt fully included and fulfilled intellectually because she accomplished the same learning outcomes that other students 
did (and in Kate's case better than most). It was very important to Kate, and it is very important to the integrity of college curricula, that the level of academic rigor in a course not be compromised in an effort to accommodate a student with disabilities. If we are thoughtful about what constitutes the essential elements of our courses and creative about how students can acquire and demonstrate knowledge, there need be no sacrifice of rigor in designing universally accessible courses.

Thoughtfully following the principles of Universal Instructional Design also places teachers in the position of already having "accommodated" virtually any student who enrolls in their courses. The stress and the inconvenience of last-minute accommodations, which burdens both teachers and students, are eliminated. Because Universal Instructional Design principles incorporate well-established principles for good teaching, UID courses become better courses all around. Our courses are much improved, and we have discovered that virtually all students appreciate having alternative ways to acquire and demonstrate knowledge.

Another very important discovery of this case was the sense of empowerment that accrued to Kate as she engaged in these courses. In all three courses, Kate's self-confidence in her ability to achieve her potential rose markedly. As she became an integral part of group achievement, she learned that she could participate in and significantly contribute to group work, something she previously had believed she could not do. In the biology lab in particular, she learned that the onus for success was not hers alone but was shared by her and those who designed and delivered the curriculum. This realization, coupled with the availability of alternative ways of demonstrating her knowledge, gave her the confidence to explore new ways of learning. As her self-confidence and array of learning tools increased, she finally felt empowered to design her own unique and very challenging major: "public policy and the ethics of inclusion of minorities." Kate currently is completing her senior year with a cumulative grade point average of 3.9. She plans to attend graduate school in the areas of history of science and public policy. Kate's future is hers to determine and that is as it should be.

\section{References}

Bowe, F. G. (2000). Universal design in education: Teaching nontraditional students. Westport, CT: Bergin \& Garvey.

Foster, S., Long, G., \& Snell, K. (1999). Inclusive instruction and learning for deaf students in postsecondary education. Journal of Deaf Studies and Deaf Education, 4, 225-235. 
CHAPTER $13 \mid 183$

Implementing Universal Design

Higbee, J. L. (2001). Implications of Universal Instructional Design for developmental education. Research and Teaching in Developmental Education, 17, 67-70.

Hill, J. L. (1996). Speaking out: Perceptions of students with disabilities regarding the adequacy of services and willingness of faculty to make accommodations. Journal of Postsecondary Education and Disability, 12, 22-43.

Kalivoda, K. S., \& Higbee, J. L. (1998). Influencing faculty attitudes toward accommodating students with disabilities: A theoretical approach. The Learning Assistance Review, 3 (2), 12-25.

Preston-Sabin, J. (1997). Angela: Capitalizing on individual strengths. In B. M. Hodge \& J. Preston-Sabin (Eds.), Accommodations-Orjust good teaching? (pp. 82-83). Westport, CT: Praeger.

Seymour, E., \& Hunter, A. (1998). Talking about disability: The education and work experiences of graduates and undergraduates with disabilities in science, mathematics, and engineering majors. Boulder, CO: The University of Colorado.
Silver, P., Bourke, A., \& Strehorn, K. C. (1998). Universal Instructional Design in higher education: An approach for inclusion. Equity and Excellence in Education, 31 (2), 47-51.

West, M., Kregel, J., Getzel, E., \& Zhu, M. (1993). Beyond section 504:

Satisfaction and experiences of students with disabilities in higher education. Exceptional Children, 59 (5), 456-467.

U.S. Census Bureau. (2001, March). Americans with disabilities: 1997. Retrieved October 8, 2001, from U.S. Census Bureau Access: http:// www.census.gov/hhes/www/disable/ sipp/disab97/ds97t3.html 
184 CHAPTER 13

Empowering Students 